\title{
Workshop on Building Occupant Movement During Fire Emergencies, June 10-11, 2004, National Institute of Standards and Technology
}

Editors:

Richard D. Peacock Erica D. Kuligowski

Sponsored in part by U.S. General Services Administration

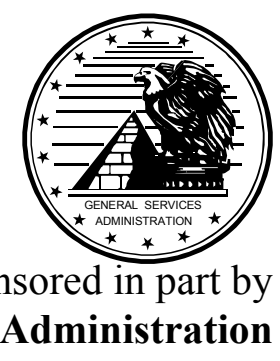



NIST Special Publication 1032

\section{Workshop on Building Occupant Movement During Fire Emergencies, June 10-11, 2004, National Institute of Standards and Technology}

Editors:

Richard D. Peacock Erica D. Kuligowski

Fire Research Division Building and Fire Research Laboratory

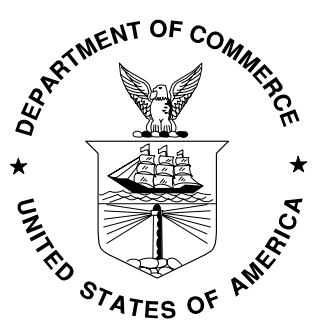

U.S. DEPARTMENT OF COMMERCE

Donald L. Evans, Secretary

TECHNOLOGY ADMINISTRATION

Phillip J. Bond, Under Secretary of Commerce for Technology NATIONAL INSTITUTE OF STANDARDS AND TECHNOLOGY 



\section{Contents}

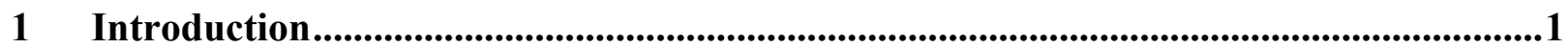

2 Codes and Standards Requirements for Building Evacuation ...........................................3

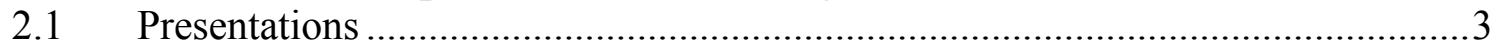

2.2 Session Summary .....................................................................................

2.3 Integrating Physical Systems and Human Behavior Using Codes and Standards

Requirements for Building Evacuation................................................................6

2.4 Protected Elevators For Egress And Access During Fires In Tall Buildings ......12

$3 \quad$ Building Egress Strategies......................................................................................................21

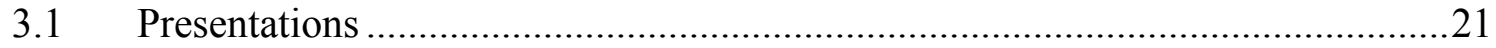

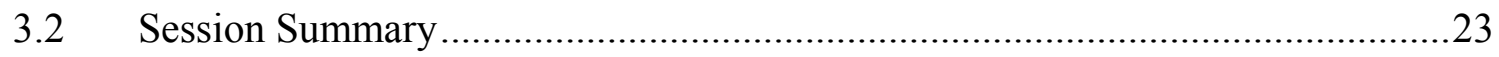

3.3 A Critical Review of Emergency Evacuation Simulation Models ......................25

3.4 An All-Hazards Approach is Needed to Support Building Movement Strategies51

3.5 Achieving Situation Awareness is the Primary Challenge to Optimizing Building Movement Strategies ......................................................................................53

4 Data Needs for Predictive Building Movement Models ......................................................55

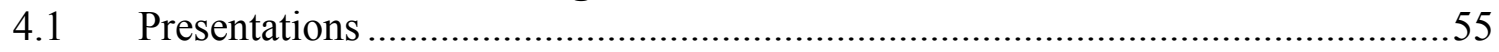

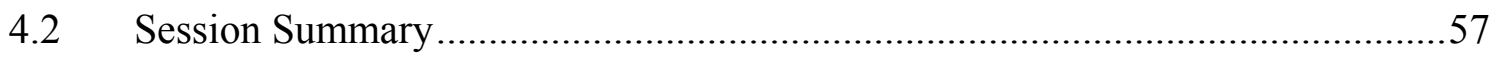

4.3 Available Data and Input Into Models...............................................................60

4.4 Review of 28 Egress Models ..........................................................................66

4.5 Estimating Evacuation Time Components: Lessons from Nuclear Power Plants, Hurricanes, and the First World Trade Center Bombing .....................................89

4.6 On Not Putting the Cart before the Horse: Design Enables the Prediction of Decisions about Movement in Buildings ..............................................................94

$5 \quad$ Workshop Summary.............................................................................................97

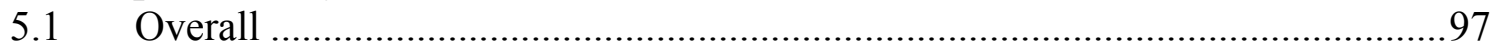

5.2 Specific Needs Obtained From Workshop Participants ……………………........97 


\section{Acknowledgements}

This workshop was unique for the staff of the Building and Fire Research Laboratory, bringing together both engineers, social scientists, and those with responsibility for building management during emergencies together for intensive discussions of occupant behavior during fire emergencies. The cross-pollination of these diverse disciplines provided for a far broader range of discussions and insights for workshop participants than a typically more-focused set of presentations. Richard Bukowski, NIST; Dr. Dennis Mileti, University of Colorado; Mauro Atalla, United Technologies Research Center, Erica Kuligowski, NIST, and Guylène Proulx, National Research Council of Canada served as session chairs for the workshop. Their assistance in planning and conducting the workshop and particularly in facilitating the extended discussion sessions is gratefully acknowledged.

The workshop would not have been possible without the willing participation of all the presenters. The presenters included Norman Groner, associate professor at John Jay College of Criminal Justice, the City University of New York; Brian Rhodes, senior engineer at Hughes Associates; Daniel O'Connor P.E., Vice President of Engineering for Schirmer Engineering Corporation; Jeffrey Tubbs, P.E., Associate and Staff Leader of Arup's Westborough Office; Brian J. Meacham, PhD, P.E., Principal Risk \& Fire Consultant for Arup; Richard W. Bukowski P.E., FSFPE., Standards and Codes Coordinator for the Building and Fire Research Laboratory of the National Institute of Standards and Technology; Gabriel Santos, Department of Sociology and Criminal Justice at the University of Delaware. Dr. Benigno Aguirre. professor in the Department of Sociology and Criminal Justice and a senior faculty member of the Disaster Research Center of the University of Delaware; Dr. Dennis S. Mileti, Emeritus Professor at the University of Colorado at Boulder; Prof. Elise Miller-Hooks of the College of Engineering, University of Maryland; Dr. Gregory Luther, principal engineer at United Technologies Research Center; Christos G. Cassandras, Professor of Manufacturing Engineering and Professor of Electrical and Computer Engineering at Boston University; Shi-Chung Chang, visiting research scholar at the Electrical and Computer Engineering Dept., University of Connecticut.; Peter B. Luh, SNET Professor of Communications and Information Technologies at the Department of Electrical and Computer Engineering, the University of Connecticut; Bo Xiong, Department of Electrical and Computer Engineering, the University of Connecticut; Laurent Michel Assistant Professor of Computer Science and Engineering, University of Connecticut; Dr. Rita F. Fahy, Manager of Fire Data Bases and Systems, National Fire Protection Association; Erica Kuligowski, Fire Protection Engineer in the Fire Research Division at the National Institute of Standards and Technology; James Lord, Fire Consultant for Arup; Dr. Michael Lindell, Hazards Reduction and Recovery Center, Texas A\&M University; and Dr. Guylène Proulx, Senior Researcher in the Fire Research Program of the National Research Council Canada. The contributions of all the presenters are gratefully acknowledged.

Finally, the editors would like to thank all the workshop participants from diverse backgrounds who provided their expertise in all the workshop sessions and extended discussion periods during the two-day workshop. 


\title{
Workshop on Building Occupant Movement During Fire Emergencies, June 10-11, 2004
}

\author{
Richard D. Peacock and Erica D. Kuligowski, Editors
}

Fire Research Division; Building and Fire Research Laboratory

\section{Introduction}

Both before and since the World Trade Center tower collapses, there have been far too frequent events in which there was extensive life loss because the time needed for safe evacuation from a threatened building was not available - it was less than the time available for escape. There is a broad range of emergency scenarios for which there is an alarming gap between the public expectation of safety and the ability to provide it. These include man-made threats, natural disasters, and the more common system failures (e.g., gas leaks and power outages). The urgency of response to knowing something is very wrong within a building is now being accentuated and perhaps even changed, as the old paradigms of "orderly movement will get you out in time" and "find a safe part of the building and wait for rescue" are open to question. Thus, the need for accurate, quantitative assessment of people movement in emergencies has never been greater than it is today.

To this end, the Building and Fire Research Laboratory (BFRL) at the National Institute of Standards and Technology (NIST), in cooperation with the United Technologies Research Center, hosted a two-day workshop focusing on needed research on occupant behavior and movement during building emergencies. This workshop was motivated by a renewed interest in how buildings should be evacuated during fire emergencies and by the desire to provide a forum for the exchange of experiences among the fire and non-fire communities working on emergency egress. Organized into several sessions with specific topics areas, several presentations were included in each session, with an extended period for discussion at the end of each session. Papers highlighting each session are included in this report. For each workshop session, the session moderator prepared a summary of key points of research interest from the presentations and discussion. Additional details, including presentation visuals, are available on the NIST website at http://fire.nist.gov.

The workshop sessions were:

- Codes and Standards Requirements for Building Evacuation

- Building Egress Strategies

- Data Needs for Predictive Building Movement Models

Each of these sessions is presented below with abstracts for all the presentations, papers highlighting each session, and a session summary. 


\section{Codes and Standards Requirements for Building Evacuation}

Several recent events have motivated discussions on how to best protect and safely evacuate building occupants during fire emergencies. As a result, modifications to current building and fire codes, such as stairwell capacity or the use of elevators, are being considered. This session aims to provide insight on egress code characteristics in countries around the world as well as efforts to change codes involving the life safety of buildings by industry, code developers, and first responders. It is also of interest to discuss how to guarantee certain levels of traffic performance during evacuations.

\subsection{Presentations}

"Integrating Physical Systems and Human Behavior Using Codes and Standards Requirements for Building Evacuation,” Norman Groner, John Jay College, CUNY

Codes need to be based on a fundamentally different approach to incorporating considerations of human behavior. Past approaches based on physical systems representations do not serve well when integrating physical systems approaches with the goal-driven adaptive performance of people. One potentially viable approach might be a single holistic systems representation based on the achievement and preservation of desirable systems states

\section{"The Use of Egress Modeling in Performance-based Code Applications," Brian Rhodes, Hughes Associates, Inc.}

The presentation will address how egress modeling is being used by fire protection engineering consultants to address performance-based design problems. The discussion will focus on specific issues/problems encountered in recent design projects and their effect on egress modeling.

\section{“Overview of the SFPE Engineering Guide on Human Behavior in Fire," Daniel O'Connor, Schirmer Engineering}

The presentation will address the development and content of the Engineering Guide on Human Behavior in Fire. The key chapters on occupant characteristics, human response to cues, decision making and movement will be outlined. This will provide an overview of the qualitative and quantitative information available to assist engineers in evaluating or addressing evacuation and /or relocation scenarios.

\section{“Developing Trends from Deadly Fire Incidents: A Preliminary Assessment," Jeffrey Tubbs (presenting) and Brian Meacham, Arup Fire}

A number of tragic fire incidents have refocused the design, engineering and enforcement communities upon the need for critical life safety features within buildings. This presentation will overview the ten most deadly assembly fires, and present some of the commonalities 
between these incidents. A case study will also be presented to review how egress components were used during The Station nightclub fire event.

\section{“Use of Elevators for Egress and Firefighter Access," Richard Bukowski, NIST}

The events of September 11 have generated renewed interest in the use of protected elevators for egress and access. U.S. building codes contain requirements for accessible elevators for assisted evacuation of people with disabilities. Firefighter lifts, required in tall buildings in some countries, are being discussed to improve both the safety and efficiency of firefighting operations. The desire for increased egress capacity of tall buildings to facilitate simultaneous evacuation has rekindled interest in elevators as a secondary means of egress for all occupants. Elevators used for each of these purposes share many of the same design characteristics and the need for an extraordinary level of safety and reliability.

This paper will review the technology, safety, and reliability issues associated with the use of elevators during fire emergencies for all three of these purposes and the solutions being considered to address them. Operational procedures and arrangements that influence system design considerations will be suggested. An innovative system for operating the elevators under the remote, manual control of the fire service will be described. Important human factors issues including communication, signage, and training will be identified.

\subsection{Session Summary}

The session addressed several themes that serve as an effective summary. These fall under four main categories: 1) A definition of risk for which we are designing buildings 2) Reactive vs. proactive environment for code changes 3) An integrated model for evacuation from a building and 4) Performance-based design.

The first theme of the codes and standards discussion revolves around the question that was continually asked by several participants, and that question is, "For what risk should we be designing buildings?" Without an answer to this question, code developers and all others involved in the process have to struggle between designs that will prevent an infrequent airplane attack to a building vs. the more likely smaller-sized fire in a building.

Related to the first theme of risk, the second theme that was discussed in the codes session involved the reactive vs. proactive methods for code changes. Some participants expressed the danger in making reactionary code changes, for instance, changes in the requirements for night clubs in Rhode Island in response to the Station nightclub fire. However, if only a select number of states make the same changes, the code requirements get established out of fear instead of based on solid evidence that this change is appropriate. Also, instead of waiting for an event to happen that encourages a change in the codes, suggestions were made to be more pro-active in anticipating problems in the codes and making those changes before a large loss of life and/or property occurs.

The third theme discussed in the codes and standards session was the topic of developing an integrated model. There is a need to understand how the people, the building, and the 
environment react together. This involves an integrated "model" and more of a systems view of the evacuation. Suggestions were made to use technology in buildings (sensors) to help people during their evacuation. For instance, giving them specific information on which route to take or which elevator is in service, and providing them with a sensor at each door to let them know if there is fire or smoke behind the door.

Another related comment made during this discussion was that even if a building is designed a certain way and management trains their employees to follow certain safety procedures, there is no current way to legally bind employees to follow the procedures. A suggestion was made that codes should be the link to ensure that employees follow the procedures for which they were trained in an emergency.

The fourth theme of the codes and standards session involved performance-based design of buildings. This discussion brought up the need for data in certain areas to aid designers of building systems. For instance, when engineers are faced with a unique stair structure, such as a spiral stair, they lack the data which explains how the unique stair will affect the egress of the occupants.

The session chairs of all three sessions were asked to summarize the session discussion answering the following four questions.

- What is the current state of knowledge from research and in theory?

- What is the current state of putting that theory into practice?

- What is the gap between that and where we need to be?

- What activities and resources are needed to close this gap?

The current state of research in the field of fire evacuation is that we are in a vague period in code development. We are still asking the question of what risks we should design for. We are also in a state of transition with the use of elevators in emergencies.

The presentations and discussion established that there were several gaps in the data used for performance-based design. Also, there were gaps in the reasons given for changes in the codes. Some participants noticed that changes in the codes follow a similar pattern of significant changes in response to large-scale events, such as September 11 or the MGM Grand fire. To bridge this gap, a better understanding of the design risks should be established as well as a more pro-active environment for code changes in order to avoid large loss of life and property in the future. 


\title{
2.3 Integrating Physical Systems and Human Behavior Using Codes and Standards Requirements for Building Evacuation
}

\author{
Norman E. Groner \\ John Jay College of Criminal Justice, City University of New York
}

\begin{abstract}
Summary
Codes need to be based on a fundamentally different approach to incorporating considerations of human behavior, especially where they regulate the production of performance-based designs. Codes have been based on traditional physical systems engineering approaches based on assumptions about occupants characteristics. The approach does not yield effective designs because (1) satisfactorily conservative assumptions cripple the design process, and (2) people are not credited for their abilities to adapt to dynamic scenarios. Instead, we need to integrate physical systems approaches with the goal-driven adaptive performance of people. Code-based designs need to specify realistic performance objectives for people as well as physical systems. Work by Groner and Williamson provides one possible approach towards integrating physical systems and human goal-directed behavior in a single holistic systems representation based on the achievement and preservation of desirable systems states.
\end{abstract}

\section{What is the current state of knowledge from research and theory?}

Building and fire codes are traditionally prescriptive, that is, they inflexibly specify the precise minimum requirements for buildings. Improvements to prescriptive codes occur incrementally, often based on incidents that provide evidence that existing provisions are based on faulty assumptions. Of considerable importance is the tendency of prescriptive requirements to protect against the repetition of historical events. Changes to prescriptive requirements that anticipate scenarios without historical precedence are difficult to institute.

Because they are reactive, prescriptive codes implicitly reflect historically prevalent naïve and unsubstantiated theories about human behaviors. As an example, the belief that people would "panic" or behave irrationally and selfishly was a predominant, but naïve and invalid theory. The Life Safety Code ${ }^{\circledR}$ included many references to "panic" that are still being weeded out. A few decades ago Stahl and colleagues (1982) conducted a National Bureau of Standard's sponsored survey of implicit assumptions about human behavior in the Life Safety Code ${ }^{\circledR}$, along with evidence to the their validity, and concluded that most were unsupported by research. Pauls' research on movement down stairs revealed that code assumptions relating stairway width to flow rates were faulty.

In contrast to prescriptive codes, performance-based codes are intended to facilitate engineered solutions to design problems. As such, theory is central to the quality of performance-based designs. Unfortunately, performance-based code approaches retain a reliance on assumptions about occupant characteristics, making them vulnerable to the same unsubstantiated and naïve theories that underlie prescriptive provisions. 
I believe that much of the problem results from the fire protection engineering design community's tendency to rely on a physical systems representation of human behavior. (Groner, 1998, 2002; Pauls and Groner, 2002) This physical systems-centered approach directs engineers to consider humans as systems components that should respond with predetermined behavior. "Traditional system-centered design treats users as just another resource to be assigned and optimized to meet operational goals." (Stanney, et. al, 1997; p. 639) The physical systems view is causally-based; human responses are "caused" by certain stimuli without relying on theory about the unobservable cognitive processes that people use to understand those stimuli. Not surprisingly, engineers are comfortable with this familiar paradigm.

In fire protection engineering, this view is exemplified by the idea that people are supposed to evacuate buildings when they hear alarm signals. Research and experience demonstrates that the approach fails in most settings. In reaction to this failure, we often call for more training in a problematic attempt to strengthen the causal association between stimulus and response. But this mechanical response runs counter to natural human tendencies. Training is an unreliable fallback to building designs based on faulty assumptions about human behavior.

The physical systems view mirrors the behaviorist perspective championed by B. F. Skinner wherein mental processes that can not be directly observed are excluded from theory. The behavioral sciences have rejected dogmatic behaviorism, and the manner in which codes incorporate human behavior will have to follow suit. Requirements must be based on the understanding that humans are information-processing adaptive agents that pursue goals aimed at protecting themselves, others and valued artifacts.

\section{What is the current state of putting that theory into knowledge?}

Performance-based design solutions are the best means for fully incorporating human behavior into code-complying designs. Unfortunately, current approaches still rely on the use of assumptions about "occupant characteristics." Taking the NFPA Life Safety Code ${ }^{\circledR}$ as an example, the performance-based design team is asked to specify "occupant characteristics" as a means to constrain design solutions. Because the design doesn't control "occupant characteristics," the engineer should assume the worst plausible set of characteristics that can characterize the building's occupants.

Further, in the Life Safety Code provision for the performance-based option, the design team engineer is asked to perform calculations like the following: "For each design fire scenario and the design specifications, conditions, and assumptions, the design team can demonstrate that each room or area will be fully evacuated... [And that] the timing of such an evacuation means that no occupant is exposed to fire effects. Such an evacuation requires calculation of the locations, movement, and behavior of occupants, because fire effects and occupants are kept separate by moving the occupants." (Section A.5.2.2, all references are to the 2004 edition.) An appendix note to Life Safety Code provisions explains that "The use and occupancy should not change to the degree that assumptions made about the occupant characteristics... and existence of trained personnel are no longer valid." (A.5.1.7) The Code recommends a list of "assumptions [that] can address a larger number of factors that are components of these basic performance characteristics." (A.5.4.5.2) Among these factors are commitment, role, social affiliation, 
alertness - all cognitively related factors about which the designers will have to make conservative assumptions to guarantee that people will be adequately protected.

When basing designs on assumptions about occupant characteristics, how conservative is conservative enough? The answer is that the assumptions will need to be so conservative that the design process will be blocked. Take, for example, the problem of making an assumption about the amount of time that people take before responding to an alarm. We know that in many settings, people won't quickly respond to an alarm in the absence of additional cues, so it is conservative to assume the no one will respond to a simple alarm signal in the absence of confirming cues. We know that people respond to additional information provided by emergency response teams, but in many buildings, emergency response teams don't respond reliably, so the designer conservatively should assume that it won't happen at all. When all such conservative assumptions about human responses are taken together, performance-based design becomes impossible.

\section{What is the gap between that and where we need to be?}

The approach of exclusively relying on assumptions about occupant characteristics is a faulty method for incorporating human behavior into building designs, regardless of whether the approach is prescriptive or performance-based. We know that such needed conservatism does not accurately reflect human response because people actively work to understand situations and adapt according to the manner in which the incident evolves. An approach that credits people with this capability is needed.

A design approach is needed whereby designers establish performance goals for both the built features and the people occupying the building. The design then enables not only the design of physical components that contain and suppress the fire, but also the design of a cognitive task environment that enables people to respond adaptively to the evolving event. Performance-based code approaches need to establish "performance objectives" for people that enable human adaptive capabilities (Groner, 1996). By designing buildings that support performance objectives for people, we will also enable more accurate and reliable predictions of human actions and reaction times. Prescriptive codes are already missing important opportunities to support people in their efforts to adapt to building emergencies (Groner, 1998).

There are two principle gaps to our writing code provisions that incorporate performance objectives for people:

We must learn how to devise human performance objectives that are compatible with the goals that people normally try to pursue during building emergencies. We have learned the hard way about using a performance objective that is not compatible with natural human responsesexpecting people to immediately respond to uninformative alarm signals. We need a more sophisticated approach.

We must learn how to integrate human performance objectives into a holistic representation of how protective systems, including building layouts, both active and passive fire protection 
systems, occupant characteristics, and designed procedures work together to achieve high level design objectives like those specified by the Life Safety Code (4.1; 4.2).

\section{What activities and resources are needed to close this gap?}

The "first gap," devising good human performance objectives, can be achieved using two complementary approaches:

Relevant theory and empirical research needs to be reviewed for its relevance and guidance. Some of the research is specific to human behavior in building fires, but most of the relevant theory and research can be found in fields such as disaster sociology, cognitive science, organizational theory, and cognitive ergonomics. Returning to the example of human responses to simple alarm signals, each of these fields contributes theory and findings that would lead designers to avoid this as a performance goal.

Additional empirical research into real incidents should be conducted with the intent of capturing data about the goals that people naturally pursue given their "occupant characteristics" and the types of situations in which they find themselves during building emergencies. This type of information has rarely been collected, although data that specifically related occupants' behaviors to perceived situations and goals has been collected as part of the NIST investigation of evacuations during the WTC building disaster. (Averill, et al., 2003)

In response to the "second gap" of integrating human performance objectives into a holistic representation of systems performance, we need modeling approaches that facilitate the design of protective systems for buildings that include human performance objectives. Better yet, the models will fully integrate human and building performance into a holistic systems representation. In my view, the development of such models requires real design problems and collaborations designers (e.g., fire protection engineers) and behavioral science or human factors specialists.

First and foremost, to account adequately for the goal-seeking information-processing reality of human behavior, building design needs to change from systems-centered design to user-centered design. "User-centered design...considers users' roles and responsibilities as the key design objective to be met and supported by advancing technologies." (Stanney, et. al, 1997; p. 639)

In collaboration with R. Brady Williamson at University of California Berkeley, I developed an approach that provides a formal systematic approach towards integrating human adaptive behaviors into fire protection engineering design (Groner and Williamson, 1997; Groner and Williamson, 1998). The approach is based on desirable systems states, a construct that can be used to both characterize engineering design goals and the goal-driven adaptive behavior of people. In fire protection engineering, the behavior and development of fires is often characterized as discrete states. The practice of fire engineering largely involves the design of systems intended to prevent fires from transitioning to less desirable states (e.g., flashover, spread beyond the room of origin). Stated differently, design goals for both the built environment and human occupants involve the preservation or restoration of desirable system states. Active and passive building systems and people pursue these goals independently or in concert. 
The approach has been used to qualitatively model problems related to fire scenarios in a university library and the effects of hardening natural gas supply lines during an earthquake. While the few attempts to use the approach to integrate physical systems and human performance have been qualitative, there is no inherent reason why the approach cannot be used to as a basis for quantified risk analysis by calculating the probabilities of transitions between different states.

\section{References}

Averill, J. D., Kuligowski, E., Lawson, R., Peacock, R. D., Reneke, P. A., Groner, N. E., Mileti, D., \& Proulx, G. Collection Methodology for World Trade Center Evacuation and Emergency Response: Telephone Interviews, Face-to-face Interviews, Focus Groups and Population Sampling. Gaithersburg, MD: National Institute of Standards and Technology.

Groner, N.E. (1996) Viewpoint: Putting people into the performance-based design option, Fire Technology, Vol. 32, No. 3, Aug/Sep. pp. 281-284.

Groner, N. E. (1998) People power: Experts designing fire protection systems for buildings should think of people as part of the solution. Canadian Consulting Engineer, Vol. 39, Special Issue (May), pp. 30-32.

Groner, N. E. (2001) Intentional systems representations are useful alternatives to physical systems representations of fire-related human behavior. Safety Science, Vol. 38, pp. 85-94.

Groner, N. E. (2002) Viewpoint: A Future Where Engineering Supports People Adapting to Survive Fires. Fire Protection Engineering, No. 16 (Fall 2002) p. 3.

Groner, N. E. and Williamson, R. B. (1997) Using a Table Of Desirable Systems States to Integrate Models of Fire Development with Active System And Human Responses to a Fire Scenario, Proceedings of the Fire Risk and Hazard Assessment Research Application Symposium, Society of Fire Protection Engineers, pp. 142-151.

Groner, N. E. and Williamson, R. B. (1998) Scenario-Based Goal Decomposition: A Method for Implementing Performance-Based Fire Safety Analysis, Proceedings of the Second International Conference on Fire Research and Engineering, pp. 200-211.

Pauls, J., and Groner, N. E. (2002) Human factors contributions to building evacuation research and systems design: opportunities and obstacles. Proceedings of the Workshop to Identify Innovative Research Needs to Foster Improved Fire Safety in the US, 15-16 April 2002. Washington, DC: National Academy of Sciences, forthcoming.

Stahl, F. I., Crosson, J. J., \& Margulis, S. T. (1982) Time-based Capabilities of Occupants to Escape Fire in Public Buildings: A Review of Code Provision and Technical Literature (NBSIR 82-2480). Gaithersburg, MD: National Bureau of Standards 
Stanney, K. M., Maxey, J. L., \& Salvendy, G. (1997) Socially Centered Design. In Salvendy, G. (Ed.) Handbook of Human Factors and Ergonomics, 2nd Edition. New York: Wiley. 


\title{
2.4 Protected Elevators For Egress And Access During Fires In Tall Buildings
}

\author{
Richard W. Bukowski, P.E., FSFPE \\ NIST Building and Fire Research Laboratory
}

The events of September 11, 2001 have generated renewed interest in the use of protected elevators for egress and access. U.S. building codes contain requirements for accessible elevators for assisted evacuation of people with disabilities. Firefighter lifts, required in tall buildings in some countries, are being discussed to improve both the safety and efficiency of firefighting operations. The desire for increased egress capacity of tall buildings to facilitate simultaneous evacuation has rekindled interest in elevators as a secondary means of egress for all occupants. Elevators used for each of these purposes share many of the same design characteristics and the need for an extraordinary level of safety and reliability.

\section{History}

The development of the passenger elevator is tied directly to the emergence of tall buildings. While various types of freight lifts were found in warehouses and factories these were considered too dangerous to move people. In 1854 Elisha Graves Otis demonstrated an automatic safety brake that changed the landscape. Within a few years his steam elevators had eliminated one of the major limits to building height. But while elevators proved to provide one of the safest forms of transportation there were instances where people were killed while using elevators during building fires. Heat sometimes activated call buttons bringing cars to the fire floor where smoke prevented the doors from closing (light beams are used to detect people in the doorway) and water in the shaft sometimes shorted out safety devices. Thus the use of elevators for occupant egress or fire department access was discouraged.

In the 1973 the elevator industry developed a system that recalls the elevators and takes them out of service if smoke is detected in the lobbies, machine room, or hoistway. Mandated in the Safety Code for Elevators and Escalators (ASME A17.1) for all (automatic) passenger elevators this system involves two, distinct phases of emergency operation. In Phase 1, the detection of smoke or heat in specific locations results in the elevators being immediately recalled to the ground floor (unless this is where smoke was detected), the doors open, and the elevators are locked out of service. The responding fire department can then choose to use the elevators under manual control of a firefighter in the car by use of a special firefighter key, in what is

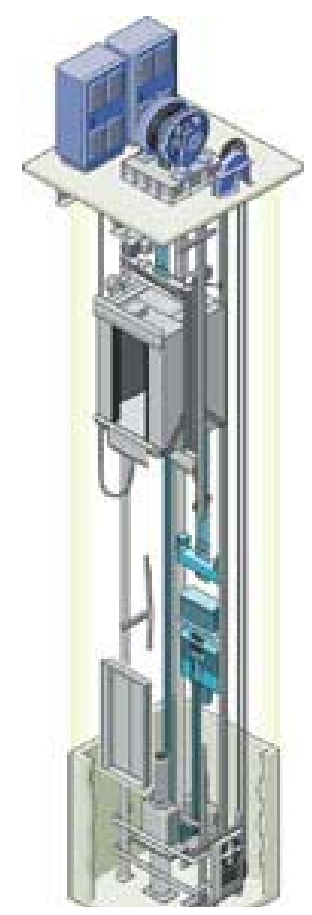

Figure 0 - Typical electric elevator called Phase 2 operation. While Phase 2 is sometimes used to evacuate people with disabilities, some fire department "standard operating procedures" for high-rise firefighting depend on the stairs for access, staging, and operations. ASME publishes a Guide 
for Emergency Personnel (ASME A17.4) that includes detailed instructions for firefighters' service operation.

\section{Current Requirements For Emergency Use Elevators}

All U.S. building codes contain a requirement for accessible elevators as a part of the accessible means of egress in any building with an accessible floor above the third floor. These requirements are all identical, being extracted from the ADA Accessibility Guidelines (ADAAG) and mandated under the Americans with Disabilities Act (ADA).

A recent survey by the International Organization for Standardization (ISO) TC178 Committee identified at least twelve countries that require firefighter lifts in tall buildings (generally those exceeding $30 \mathrm{~m}$ in height) to provide for fire department access and to support operations as well as to evacuate people with disabilities (ISO, 2002). England has such a requirement supported by a British Standard (BS 5588 Part 5) requiring firefighter lifts in buildings exceeding $18 \mathrm{~m}$ (60 $\mathrm{ft}$ ) in height (BSI 1991). Firefighter lifts are also provided in the Petronas Towers, the world's tallest buildings in Kuala Lumpur, Malaysia.

The NFPA's Life Safety Code (NFPA 101) includes provisions for egress elevators to be provided as a secondary means of egress for air traffic control towers where the small footprint prohibits two, "remote" stairs. These are secure facilities not open to the public and with limited numbers of occupants.

While the above requirements exist for elevators for emergency use by firefighters and people with disabilities, there are currently no codes or standards in the world for egress elevators for use by building occupants. There is, however, an example of a structure that uses elevators as the primary means of egress and fire service access. This is the Stratosphere Tower in Las Vegas, Nevada (Fig 2). Essentially an eleven-story building sited atop an $250 \mathrm{~m}$ (800-foot) tower, it has a single emergency stair that is considered impractical. Thus the four, double deck elevators are designed for emergency use. One is reserved for use by the fire department with the remaining three used under manual control to evacuate all occupants from the two lower floors that are designed as areas of refuge. Occupancy of the tower is limited to the number of people that can be evacuated by the elevators in one hour (Quiter 1996).

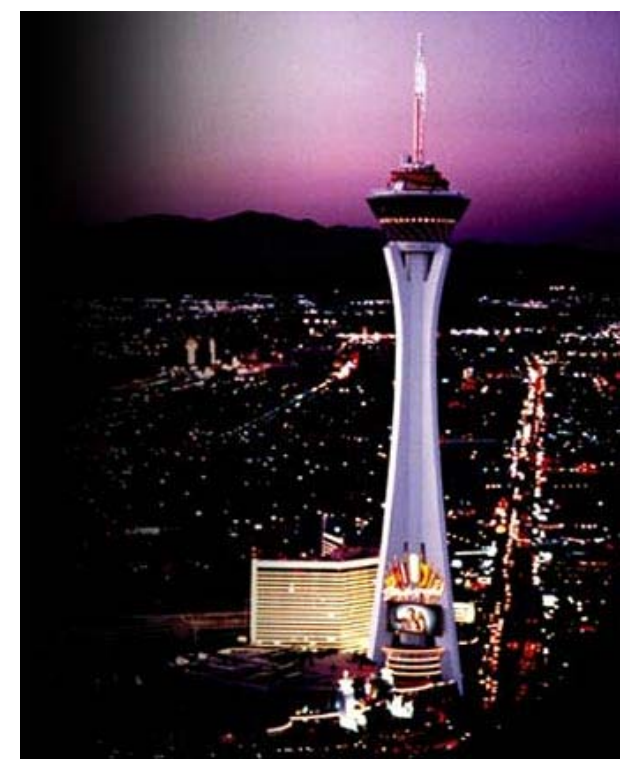

Figure 0 - Stratosphere Tower in Las Vegas

\section{Common Characteristics}

Whether for access by the fire service or for egress, elevators provided for use in fire emergencies share several characteristics intended to assure safety and reliability. They are required to be installed in a smokeproof hoistway constructed to a 2 -hr fire resistance and 
pressurized against smoke infiltration. Enclosed lobbies are required on every floor, which are also 2-hr (1-hr in fully sprinklered buildings) and pressurized. In fact, the lobby is crucial to safe operation since elevator doors are particularly susceptible to jamming under even mild pressure differences. Thus, the smoke control system should pressurize the shaft and lobby together so that there is a minimal pressure difference across the door.

The lobbies are provided with a 2-way communication system to the building fire command center so that people in the lobby can be informed of the status of any impending rescue. Emergency power to operate the elevator in the case of main power failure is also specified. Water intrusion into the hoistway can short out safety components such as switches that prevent the doors from opening unless there is a car present, and even the safety brake; so water protection or waterproof components are needed.

Within the United States, any use of the elevator for fire service access or for rescue of people with disabilities is done under manual control of a firefighter in each car under Phase 2 recall. The elevator industry cannot guarantee that its automatic controls will react appropriately to all hazards that might occur and cannot assure safe operation. Thus, the trained operator must be able to recognize hazardous conditions and cease operations. This represents a resource allocation problem for most fire departments that simply cannot assign a firefighter to every car. Further, the susceptibility of safety controls to failure from water results in a requirement for an automatic shutdown of elevator power before activation of fire sprinklers in the machine room or hoistway. This would result in any operating elevator cars to suddenly come to a halt.

\section{Solutions For Reliable Emergency Elevators}

The first solution is to eliminate the susceptibility to water by using waterproof components and eliminating the requirement to shut down power. Next is to eliminate the need for firefighters to operate each car.

Here we propose operating the elevators under remote manual control. The elevator industry would identify every parameter critical to the safe operation of the elevator and these would be monitored and displayed in real time on the standard fire service interface (Bukowski 2000) recently implemented in the National Fire Alarm Code (NFPA 72). This interface was developed as a tool for incident management that can collect information from its own sensors and other building systems (through a common communication protocol such as BACnet) and display the information in a format common to all manufacturers' systems. The interface further supports specific control functions so that the operator could manually initiate recall if any monitored parameters exceed the allowable operating envelope (Fig 3).

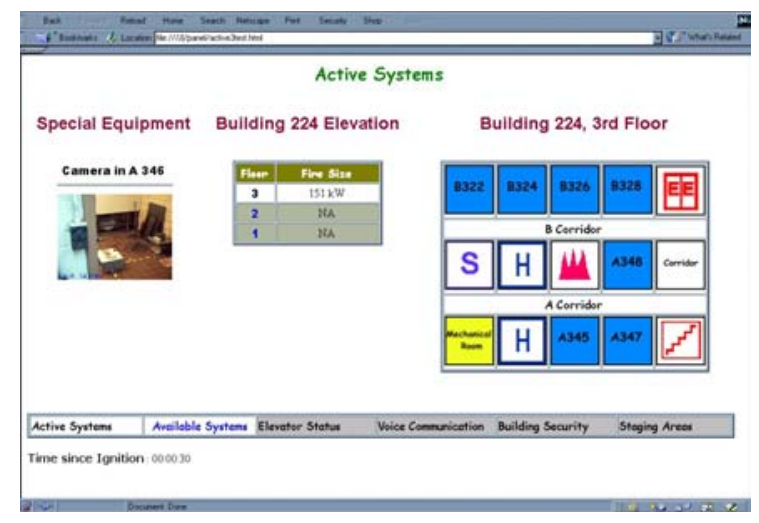

Figure 0 - NIST prototype fire service interface 
Because continuous monitoring of the system is crucial to safe and reliable operation, we propose incorporating a triple redundant communication pathway. The fire alarm system is currently required to incorporate two redundant communication trunks usually run up the two stairways. Either trunk is sufficient for the full system operation and two-way communication to the entire building. While these trunks are "remote" it is possible that a single event could sever both trunks, rendering the portion of the system above the breaks inoperable. We propose providing a wireless link between the bottom (generally the fire command center) and the top of the system as a third, independent pathway. This would maintain full operation of the system should both trunks fail. This would add little cost, ensure high reliability, and can be done with current technology.

One outstanding reliability question involves the provision of emergency power to the elevators. Most tall buildings have triple redundant power systems with generators on site. The problem is that the power is generated at the base of the building and the hoisting and controllers are at the top. How do we provide a reliable transmission path between the two? It may be possible to use a battery/inverter system in the machine room with sufficient capacity to move the cars safely to

the bottom. Similar systems powered from small batteries are used in seismic areas to move cars a single floor.

\section{Development Of Operating Procedures}

Prior research and recent advances can address all of the technology issues identified as critical to the safe and reliable operation of elevators during fires. The remaining piece is the development of operating procedures for access, egress, and rescue of the disabled that are sensitive to the human factors issues and to the need for these activities to occur simultaneously in tall buildings. Thus the systems must be designed and used such that they do not interfere with all these uses.

\section{Firefighter Lifts}

Many US fire departments have adopted operating procedures for fires in tall buildings that incorporate elevator access that are similar to those described in a draft CEN/ISO standard (CEN) for firefighter lifts. The primary differences relate to the fact that most firefighter lifts are dedicated to this use and thus are immediately available to the fire service on their arrival. In the US firefighters use the passenger elevators that are either still operating or are waiting at the ground floor in Phase 1 recall.

The procedure is for the firefighters to use the lift to transport people and equipment to the protected lobby 2-3 floors below the fire floor where they stage for their suppression operations. The firefighters then move up the stairway to the fire floor with a standard length of hose (30 m is common in the US and $60 \mathrm{~m}$ in Europe), which is connected to the standpipe located in the stairs. This is important because once charged with water the hose becomes very stiff. The hose is usually looped down the stairs and back up so that it can be advanced onto the fire floor more easily. Working from the stairway also provides a protected area to which the firefighters can retreat in case the fire threatens them. The common hose lengths dictate the distribution of 
firefighter lifts within a building in the same way as the distribution of standpipes. For example, the New York City building regulations require standpipes located so that one is within $40 \mathrm{~m}$ (125 feet) - $30 \mathrm{~m}$ (100 feet) of hose plus $10 \mathrm{~m}$ (25 feet) of water throw from the nozzle of any point on a floor. Figure 4 is an illustration of firefighting procedures utilizing a firefighter lift, taken from the CEN/ISO draft.

This operating procedure highlights the importance and interrelationship of the firefighter lift, protected lobbies, associated stairway and standpipe. These components form a system described in BS5588 as a firefighting shaft. The need for an associated stairway impacts on the arrangement of the components and on the designation of multiple cars of an elevator group as firefighter lifts. It also raises issues of the firefighting lift and stair used for occupant egress.

\section{Egress Assistance for People with Disabilities}

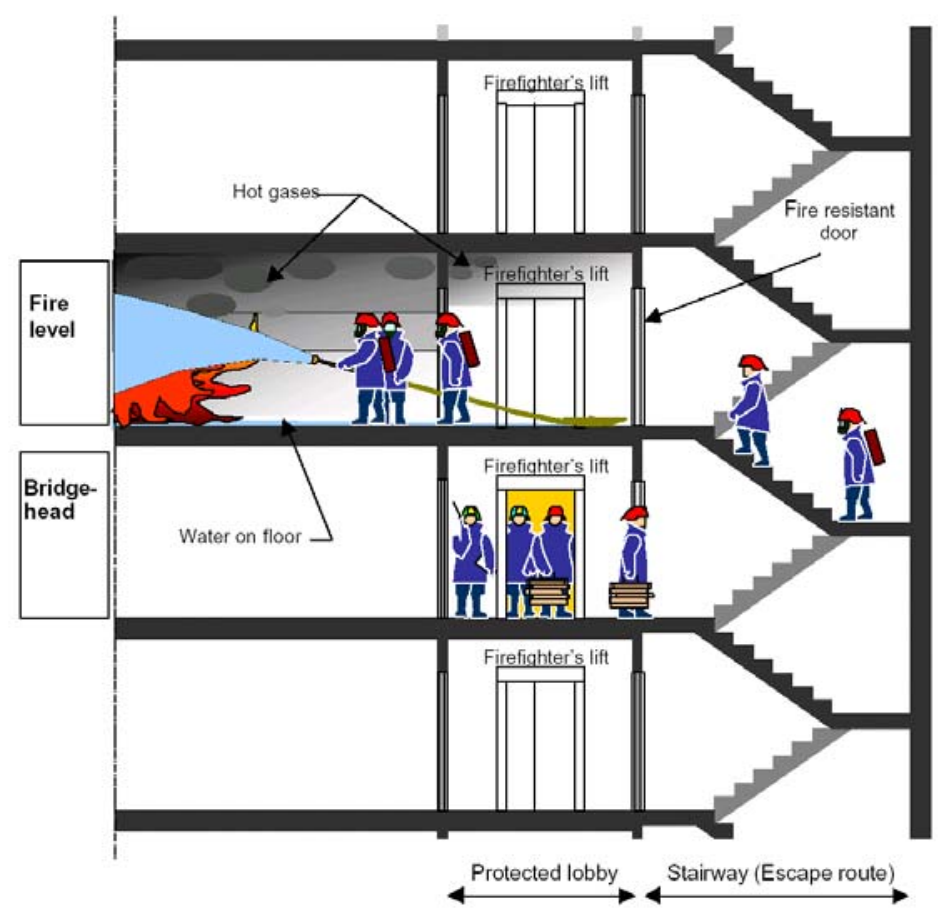

Figure 0 - firefighter lifts carry people and equipment to the floor below the fire with attack staged from the stairs ${ }^{9}$

Standards for firefighter lifts all include their use by firefighters to provide evacuation assistance for people with disabilities. Even in the US where there are no firefighter lift standards the building codes require accessible elevators (part of an accessible means of egress) that are used by the fire service to evacuate people with disabilities. The procedures generally are that such occupants proceed to the protected lobby (sometimes called an area of refuge) and request evacuation assistance through a two-way communication system (to the fire command center) provided.

Not covered is any procedure for coordinating the use of the lift for evacuation assistance with that of firefighting. First priority will be given to moving firefighters and equipment to the staging floor to allow the start of suppression operations. Then a firefighter would presumably be assigned to begin to collect waiting occupants in the lift under manual control. Command staff in the fire command center could inform the operator on which floors there are occupants waiting and these could be gathered in some logical order and taken to the ground floor. If there are more occupants than can be assisted in a single trip there is a question about the order in which they are removed. Presumably, this would be done for the floors nearest the fire first, then above the fire and finally below the fire. Because these people are required to wait it is especially important to provide this two-way communication system to the lobby (Fig 5) so that 
they can be reassured that assistance is coming. The real-time monitoring system described earlier would assure that conditions in the occupied lobbies remain tenable.

\section{Occupant Egress Elevators}

As mentioned earlier, with only rare exceptions for special cases, elevators are taken out of service in fires and people are advised never to use elevators during fires. This policy does not represent a severe hardship for most buildings and occupants, but poses problems for people with (mobility) disabilities and for tall buildings where stairway egress times can be measured in hours.

Operational procedures for occupant egress elevators raise some interesting issues. First, how can overcrowding be avoided? Elevators have weight switches that disable an elevator that is overcrowded. Without a floor warden or firefighter controlling the loading it is likely that occupants may attempt to overcrowd an elevator during emergency evacuation. Similarly, the elevators are unlikely to be capable of handling a large fraction of the floor load - the system specified for air traffic control towers is designed for elevator evacuation of not more than half the occupants. How will

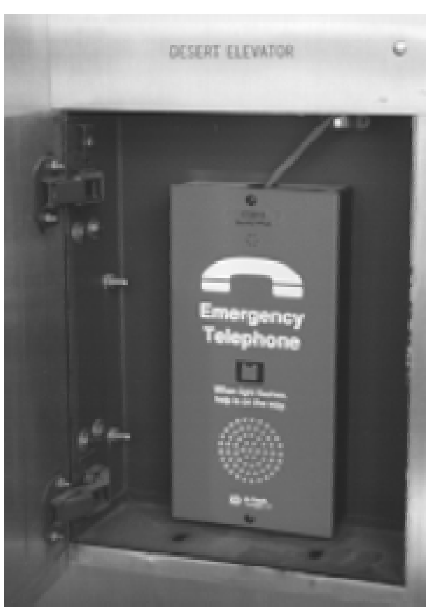

Figure 0 - Maintaining communication with waiting occupants is crucial at least half the occupants be encouraged to take the stairs? One possibility is to limit the capacity of the lobbies so the excess is forced into the stairways. Another is the phased direction of the elevators to evacuate floors near the fire first. If occupants have the choice of waiting in the lobby or beginning to move to safety down stairs, what choice will they make?

Egress elevators are most likely to be utilized in tall buildings and here the elevator systems are vertically zoned in 30- to 40-floor sections. How would elevator evacuation be operated with vertically zoned elevators? One example where this is being done is for an 88-story building currently under construction in Melbourne, Australia. In the Eureka Place Tower, elevators in the third of the building containing the fire are taken out of service and occupants all use the stairways to the next (lower) transfer floor where they board express elevators to grade. People with disabilities are assisted by firefighters in their dedicated lifts within the zone of origin. This strategy is similar to the Petronas Towers where occupants above the sky bridge level use stairs to that level, move across to the other tower, and use the elevators to grade.

\section{Coordination of emergency elevator uses}

Finally, the complete integration of the elevators into the emergency operational plans in tall buildings presents some coordination issues that will need to be addressed. One example is whether firefighter lifts and egress elevators can share common lobbies (Fig 6). Occupants awaiting egress may interfere with staging of suppression operations. Another is access to stairs and the use of the stairs for mounting the fire attack as discussed previously. A third is the sequence of egress operations. First priority would be given to egress of occupants from a few floors around the fire floor. Next a group of floors above the first group should be evacuated but if a disabled person enters a lobby on another floor at what point should that person be 
extracted? These sequencing delays would likely cause people on other floors to use the stairs rather than awaiting the elevators. Should people above the fire take the stairs to a point and then transfer to the elevators while people below the fire should take the stairs all the way? NIST plans to incorporate elevators into evacuation models so that a series of simulations can be conducted to identify the most effective operational procedures. NIST is also working with the US elevator industry to develop control software that can adapt to changing conditions and maintain safe and reliable operation of the elevator system.

\section{Concluding remarks}

Operational procedures and sequencing will have an effect on the design and arrangement of the entire egress system and need careful thought. The operational procedures selected must take into account complex human behavioral issues to be successful and also have significant impacts on the

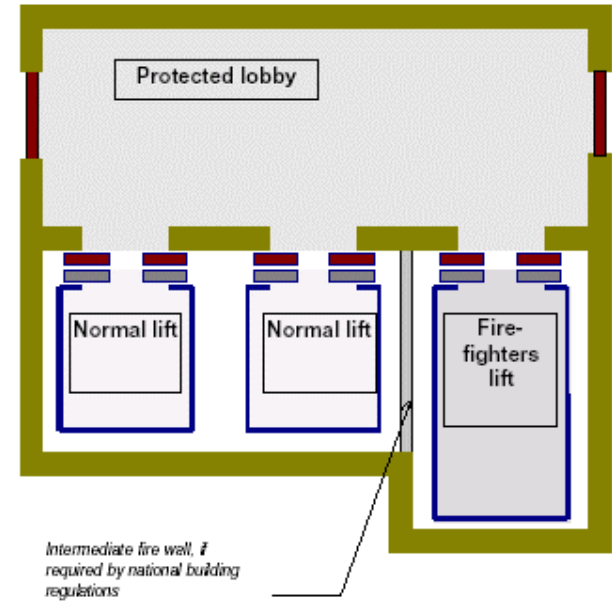

Figure 0 - Will shared lobbies lead to interference between operations and egress? design and arrangement of the systems. Thus these issues should be discussed and resolved as a system so that appropriate requirements can be developed for standardization. Finally, there are significant advantages in developing common approaches globally. With the degree to which people travel internationally it is highly advantageous to have consistent emergency procedures so that people know how to react and do not depend on instructions that may not be understood clearly due to language difficulties.

\section{REFERENCES}

ASME, Safety Code for Elevators and Escalators, ASME A17.1-2000, American Society of Mechanical Engineers, NY, 2000.

BSI, Fire Precautions in the Design, Construction, and Use of Buildings, BS 5588 Part 5 1991, Code of Practice for Firefighting Lifts and Stairs, British Standards Institution, London.

Bukowski, R. W. Development of a Standardized Fire Service Interface for Fire Alarm Systems. National Institute of Standards and Technology, Gaithersburg, MD Fire Protection Engineering, 4,6-8, SFPE Bethesda, MD, Spring 2000.

CEN, Safety rules for the construction and installation of lifts - Part 72:Firefighter lifts, CEN TC10, Committee for European Standardization, Brussels, BE.

International Organization for Standardization, Comparison of worldwide lift (elevator) safety standards - Firefighters lifts (elevators), ISO/TR 16765:2002(E), Geneva, Switzerland, 2002. 
NFPA, Life Safety Code NFPA 101 (2000 ed.), National Fire Protection Association, Quincy, MA, 2000.

NFPA, National Fire Alarm Code NFPA 72 (2002 ed.) National Fire Protection Association, Quincy, MA 2002.

Quiter, J. R. Application of Performance Based Concepts at the Stratosphere Tower, Las Vegas, Nevada. Rolf Jensen and Associates, Inc., Deerfield, IL. Fire Risk and Hazard Assessment Symposium. Research and Practice: Bridging the Gap. Proceedings. National Fire Protection Research Foundation. June 26-28, 1996, San Francisco,CA, 118-126 pp, 1996. 


\section{Building Egress Strategies}

Investigating and revising the evacuation strategies of buildings have become a primary focus for safety officials in the U.S. and around the world. Large-scale evacuations during natural disasters such as floods and earthquakes have been the subject of extensive research resulting in an understanding of information exchange and evacuee behavior consistent with emergency planning needs for such events. The purpose of this session is to discuss the use of predictive models in developing new evacuation strategies and current procedures for training and information exchange, especially in tall buildings. Although NIST is interested in "egress strategies," the body of knowledge we would like to access is how human beings behave in response to emergency information and/or life threatening events such that they take protective actions (and only ONE of the appropriate protective actions during a fire may be egress). Also, it is a goal to provide a forum for researchers working in relevant fields (social science, fire protection, human factors, traffic planning, numerical analysis, controls, etc.) to discuss similarities between evacuation from buildings and other systems, for instance the evacuation from cities. Desirable outcomes of this exchange of information are: (a) a discussion of the issues related to egress at a basic level to propose possible near-term solutions for fire officials, and (b) identification of knowledge gaps that need to be addressed in the mid-term.

\subsection{Presentations}

\section{"A Critical Review of Emergency Evacuation Simulation Programs from a Social Science Perspective," Gabriel Santos and Benigno Aguirre, University of Delaware}

The paper presents a critical review of selected simulation models, including (1) flow based, (2) mesoscopic, (3) cellular automata, (4) agent-based, and (5) activity-based models, as well as of three simulation models--FIRESCAP, EXODUS, and the Multi-Agent Simulation for Crisis Management--that incorporate social scientific processes. It concludes by pointing out the so far ignored insights that could be derived from a dual emphasis on the social psychology of the actor and on macro social organizational features such as norms and values shown in Turner and Killian's (1987) emergent norm theory of collective behavior. It concludes with a number of predictions derived from ENT regarding the effects of social organizational variables on the timing of evacuation behavior.

\section{“WTC Evacuation Study," Robyn Gershon, Columbia University, NY.}

Data on the qualitative phase of the WTC Evacuation Study will be presented. Special emphasis will be placed on the individual, organizational and structural factors that affected evacuation. Preliminary findings based on the data will be discussed.

\section{"Public Behavior in Response to Warning Information," Dennis Mileti, Natural Hazards Research Center, University of Colorado}


This presentation will refer attendees to the over 300 publications in the social sciences regarding public response to risk information. It will summarize this literature regarding the state of the art for public warning response (which includes evacuation) and pre-emergency public education. Bibliographies and summary papers will be made available to workshop participants.

\section{"Developing Robust Evacuation Instructions within an Intelligent Evacuation, Rescue and Recovery System," Elise Miller-Hooks, University of Maryland}

A concept for an expert system will be described that, through the use of sensor technology, can permit real-time assessment of the extent of blast damage to a building, can recommend immediate actions that can be taken to mitigate the situation and prevent further deterioration, and can be used to aid the rescue workers and evacuees in rescue efforts and safe egress. The key capabilities of this system stem from the electronic integration of two critical components: a near real-time intelligent BDA/TVA tool and on-line egress-related optimization techniques. Methodologies will be discussed for determining optimal and robust tactical and operational strategies for rapidly evacuating a large burning building or a building that has come under attack by enemy or natural catastrophe. These procedures explicitly consider the inherent dynamic and uncertain nature of circumstances requiring evacuation. Therefore, they give rise to robust evacuation plans with lower probability of failure than paths determined otherwise, enabling faster and more efficient evacuation of a building in the event of military attack, fire, natural disaster, discovery of a hazardous material or biological agent, or other circumstances warranting quick escape.

\section{The Challenge of Creating Protective Environments: Leveraging Information for Dynamic Feedback, Gregory Luther, United Technologies Research Center}

Building systems are increasingly equipped with sensors, communications and computing technologies to deliver cost effective operations, security, and building management services. Advancements in building state awareness through wireless sensor networks, video surveillance, and RF ID's can be leveraged using data mining and reasoning algorithms that enable emergency personnel to manage large amounts of data more quickly in order to make higher fidelity decisions that will protect people from harm. This sequence of awareness, communication, planning and action comprises a feedback loop that creates and maintains dynamic protective environments. It must be considered in the design and implementation of effective egress strategies. Modeling capabilities for threat evolution and occupant motion, an integrated concurrent design process, and demonstration projects are necessary elements for progress towards safer building systems.

\section{"Sensor Networks and Elevator Control for Optimizing Building Evacuation," Christos Cassandras, Boston University}

Emerging wireless sensor network technologies provide unprecedented opportunities for "smart" building management leading to lower costs, higher efficiency, and better security. In emergency situations, sensor networks can play a critical role in supplying real-time information which can be used in conjunction with appropriate elevator dispatching control for building evacuation. 
This presentation will overview modeling and analysis methodologies required to actualize the potential of new technologies for smart building management, discuss the problem of optimal evacuation, and show how its solution is sometimes counterintuitive.

\section{"Coherent Configuration and Operation of Building Traffic Systems," Shi-Chung Chang (presenting), Peter Luh, Bo Xiong, and Laurent Michel, University of Connecticut}

Life-cycle optimization of building traffic systems is to exploit various technologies for the configuration, operation, and adaptation of these systems for improved efficiency, reduced costs, enhanced security, and greater occupant satisfaction. Formal models, methods, and tools are largely missing even in their outline forms. Using normal and egress modes of elevators as a conveyer example, this paper presents a methodological framework for coherent configuration and operation optimization of building traffic systems. In the framework, formal semantics serves the coherence specification in a multi-model, multi-mode, and people-in-loop environment. A price-based decomposition and coordination approach then solves the problem for both normal and emergency modes while considering the interactions with HVAC systems.

\subsection{Session Summary}

The objective of this session was to discuss the use of predictive models and emerging technologies in the development of new evacuation strategies. The emphasis was on tall buildings. Three main themes emerged from the presentations and discussions: a large body of knowledge in the area of human response in emergencies is available but largely untapped, the ability to develop predictive models is available but data is required for validation, new technologies are becoming mature to the point where they can be used to improve occupant safety and provide early information to first responders but technology development and demonstration projects need to be appropriately resourced.

The current state of knowledge in the area of human response related to egress conditions is represented by several studies conducted over the last decades on emergency evacuation of cities, mostly in the context of earthquakes and nuclear disasters. One part of these studies was focused on developing an understanding of human response and the factors that influence it. In recent years, studies have focused on building and ship egress, however the number of such studies is still small. Several speakers suggested that this body of knowledge remains largely untapped by the community studying building egress. In the current state of the practice evacuation plans are developed to be executed during emergencies. These plans do not rely on the use of real-time information or knowledge of how to influence human behavior in stressful situations to guide occupant egress.

Several models have been developed in recent years to predict human behavior during emergencies. There is a wide variation in what aspects of human behavior are accounted for, ranging from pure kinematics, to flow-type models, to cellular-automata, to rule-based models. One common thread in the discussions is the unavailability of reliable data to independently validate existing and future models. Another aspect is the ambiguity regarding the required level of accuracy as a function of the questions being investigated. For example, is a flow model sufficient for the design of egress routes or should more complex social interactions such as 
leader behavior be included? For a given application, how does one establish that models provide the required accuracy level? Lastly, when should models be used, in design of highprofile buildings or in more routine building and egress design?

Several speakers addressed emerging technologies and their potential use as a means to achieve safe and controlled building egress. Projects sponsored by the Department of Defense over the past two decades have produced technologies that could be adapted to increase building safety. Examples are sensor networks, large-scale optimization methods, distributed control and actuation, and supervisory control. These and other technologies have been successfully used to enable remote sensing of battlefields, perform real-time threat assessment, and control autonomous flying drones. However, most of these technologies are too expensive or require adaptation for deployment in typical buildings.

The discussion highlighted the need to address the main obstacles first while producing results that could be used by first-responders in the short-term. The main obstacles identified were the following:

- The gap between social sciences and engineering needs to be bridged. The effectiveness of new technologies is dependent on their ability to be integrated in inhabited environments and used by building occupants. For example, how do we use existing knowledge and technologies to direct occupant behavior in a desirable manner? What procedures can rely on the automated operation of building systems and which cannot?

- Reliable and readily available experimental data needs to be measured and used to validate predictive models. Technological and social barriers to acquire the data were mentioned, such as occupants' reluctance to participate in drills and the absence of automated ways to record traffic flow that extract the necessary information for model development.

- There is a lack of models capable of accurately predicting the population response during an evacuation. For example, there are several studies on the possible use of elevators during egress situations with widely different conclusions on its feasibility. Discrepancies like this decrease the confidence in the use of models as tools to develop new egress strategies.

- Full-scale test sites are needed to demonstrate solutions. The adoption of new solutions would be faster if demonstration projects in inhabited buildings were pursued and used to gather feedback from stakeholders.

The participants in this session made several core recommendations. They identified a basic need to create mechanisms that enable joint work on building egress among national laboratories, academic researchers and industrial concerns. They identified the need for key stakeholders to develop a roadmap that articulates a development and demonstration path for new solutions. Both funding and test sites would be identified as part of the execution of this vision. Finally, they identified the need to tackle several urgent projects of smaller magnitude in the near term. These projects will address central parts of a longer-term vision, but they have high urgency and longer lead-times. These near-term initiatives and their stakeholders should be identified along with the appropriate funding mechanisms that will bring teams and resources together. 


\title{
3.3 A Critical Review of Emergency Evacuation Simulation Models
}

\author{
Gabriel Santos and Benigno E. Aguirre \\ Disaster Research Center, University of Delaware
}

\section{NIST Workshop on Building Occupant Movement during Fire Emergencies June 9-10, 2004}

The paper presents a critical review of selected simulation models including (1) flow based, (2) cellular automata, (3) agent-based, and (4) activity-based models, as well as of three simulation models that incorporate social scientific processes--FIRESCAP, EXODUS, and the Multi-Agent Simulation for Crisis Management. It concludes by pointing out the so far ignored insights that could be derived from the fields of social psychology and social organization. A number of predictions regarding the effects of social organizational variables on the timing and movement of evacuating groups are presented.

We offer a critical review of selected simulation models of evacuation behavior based on published descriptions of their characteristics rather than on empirical tests of their claims (compare to Kuligowski, 2003). A second section of the paper identifies social sciences approaches that could improve present day simulation models. Our argument is that the social sciences could provide important new directions to simulation models of emergency evacuations; to the extent that simulation models are attempting to incorporate actual human social behavior, a dialogue among engineers, computer scientists, fire scientists, and social scientists would render such models more accurate and realistic. So far, as we will show, the absence of this dialogue has impacted many of these models.

It is useful to think of evacuation behavior during emergencies, commonly referred to as emergency egress, as having three distinct analytical dimensions: the physical location of the evacuation (the environment and its configuration from which to evacuate, as well as the configuration of the hazard); the existing management of the location (the managerial policies, procedures, and controls deployed at evacuation); and the social psychological and social organizational characteristics impacting the response of persons and collectivities that participate in the evacuation. It is much more common in the literature to find consideration of the first two dimensions, as exemplified in Elliot and Smith's analysis of football stadia disasters in the United Kingdom (1993), than of the third, despite the fact that real advances in our understanding of emergency evacuations will depend on their holistic integration.

\section{Traditions in the Study of Emergency Evacuation}

One of these traditions focus on the physical, engineering dimensions impacting smoke control and the movement of people in buildings (Gwynne, Galea, Owens, Lawrence, 2000). It calls attention to the impact on evacuation movement of the presence and location of exit signs, position of exits, width and other conditions of stairs. Increasingly, it also recognizes the importance of emergency training and the existence of programs of exercises, drills, constant monitoring of safety in buildings (Pauls, 1978), and appropriate building code legislation 
(Jennings, 2000). A key part of this tradition is evacuation simulation models. Such models have burgeoned, a development that demands particular attention to the needed inclusion of insights from the social scientific literature as they pertain to group integration and emergent group processes. We next review a single model from some of the most widely known simulation methods, including (1) flow based, (2) cellular automata, and (3) agent-based models. We also examine three models that incorporated social dimensions, the FIRESCAP, EXODUS, and Multi-Agent Simulation for Crisis Management.

\section{Flow-Based Modeling}

EVACNET4. The EVACNET4 model employs a flow-based approach that models the density of nodes in continuous flows (Kisko, Francis, and Nobel, 1998). EVACNET4 enables the user to construct a simulated physical environment as a network of nodes. The nodes represent physical structures, such as rooms, stairs, lobbies, and hallways that are all connected and comprise a single structure from which an evacuation is executed. The user defines the "contents" of the all nodes-as-network, a step that involves the determination of how many people the particular node may contain. Certain nodes are designated as "destination nodes," thus identifying all of the possible terminal points of occupant egress. For each node, the usable area (UA) must be calculated and allowance is made for the presence of closets, equipment, and other such items, as well as the space which persons place between themselves and a wall. This latter feature entails the inward projection of each node wall by 6 inches. Besides nodes, the model also requires the provision of specification for arcs. Arcs are passageways between building components. The user must supply a "traversal time," or the amount of time periods it takes to cross the passageway, and an "arc flow capacity," which delimits the amount of human occupants that can traverse the passageway per time period.

In terms of human occupants, the node capacities are directly linked to the "queuing level of service (LOS)" (pg. 23). The LOS offers a set of parameters grouped in a range from A to F that define the average pedestrian area occupancy, the average inter-person spacing, and a brief qualitative description of conditions as evacuees would experience them. For example, Queuing Level of Service "A" posits 13 sq. ft. of average pedestrian occupancy and 4ft. of inter-person spacing, which in practice corresponds to "standing and free circulation through the queuing area is possible without disturbing others within the queue" ( $i b i d)$. Level of Service "E" delineates the most "extreme" evacuation conditions in which persons are in direct physical contact with others around them, no movement is possible within the queue, and "the potential for panic exists" (pg. 24). This brief allusion to panic will receive more attention below. For purposes of the simulation, the user divides the usable floor space by the area occupancy level to generate a tentative node capacity. The only other factor that would alter this figure is accounting for the ratio of allowable hallway floor loading to average weight of an occupant.

The arc capacities are determined on the basis of information derived from another set of service classifications, very similar to those associated with node capacities, called "Walkway Level of Service" and "Stairway Level of Service" $(25,27)$. These also provide a set of parameters that define average flow volume, average speed, and average pedestrian area occupancy. These calculations relate to hallways, stairwells, doors, and escalators. The average speeds assigned to each stairway LOS are based on the research of Fruin $(1970,1971)$, which assumes two separate 
sets of measurements for an indoor stairway and an outdoor stairway. The assumed indoor stair has a 7-inch rise $(17.8 \mathrm{~cm}), 11.25$-inch $(28.6 \mathrm{~cm})$ tread, and 32-degree angle. The outdoor stair has a 6-inch rise $(15.24 \mathrm{~cm}), 12$-inch $(30.5 \mathrm{~cm})$ tread, and 27 -degree angle. In developing the general model attributes as they relate to stairwells, the authors relied heavily upon Jake Pauls' $(1978,1980)$ flow model (22). Finally, with respect to arc definitions and data, the Width Restriction (WR) associated with each arc, usually a doorway that stands between the nodes of an arc, determines the Dynamic Capacity of an arc. Determining the dynamic capacity involves multiplying the width restriction (WR) of an arc by its average flow volume (provided by the LOS) and then by the chosen time period. EVACNET4 provides the user, at the conclusion of these calculations, the option of viewing a list of all of the specifications associated with all the nodes and arcs of the constructed network model.

EVACNET4 takes the completed network model and determines an optimal plan to evacuate the building in a "minimum" amount of time. This is achieved using an advanced capacitated network flow transshipment algorithm, a specialized algorithm used in solving linear programming problems with network structure. The user is provided a summary of results for the specified model, including total time periods, congestion factor, average number of periods for an evacuee to evacuate, and number of successful evacuees. In EVACNET4 the egress of evacuees is determined almost entirely on the basis of physical constraints such as the usable area average, flow rates, and the particular configuration of nodes. It is designed to produce results that take account of a fixed set of environmental features, assumed travel speeds, and an arrangement of varying levels of service. No provision is made for motion rules that attend to social interaction or group processes. Like other models of this sort, most social interaction elements are rendered irrelevant or superfluous because evacuation times depend primarily upon node capacity and traversal times. The consequence is that several sociological assumptions can be made but not articulated or translated into attributes or algorithms relating to the motion of persons. Indeed, this model does not lend itself to agent modeling, for it makes the incorrect assumption of agent homogeneity. The only control the user may exercise "over persons" is in setting the preliminary contents of rooms, and perhaps in setting the travel speeds. Once again, however, this relies upon viewing the movement of evacuees as a continuous flow, not as an aggregate of persons varying in physical abilities, individual dispositions and direction of movement.

The absence of agent attribute specification eschews the need to consider the sociological aspects of group decision-making processes (see below) that inhere in all emergency evacuations. The prospect of more realistic results is impeded by the lack of consideration of the more emergent and variable aspects of evacuations - namely, the behavior of evacuees that together comprise a set of groups, each of which are characterized by varying levels of integration or conflict as well as different definitions of the situation. Flow-based models, such as EESCAPE and EGRESSPRO, bypass social factors because the simulation is couched on the assumption that if the user can manipulate walking speed, physical constraints in walkways and stairways, density, and distribution of persons across the building, then this is sufficient to estimate the flow of the process of evacuation without accounting for the social behavior of individual evacuees. (Kendik, 1995; Simenko, 2001). 


\section{Cellular Automata}

EGRESS. The central difference between cellular automata modeling of evacuations and all other modeling types involves the discretization of space. This program discretizes space and models the node density in individual floor "cells." In EGRESS, the evacuees are modeled as "individuals" on a grid (AEA Technology, 2002). The grid is part of a plot plan designed by the user of the program. The program permits the testing of evacuation from a plot plan of any desired structure with metric dimensions of up to several square kilometers. The simulation technique of cellular automata frames the movement of an evacuee in this plot plan as a series of "time-steps," whereby the simulated person moves from cell to cell on the basis of a throw of a weighed die. Furthermore, "the weights required for the die are calibrated against information on speed, or flow, as a function of density, so that the experimental data can be adequately represented where it is valid" (ibid). Evacuees modeled within this program, then, are assumed to maintain a certain amount of space between themselves and other evacuees. The movement of the evacuee can also be compared to the progression of hazardous substances or smoke. The strength of EGRESS as a simulation program is found in its capability to execute this sort of comparative analysis an answer to the question of how the flow of toxic substances inhibit the timing and rate of egress. However, like several models reviewed in this paper, it is overly concerned with the tracking of the movement of an individual, not the social behavioral antecedents and processes that inform any single episode of egress. Other models to which the same comments may be applied are Pathfinder and TIMTEX.

The "magnetic model" of Okazaki and Matsushita (1993) illustrates the above-mentioned problem. It "equips" the individual occupant with certain specialized features pertaining to movement but not with calculations relating to social capacities. Each occupant has three different methods of walking (indicated route, shortest route, and wayfinding) and can join a group (http://www.anc-d.fukui-u.ac.jp/ sat/ECS93.pdf). The group-joining function, however, is not the result of an individual, or set of individual, probabilistic calculations rooted in conceptions of social interaction. Instead it is solely dependent on the size of the population: groups are formed only if the population grows to a certain size and then the group travels toward a common destination with the same start time, orientation, and method of walking (Okazaki and Matsushita, 1993: 6-10).

One of the problems with these models is that the culturally-appropriate norms regulating personal space break down in situations of crisis such as emergency evacuations, so that it is very difficult to know a priori what values to use for the setting of this parameter in the simulation models. Moreover, very often it is the case that to understand the initiation and speed of movement of the evacuee we must also understand the pattern of movement of his or her group. Thus, primacy must be placed in conceptualizing the evacuee as embedded in a web of social norms and in command of certain communicative abilities, making necessary to include in simulation models symbolic interaction processes and group decision making. 


\section{Agent-Based Modeling}

SIMULEX. The SIMULEX Version 2.0 evacuation simulation program features an advance in the area of evacuation simulation software, for it "individualizes" the movement of groups. That is, it fixes a certain set of attributes to each "person," so that "the walking speed of each person is assessed independently of the average density of a group in a defined area" (Thompson and Marchant, 1995: pg. 132). As Thompson and Marchant indicate, the model allows each person to decide upon his or her own walking speed. Beyond this improvement, the program also takes several other factors into account, which are included in the derivation of motion algorithms. It includes several factors such as physical motions and gestures (body swaying and twisting), the proximity of other evacuees, the shape of the building structure, and the influence of sex (male or female) and age (parameters defined for persons 12-55 years old) that are said to have social significance but that are not based upon concepts or information about social relations, culture, or group integration. Instead, the program assumes the presence of a rational agent able to assess the optimal escape route and the agent's ability to avoid physical obstruction and "overtake" other persons that are conceptualized as impediments to movement.

During the preparation phase in which the density of the population is determined (and then entered into SIMULEX), it is mentioned that "a grid of occupants, with regular spacing between each person is then located within available space of the populated area" (pg. 138). The use of the term "regular spacing" is apparently based on research findings (perhaps from Ando et al. or Bryan), but it is not clear from whom the figure is derived or whether they could be adjusted for "seasonal differences." That is, as Pauls (1975) has shown in various reports, the wearing of heavy winter clothing as opposed to light, casual wear influences walking speed and hence any basic assessment of personal space. Moreover, as a number of studies in the sociology of collective behavior have demonstrated, people are very seldom if ever evenly spaced in public areas. Rather the typical configuration of people distributed in space in gatherings in public areas is that of the small group in circles and semi circles, which would be a much more preferable assumption than regular spacing.

The authors indicate that the evacuation simulation consists of a "series of repeated analytical loops... at each time-step, the position and attributes of each individual are retrieved... [and] the processing for the whole population occurs sequentially in the order of the person nearest to exit first, to the person furthest from the exit, last" (pg. 142). Do these analytical loops entail that as the program is working out the motion of a person, say, five meters from the exit (which it will do first), there is "nothing" occurring with a person that is 20 meters away and perhaps still in a room, that is, not until the "cycle comes back" to him or her. If it does, then this procedure ignores the fact that gatherings of people in evacuations are more appropriately conceptualized not as the sum of disaggregated sections but as totalities experiencing dynamic processes. As such, communication is often impeded from front to back to front of the gathering (Johnson, 1987), with attending misunderstandings as people try to move towards exits. It is also the case that people in a gathering are not uniformly motivated to participate in the central theme of the gathering, so that often the people to the front of the gathering before the crisis materializes, or those closest to where the action is, have greater commitment to the event that is taking place; they may be self selected on the basis of age, marital status, gender, and other characteristics that 
will have an impact on their evacuation behavior as they respond to the crisis (Seidler, Meyer and Mac Gillivray, 1976).

Sequential processing also raises other problems. There are many cases in which widely differing conduct is occurring simultaneously during an evacuation. For example, individual persons may be exiting a building at one location while at another spot there is a group of persons considering how to help an elderly person travel through the corridors. A general movement of all persons toward building exits at all times is not typical, even if varying in flow speed at different locations. Some research has demonstrated that in many instances there may be a "front-to-back-to-front" dynamic in evacuation movement. Johnson et al. (1994) identified the reentry of evacuees or reversal of motion among evacuees who were concerned with the well being of unaccounted group members that remained within the Beverly Hills club. In his study of the 'stampede' at "The Who" concert, Johnson (1987) also found that those at the back trying to enter the auditorium were largely unaware of what was happening at the front of the gathering, as the huddled mass near the front gate desperately tried to survive the crush. The mutual ignorance of each segment of the gathering contributed to an unfortunate situation whereby the group attempting to escape the crushing effect clashed with the group trying to enter the building. The police's initial misunderstanding of what was happening, so that instead of opening the gates to let people into the building they kept them closed, aggravating the problem. The general insight to which this study contributes is that different people and groups in different areas may have markedly divergent views of the on-going situation. The last comment above leads to the most important set of recommendations and questions related to SIMULEX. Is it possible to apply motion algorithms to incorporate spatial-temporal and social characteristics of interactive processes that are associated with the emergence of norms and new definitions of the situation? This goal would involve the incorporation into the model of processes of social interaction such as milling and key-noting impacted, as Weller and Quarantelli suggested (1973), by pre-established and emergent social relations, and preestablished and new or emergent norms_ rules for conduct.

To a limited extent, the program (Version 2.0) accounts for size of the group, potential physical incapacity, and visibility. We are not certain if it incorporates the effect of major physical disability and the subjective elements involved in recognizing signs of danger (see below). In terms of the first, perhaps calculations related to persons that are portrayed in the simulation as nearest to the source of fire or harmful substances could be adjusted for a range of severity of injury or probability of injury. In terms of the second, environmental features must be available to sensory perception before they can be interpreted as dangerous. The subjective availability and interpretation of the environment comes before the formation of a subjective awareness of danger. Thus, some adjustment must be made in the simulation model for movement from one spatial block to another when one block contains persons cognizant of an extreme threat and in collective agreement of the threat as opposed to persons in another block who are monitoring the environment but who have not developed the cognition or the collective awareness, or even people who cannot monitor the environment and have no possibility of developing an awareness of the threat. It is also the case that even if subjective understanding of danger exists in an individual, it may not be enough to cause his or her evacuation behavior, for other social organizational considerations may militate against it, such as group consensus regarding the 
inappropriateness of the evacuation response, or subcultures that discount the message and the severity of the possible effects.

The social scientific literature attests to the importance of social control (evacuation management personnel) agents in emergency evacuations. Yet SIMULEX does not appear (at least in the 2.0 and 3.0 versions) to address the function of social control systems even though they often provide important information and constraints. How can their issuing of warnings or directions for movement be integrated into the simulation? Later on we address the problem of leadership. The testing of the SIMULEX model within the Superstore building points to the potential problem of intra-group and inter-group conflict surrounding the appropriate definition of the situation (see below), that is to say, there may be various sub-groups, some comprised of persons who are quite cohesive (maybe even kin), each of which are proceeding through a building only to confront other groups at a particular juncture in the building. Depending on the social characteristics and emergent practices (agreed upon definitions) assumed by each group, various consequences might ensue once they start interacting with each other and exchange information. The presence and uniformity of social control agents and the dissemination of evacuation directions may further modify the outcome of these interactions. Different building and settings and occasions will have different mixes of groups. It is reasonable to assume that different proportions of strangers, kin, and workmates characterize the groups in a gathering of a Fourth of July celebration as opposed to a non-holiday shopping day at the Superstore. The pre-existing and emergent normative agreement in each group as well as the probable distribution of stable and emergent group characteristics must be gauged differently from one type of gathering to another. The model may also have to allow for the inclusion of more features of the physical building during the DRAWPLAN phase. For example, certain room fixtures, furniture, and other devices may serve as resources for a group facing fire-related threats.

The EXIT89 model has the same sort of shortcomings as SIMULEX, in terms of social interaction and emergent group response. EXIT89 includes individual bodily dimensions (American, Soviet, or Austrian) and allows the specification of the number of disabled occupants, yet it does not incorporate bodily actions and gestures (Fahy, 1999). It also considers the counter-response of evacuees whose path during egress is blocked by smoke accumulation near an exit. The model determines travel time as a function of density and speed within a constructed network of nodes and arcs. The "shortest route" algorithm is combined with an individual perspective for each evacuee to track the path and progress of individual evacuees (Fahy, 1996; 1999). However, all the occupants of a certain node will initially traverse the same user-specified path, or shortest known path, to an exit. Moreover, the user is also able to set the percentage of occupants who will be assigned a delay time. These dual functions (a particular path for an entire group and delay) mimic group behavior in an implicit manner. A major drawback persists: individually tracked evacuees, although carriers of particular physical characteristics that affect the flow of evacuation, are devoid of social interactive characteristics such as monitoring others, directing, collective evaluation and collective agreement on appropriate response. The implicit inclusion of group behavior is not an ideal solution, for social interaction processes that feed emergent group processes are a crucial element in the understanding of all evacuations. The manner in which persons pursuing coordinated action relate to one another must be examined, for it will result in more diverse evacuation results and increased complexity of social action among evacuees. 
In conclusion, SIMULEX does not incorporate group level processes. The review of the agent based models (i.e. SIMULEX, EXIT89, GridFlow) and flow-based models lead to the conclusion that neither the fluid mass nor the atomized individual within or without a group should be the sole referent for evacuation simulation models and research. Even though a plethora of socially relevant factors can be included in a model and will play an influential role on evacuation rates - such as in ALLSAFE, which includes individual level of alertness, social role, social affiliation, and visual perception - none of these can serve as substitutes for association or social interaction (Heskestad and Meland, 1998).

\section{Models Incorporating Sociological Factors.}

Exodus. In comparison to other models that incorporate sociological insights, the EXODUS simulation program furnishes perhaps the most complete set of social psychological attributes and characteristics for each agent, twenty-two in all. This set includes age, name, sex, breathing rate, running speed, dead/alive, among others. The agents in EXODUS also possess a fixed degree of familiarity with the building, agility, and patience. The model simulates the egress of large numbers of persons from an enclosure, but also accounts for the eventual cessation or delay of movement due to extreme heat or effect of toxic gases. The general model has been developed into different versions that vary according to several different contexts in which evacuations may occur, including ships (maritimeEXODUS), planes (airEXODUS), and buildings (buildingEXODUS).

As a primarily agent-based model, the movement of individuals in EXODUS is established by a fixed set of motion rules. The model as a whole is comprised of five interacting sub models: movement, behavior, passenger (agent), hazard, and toxicity. For instance, the hazard model will generate values that correspond to a particular configuration of threat across the simulated environment. The toxicity model determines levels of exposure to toxic substances, which then affects the values of the variables associated with agent behavior, which in turn influences the calculations of the movement model.

Owen et al. have demonstrated the prospective contributions of this model toward the prediction of evacuation performance and realistic modeling of social behavior. EXODUS features, for instance, an "itinerary list" (thus introducing an activity-based element) whereby each individual evacuee performs a certain amount of tasks before exiting the building. The potential actions on the itinerary are manifold, such as returning to a location to pick up a purse, performing a task in compliance with safety-related instruction, or even searching for a lost child. This latter capability speaks directly to numerous empirical findings. EXODUS also contains a feature that enables the use of signage, enabling evacuees to communicate through gestures during the way finding period (Filippidis et al. 2003). The aforementioned features, in combination with other rather unique functions such as a sub-model that measures the impact of irritant products and two parameters that enable evacuees to avoid congestion during general movement and congestion at exits, mark the EXODUS evacuation model as one of the most comprehensive (along with CRISP, a model from the UK) in terms of the inclusion of multi-dimensional factors that affect decision-making during evacuation. 
EXODUS rightly directs attention to the potential need of conflict resolution during an evacuation. This behavior rule is probabilistically determined - that is, it will simply occur or not occur and hence is not reducible to smaller-scale interactions between agents. Parallel to several other models, the behavior sub-model in EXODUS determines the actions of evacuees to the "current prevailing situation on the basis of personal attributes."

EXODUS is one of a group of models that have accumulated an impressive constellation of factors that inform a more realistic evacuation scenarios. For instance, the ASERI model allows for the establishment of parameters such as age, sex, fitness, and special knowledge of the building. It also enables the evacuee to "seek for information" about the precipitating event and "inform others." This form of social interdependence, though modeled in ASERI in a very limited fashion, is crucial to any simulation program. Furthermore, the agent or evacuee can be allocated a "prepare" time in order to get dressed if sleeping during initiation of the threat or to fulfill other tasks before evacuating (Schneider, 2001). Similarly, CRISP3 provides for the capability of entering the social role and occupational data for an entire population, as well as probability calculations that determine a multiplicity of additional actions on the part of firefighters and evacuees, such as searching rooms, investigating, and even completing work (Fraser-Mitchell, 2001).

To be sure, EXODUS (and similar models) allows input from sub-models relating to the environment (toxicity) and the physical structure to alter certain behaviors that are pre-defined as not fixed, such as agility and mobility. However, as with the other models included in this analysis, there is a lack of micro-level mechanisms (probabilistic or otherwise) or other heuristics by which robust interaction within a group can generate emergent behaviors during emergency evacuation. More specifically, the EXODUS model, along with ASERI and CRISP3, do not integrate a vast catalogue of rules and probability functions that move the agent through different micro-level interactions with other agents and that (1) vary in level of social integration (for example, stranger, work associate, friend, family member) and (2) compel the agent to engage in a series of relatively quick yet sophisticated exchanges that create a collective definition of the situation for the group. Of course, an EXODUS user may direct an agent or group of agents to retrieve some item before exiting a building — but, this ability does not make a distinction between the imposition of this action upon individual entities within the program, on the one hand, and the emergence of this action as an outcome of several interactive exchanges, on the other hand. The latter option would infuse the evacuation simulation with increased social realism, for it would require highly nuanced construction of social behavioral rules that would focus attention on matters of leadership, the effects of social integration and cohesion, and the exchange of ideas among evacuees about possible courses of action (http://fseg.gre.ac.uk/fire/news.html\#exodus_news). This last point is worth stressing, for members of groups involved in evacuation have personal histories, skills, and other attributes that orient their interaction during the crisis and may eventually influence their willingness to follow the direction of the leader and the decisions the groups make.

Some simulation models do include a series of subroutines or sub-calculations for each evacuee that realistically simulates aspects of the decision-making process during emergency situations and provide the foundation for the inclusion of realistic social interaction. The model BFIRES (Stahl, 1982) involves the activation of two different sets of computer subroutines. One 
simulates perception and information gathering, while the other set of subroutines simulates information processing and decision-making. This includes a subroutine that compels the evacuee to gain information from persons that occupy the same general space and another subroutine that informs the occupant on whether the group can agree on an exit route. Another subroutine, BYSTND, determines probabilistically if an occupant will ignore a disabled person (Stahl, 1982). Another set of subroutines determines whether an occupant will or will not close a door after use. Once again, however, this level of complexity is still couched at the individual level, so that group level processes are skewed, such as the potential problem of lack of integration or conflicting perspectives.

Multi-Agent Simulation for Crisis Management (MASCM). This model improves upon other simulation models that are concerned with numerical analyses of inputs or amounts of people and structures. Murakami et al. rightly assert that the presence of evacuation leaders and the functions they serve during evacuation must be included in order to improve the validity of existing simulation models. The chief rationale for the inclusion of leaders is the expectation that they are key players in a variety of scenarios, which includes police officers, firefighters, security guards, and ushers. Indeed, Murakami et al. recognize the same set of criticisms that have been presented above, and thus aim to overcome the assumptions that permeate "traditional" simulators, including group homogeneity, unidirectional movement, and insignificance of social interaction. These researchers posit the pivotal role of leaders, especially in relation to changes in evacuation route. This feature serves as a welcome improvement to programs that only allow the user to specify whether the occupants will follow the shortest path out of a structure or, alternatively, use a familiar route, but do not furnish the computational mechanisms necessary to address (1) the existence of a leader (i.e. EXIT89 High Rise Evacuation Model), and (2) the possibility that a leader may lead a group through a path that is neither the shortest nor the familiar path, but is the only available path considering the location of the fire or threat

Murakami et al. develop a multi-agent system for crisis management that is grounded, as is the case with EXODUS, on empirical data taken from "real-world" experiments (e.g. Sugiman, 1988). These experiments serve as benchmarks against which the data from the simulation is compared. Thus, they established a feedback loop between the model and the empirical evidence - although the independent confirmation of the validity of these claims is still missing. Prior to the development of the model the authors explored the impact of social interaction as simulated in $3 \mathrm{D}$ virtual spaces, which enabled the identification of the subtleties attending the interaction of evacuees and leaders in order to develop an accurate interaction language, called Q. This interaction language governs the operations of simulated agents created by two simple multi-agent systems, FreeWalk and FlatWalk. FreeWalk generates a 3-dimensional environment that produces agents that may interact with each other verbally and perform visual gestures, such as pointing. FlatWalk produces a two-dimensional "aerial" image whereby the entire group can be monitored during evacuation; what is more, the user can track the state of individual evacuees. It is precisely in its attention to the individual evacuee that this model produces significant improvements. It enables the user to develop a distinct scenario for each evacuee. A scenario, simply put, "determines the agent's response to his environment and peers" (Murakami et al., 2002) and depicts the flow of management events. Scenarios are combined with Rules, which is another interaction language construct that specifically governs the behavior of agents. 
The rules set the parameters for agent behavior. This pair of language constructs, applied to the multi-agent systems of FlatWalk and FreeWalk, makes possible the introduction of "guarded commands" and other special forms of notation. These commands enable agents to wait for multiple events concurrently and observe the outside world while executing other actions. So, for example, a "guide agent" enters a "state of guidance" once he or she has received cues from the environment ("heard a siren"). According to the scenario set for this sort of agent, the simulated leader proceeds to "put on a cap" and enter the simulated environment. Once the "guide" agent "sees" an evacuee, he or she begins to guide the evacuee to a designated exit. These actions, in fulfillment of the pre-established scenario for that agent, can be part of a broader set of simultaneous actions. These include: (1) telling the evacuee to "Please follow me," (2) starting to walk along the evacuation route, (3) finding an evacuee at the distance, (4) waiting for the evacuee to approach and (5) listening to an evacuee speak. Actions (3), (4), and (5) represent the ability of the simulated agent to simultaneously monitor the outside world through cues and walk along the evacuation route. The untested assumption is that the evacuee thinks that the guides know what they are doing, can be heard and understood by the potential evacuees, can communicate their message effectively, and are trusted by the potential evacuees. Quite notably, Murakami et al. developed two sets of rules and scenarios for leaders: one set for the "Follow-direction Method" and another set for the "Follow-me Method." The authors chose to compare the evacuation times associated with each approach. The former involves verbally directing evacuees to an exit, while the latter involves physically leading evacuees to an exit without any appreciable verbal explanation of the route. In the scenario for the "Followdirection Method," the simulated leader is able to find those who are not moving and encourage them to do so, identify and verbally warn those who are headed in the wrong direction, and join a group of evacuees as they exit once it is determined that everyone is correctly evacuating. In the scenario for leaders using the "Follow-me Method," the leader likewise has various diverse capabilities, including the ability to identify the evacuee closest to him or her at the beginning of the egress period and lead them to the exit, to wait until those that have fallen behind recover before proceeding, and to look for another evacuee if one is lost during the guidance period.

Initially, the evacuees were controlled by the same set of rules regardless of the leadership method in use. The evacuees lacked a set of probability-based mechanisms that would represent a mode of internal information processing. That is, if the evacuee saw an exit, he or she proceeded towards it, and if he or she recognized a leader and received any type of direction to leave, such would be carried out without fail. However, after analyzing a video of actual human evacuees in a fire drill, the researchers decided that numerous alterations were warranted, all of which relate to important issues in the social scientific literature. First, some sort of delay had to be included in between the giving of direction and the decision to comply. Second, the simulation had to allow for the possibility of conflicting instructions from two or more leaders and for the potential denial of instruction if the evacuee noticed large numbers of people evacuating in a manner contrary to that instruction. The most relevant agent rules that were formulated to account for these modifications included the following: (1) disregard any instruction presented at the same time by two different leaders; (2) an evacuee does not move until the group around him moves; (3) an evacuee follows the evacuees around him or her; and (4) a given evacuee moves toward the group of evacuees who are in closest proximity. 
There are two general shortcomings associated with the MASCM simulation model and the suggestive, yet limited, alterations made in response to the empirical data. First, although the presence and chief function of guide agents (leaders) is given fairly accurate and diverse applications, there is no set of mechanisms or calculations that furnish the possibility of simulating the set of group decision-making processes involved in selecting a leader when a "guide agent" or trained professional is not present. Yet it is often the case that in evacuation situations there are no official leaders. This sort of process is best exemplified in Johnson and Feinberg's model (1977) that incorporates "milling" and consensus formation in the selection of a group leader (see below). Moreover, the activities of an internally generated group leader will have an important impact on the ability of the guide agent or outside leaders to lead the evacuees. Neither possibility is considered in MASCM.

Second, despite the acknowledgement of potentially conflicting instructions and lack of uniform response, each agent in the MASCM model still makes the decision to exit without any "thick" affiliation to a primary group. To be sure, Murakami et al. recognize the importance of adherence to some group during evacuation, but fail to pinpoint the nature of the relationships between the persons and how these are likely to affect the rate and nature of evacuation behavior. For instance, the researchers developed a rule that directs an evacuee during egress to move toward the nearest group. However, studies by Johnson and Feinberg (1994), Aveni (1977), and others suggest that such an action typically involves various social factors including the character of the relationship between the evacuees and the groups of persons with whom they were before the precipitating event and crisis materialized and with whom they began evacuating. If the evacuees were with friends, work associates, and family members, and are separated from them during the course of egress, there are strong possibilities that the evacuees would search for those persons before fully exiting or would even return to the building after exiting. Thus, persons do not always gravitate to whatever group seems to be nearby - if they do, it is because their primary group was not present in the building to begin with or that it is difficult or impossible to do so.

FIRESCAP is a computer simulation model that implements a social theoretical formulation of "collective flight from a perceived threat" (Feinberg and Johnson, 1995; pg. 247). The entire model is couched in sociological terms and makes the following claims: (1) collective flight is a social event, which (2) is guided by "normative expectations and role demands" and (3) ensues only after information is sought after and ambiguous signs from the external environment are evaluated (ibid). The egress response, Feinberg and Johnson argue, is not instantaneous. Egress is the result of a socially structured decision making process guided by norms, roles, and role relations. Feinberg and Johnson base their assertions on their own extensive research of the Beverly Hills Club Fire of 1977 (1988, 1994) and on the research of Keating (1982), Quarantelli (1981), and others. Their review of the literature led to several additional assumptions that were then introduced into the evacuation simulation model. The authors assume that ambiguity is a chief feature of the initial phases of an evacuation, and thus give particular attention to agentdriven processes of creating a definition of the situation that accounts for several interrelated factors in the evacuation process. These include (1) the difference between perceived time available and perceived time needed, (2) the level of familiarity with the location of exits, (3) the ability to avoid congestion, and (4) the ability to take turns in the exiting process or seek an advantage for the self and primary-group members (pgs. 248, 249). Competitive behavior, however, is considered to be quite rare. 
The computer simulation runs in TurboBasic, which is a deviation from the more typical use of $\mathrm{C}++$ language in many other models reviewed here. Feinberg and Johnson posit fairly common physical constraints in relation to the number, width, and location of exits (pg. 251). Specifically, their simulation runs an episode of egress as occurring in a square room that has a maximum length of 20 meters on a side. The room is laid out as an invisible grid of locations, each of which is 1 square meter in area. During a fire, the maximum occupancy of a location is eight persons, whereas the limit is set at two persons when no threat is perceived. Persons in the program are either individuals or socially tied pairs who act in concert and whose bonds cannot be broken. The actors are assigned a randomly generated perception score (from .5 to 1.5) that determines the extent to which he or she is a fearful evacuee (willing to escape without visible cues of danger) or an "objective" evacuee that will attempt to thoroughly assess environmental cues. The model further maintains information on whether the evacuee is stationary, moving, or has exited.

FIRESCAP is based on a series of decisions that occur concurrently during each cycle. The decision to begin moving in response to an announcement of an emergency is made on the basis of a changing global probability that takes into account the degree to which a visible threat is evident and the perceived number of persons that are and are not moving (pg. 253). As these decisions are made, the statuses from the end of the preceding cycle are inserted into the new cycle and the physical threat level is updated. Moreover, the individuals (as opposed to the pairs) make their decisions alone and may even decide to evacuate almost immediately given a certain level of the "fearful disposition." The model functions in such a way that members of a pair may not have the same perception level and hence do not agree on the definition of the situation furnished by the two-fold criteria presented above. This disagreement is resolved through a probabilistic deference function. Hence, this model pioneers in simulating the matter of conflict within socially embedded social relationships. Competitive behavior (regulated pushing or overtaking) may occur under certain conditions between persons that are unknown to one another, and is based on an actor's perception of available time for exiting, the actor's "fear" value, and the level of competitiveness or cooperativeness among the persons in the surrounding vicinity.

The inclusion of a disposition such as fear or deference is not entirely without precedent. The ESCAPE model determines the actions of occupants according to various Performance Shaping Factors (PSFs) and Hierarchical Task Analysis (Reisser-Weston, 1996: pg. 5). The PSFs include the organization of the work environment, certain emotional and social factors such as "deal with danger," the information available to the occupant, and the effect that certain tasks being carried out may have on evacuation. A hierarchical charting of tasks that must be carried out during evacuation complements the PSFs. Despite this inclusion of significant factors, the model only accounts for the impact of these factors by delaying the start- time of evacuation, not by actually carrying them out in the course of a simulated interaction.

In general, FIRESCAP implements a keen awareness of the multiple social criteria that persons assess before deciding to evacuate, the need for clear information about the situation and exits in order to avoid extensive ambiguity, and the significant yet somewhat fragile nature of orderly movement in the face of a major threat. However, the model disregards the use of models of 
toxicity that also influence the choice of an exit route. FIRESCAP could clearly benefit from a set of specifications that generate more diverse and realistic physical environments. Also, the creation, presence and influence of leaders during evacuation is absent from this model, as is the recognition of the multiplicity of groups that may be present in the evacuation (see below).

The relative strengths and weaknesses of the models presented above (in varying detail) point toward several key recommendations. From a social science perspective, the ideal simulation modeling approach should seek the development of sub-models that posit an active, "investigative" socially embedded agent that assesses the state of other persons and forms a definition of the situation in cooperation with others. Furthermore, these agent-centered calculations should be placed in an on-going interaction between the properties of a particular fire and other hazard and the physical surroundings in which the evacuation takes place. Moreover, it would recognize that individuals evacuate in groups, and thus that group dynamics is an essential dimension that must be considered. The best overall theoretical approach for this task appears to be some version of emergent norm theory. The forthcoming section expands upon this claim.

\section{The Reality of the Group}

The previous pages have reviewed well-known simulation models of emergency evacuations and identified their strengths and shortcomings from the perspective of the social sciences of disasters, a perspective that helps us identify what or who evacuates in emergency evacuations. Individuals and groups are the constitutive units of emergency evacuations. They evacuate. To understand what they do in the evacuation, however, it is necessary to recognize that emergency evacuations are forms of collective behavior (see below) in which there are two major types of social behaviors, institutionalized behaviors and socio-cultural emergent behaviors (Aguirre, unpublished manuscript; compare to McPhail, 1991), the second often corresponding to mass behavior and crowds. There are also two distinct moments in emergency evacuations that impact on the safety of evacuees: their decision to begin evacuating, and their actual evacuation behavior. Both are important if we are to develop accurate simulations of emergency evacuations. Socio-psychological processes that we wish to examine impact both. Moreover, these two dynamic sets of behaviors occur in specific physical settings, which at the extreme erase the distinction among them.

It is useful to differentiate physical settings in which emergency evacuations take place along the following two dimensions: Does the space allow the simultaneous perception of danger? Settings differ in the extent to which all potential evacuees receive the same warning and have access to the presence or signs of danger. At the extreme, everyone in the gathering is in the same space, can hear and see others, receives the same warning signs and perceives the danger. The opposite situation occurs in setting in which people differ in the warnings they receive and the dangers they perceive. The second dimension is the human density of the space. Settings in which potential evacuees are co present, available to each other by sight and touch, and in which their density is very high, allow for the mass effect observed in many studies of emergency evacuation (Chertkoff and Kushigian, 1999, chapter 10), in which the response of the gathering of people to the perceived presence of danger and the sense of urgency to respond to the crisis is so immediate and overwhelming that the different propensities and choices of the individual 
evacuee and his or her group are largely erased. People's responses become an important way in which other people in the gathering are warned. Instead, the individual becomes part of a mass of people moving towards the exits, and the sheer press of people eliminates most possibilities to determine his or her movement. At this extreme of mass behavior, often inappropriately called panic (Chertkoff and Kushigian, 1999), most potential evacuees and their groups do not have the opportunity to engage in decision-making regarding whether they should evacuate, with whom, when, and how. In these extreme circumstances the distinction between group and individual level emergency evacuation ceases to be meaningful. The safety engineering and architectural features of the space in which such mass behaviors take place, and the preparation and alertness of social control agents become the most important mechanisms impacting the successful outcomes of such evacuations. Social psychological and group level processes become much more important in other contexts in which this extreme mass behavior condition is absent, in settings in which all potential evacuees are not immediately available to each other visually and physically, in which there is much lower density, and in which there is variation in the warnings they receive and the signs of danger they perceive. Based on the foregoing, simulation models of emergency evacuations would do well in differentiating spaces in which evacuations take place in terms of these two ideal type sets of characteristics.

The shortcomings of the simulation models reviewed in the previous pages have in common the absence of the inclusion of relevant group level processes in evacuation simulation modeling. Most models lack an understanding of the social psychological and social organizational dimensions of emergency evacuations. While the lack of inclusion of social organizational features of emergency evacuation in these models is not surprising given the prevailing lack of interest in group level processes in the United States, the absence of social psychological processes is surprising, for the individual is usually perceived as the "real" actor in the United States and a good deal of social science research attention has been devoted to the individual actor, particularly to the study of individual threat perception and individual decision-making under crisis situations (Perry, 1978). Individual-level models of evacuation behavior (Sorensen, Vogt, Mileti, 1987) and evacuation decision-making by individuals (Perry et al., 1981, chapter 3) emphasize the importance of perceived threat (Sorensen, 1991, 157) and other factors that impact on individual's ability and willingness to act. Typical of this emphasis is the statement by Ikle and colleagues (1957) that the decision of the individual to leave a threatening situation depends on the degree of perceived threat, the motivation of these potential evacuees--- their withdrawal tendencies---and the factors that facilitate or impede their evacuation behavior, such as the perceived and or realized costs of evacuation.

Fortunately, at the social organizational level it has been possible to combine an emphasis on the social psychology of the actor (for an excellent review of this literature see Parks and Sanna, 1999) with an interest in macro features such as norms, values, status demands, leadership, division of labor and emergent generalized beliefs. Illustrative is Turner and Killian's (1987; see also Weller and Quarantelli, 1973; for a more recent version see Stott and Drury, 2000) emergent norm theory (ENT) of collective behavior. ENT is based on a symbolic interaction conceptualization of social life that emphasizes the importance of norms and social relations. It posits that nontraditional, collective behavior emerges from a normative crisis brought about by a precipitating event which, depending upon how the event is collectively perceived and interpreted by the participants, destroys, neutralizes, or no longer allows the pre existing 
normative guidelines, division of labor, power, and other social arrangements to be collectively defined as appropriate guides for action to respond to the crisis. The crisis creates a sense of uncertainty and urgency forcing people to act, and participants are forced to create a new, emergent normative structure to guide their behavior in the crisis. They mill about as they attempt to define the situation, propose cues for appropriate action, evaluate their relevant skills in terms of the new demands of the situation, and try out alternate schemes to solve the problem. Forced by the crisis to abandon their previously established social relationships, statuses, and normative guidelines regarding legitimate ways of acting, people engage in collective behavior to solve the problems created by the crisis, in effect reconstituting their groups and pre existing social relationships. The theory assumes the presence of heterogeneous actors with different backgrounds, relevant skills, perceptual abilities, and motives about what is going on, what should be done to respond to the crisis, and who is responsible to do what and when. ENT assumes that collective behavior is not irrational but social, normative behavior.

Following E. Goffman's insights (1963; for an excellent review see Brown and Goldin, 1973, chapter 8), crises-what in Goffman's term are topics for focused interaction in encounters-disrupt culturally specified occasions in specific physical settings. There is an occasion and the gathering of people enacting it. Such gatherings are composed of single individuals and of small groups. Then there is the crisis, the precipitating event that starts focused interaction in an encounter and the period of the emergency during which emergency evacuation takes place. For Goffman, interactions in these encounters are face-to-face, rich in meaning, revealing, rapidly changing, augmenting "attention to detail, an intensification of mutual dependence, and an absorption in the interactive moment" (Brown and Goldin, 1973, 154), with people moving about facilitating information dissemination. Goffman's theorization of the emergence of social organization in encounters can be reconciled to ENT, for he argues that encounters develop two types of norms that regulate them and permit their continuation through time and space. These are rules of irrelevance and of transformation. The first helps people engaged in reconstituting their groups to identify what is relevant and irrelevant about their situation, what they must attend to; the second help people incorporate into their social organizations extraneous items in such a way that the encounter is preserved (Brown and Goldin, 1973, 155-156).

Importantly for our present efforts, it is possible to derive from ENT and from Goffman's approach to social behavior in public a number of predictions for which there is some limited empirical support (Aguirre, Wenger, and Vigo, 1998). These are predictions in need of further testing and replication regarding the effects of social organizational variables on the timing of evacuation behavior that are nowadays mostly excluded from computer simulation models of emergency evacuations, for as we have tried to document, one of the near constants in simulation models of emergency evacuations is the near absence of consideration of group dynamics. This is the case even though people most often participate in public spaces in which emergency evacuations often take place in the company of significant others, in group contexts (Aveni, 1977). In this paper we extend these predictions to include the movement of evacuating collectivities.

Groups have four types of characteristics. One type is the context in which groups operate, such as the built environment. A second comes from the aggregation of the characteristics of the members of the group, for example their average age or average physical agility, as well as those 
that are combinations of two or more aggregate characteristics, such as the group's sex ratio. The third type is illustrated by group density, which combines aggregate characteristic of the groups such as their sizes with contextual characteristics such as the physical space the groups occupy. A fourth type of group characteristics is created by relationships, both present and past, among the members of the group, for example, conceptions of statuses, leadership, group cohesiveness, division of labor, communication channels, power arrangements, and the myriad aspects of group culture such as language, cultural practices regarding personal space, traditions, dominant norms, and institutions such as law, regulatory agencies, political units. Many of these group characteristics must be included in simulation models, and research is needed to identify a parsimonious set of these characteristics that would be sufficient to make simulation models effective.

Aggregate characteristics of groups such as their size and heterogeneity should be important aspects of simulation models (Aguirre, Wenger and Vigo, 1998). The size of the group faced with a crisis is an important determinant of its timing of evacuation; the bigger the group the more difficult will be for the group to decide to evacuate as a response to the crisis, for it takes more time and effort for a large group to adopt the new behavior than for a smaller group; in the large group there will be more variation and differences of opinion and relevant experiences about what to do that must be reconciled before the emergent norm is created (compare to Kelley and Condry, 1965). Similarly, larger groups will move more slowly. Groups also have implications for the evacuation movement or flow, for they will tend to move in a block formation that will create an order to the evacuation flow, particularly if such flow takes place in stairways or other constrained spaces. In such situations, solo evacuees, or people who decide to evacuate on their own and join the flow, nevertheless come in contact with the blocks formed by these groups of evacuees and are regulated by them, for they are exposed to the set of norms and new statuses guiding the behavior of these collectivities which they cannot evade. The order and regulation that is very often observed in large evacuations from multi story buildings, such as the very successful evacuations from the WTC towers in the aftermath of the 9/11 terrorist attack, is generated by the presence and movement of these groups in the stairways, which is very similar to the order and regularity of traffic flows in situations of very high vehicular density, in which vehicles move at the same lower speed and reduce changing lanes (Helbing and Huberman, 1998).

Another important characteristic of groups is their heterogeneity in age, gender, social class, physical health and vigor, and relevant experiences. Research is needed to understand how group heterogeneity impacts the decision to evacuate and the evacuation behavior. Critical mass theory (Marwell and Oliver, 1993) would predict that groups with greater size and heterogeneity will be more likely to have members---who constitute the so-called critical mass---with the relative skills and resources needed to obtain the group's public good, namely surviving the hazard. Larger groups should have a greater probability of having a critical mass of able members. It can be derived from the theory that groups are mechanisms people use to attempt to survive the hazard. Not everyone in the gathering has the same skills and resources, so that that less-endowed members will benefit from the efforts of the stronger or more experienced members to bring about the escape, presumably a reason they keep with them. Moreover, it is immaterial to the strong and the more able how many others benefit from their actions in facilitating the group escape; what matters most to them is their own survival, not excluding 
others from surviving. For non-mass behavior emergency evacuations, survival as a public good has jointness of supply, for the cost of providing it does not increase with the numbers of people who survive. Also, the usual crisis situations in which would be evacuees decide what to do are suffused with ambiguity, making it difficult to develop an accurate assessment as to whether defecting from the group will yield a higher probability of survival than staying with the group. Such evacuations are quite different from the widely discussed prisoner's dilemma (compare to Cornwell, 2003, 634).

Feelings of social solidarity, while not considered in critical mass theory, should also generate mutual assistance among the members of evacuating groups. It can be expected that the acts of members of the critical mass that benefit others in the evacuating group are not only the indirect results of their calculations of personal benefits but also come about intentionally as they try to help others. A large body of scholarship in the social sciences of disasters document that people faced with disasters and emergencies of all sorts become interdependent, cooperate, their actions taking into account the actions of others, restrained by the actions of others, so that in emergency evacuations they move together and assist each other. Social cohesion, a group level effect created by social relationships, or the extent to which people know others in the group, have established social relationships with others prior to the crisis, and have friends and other close personal relations in the group can be assumed to delay the collective decision to evacuate (Aguirre, Wenger, and Vigo, 1998) and to preserve the block effect during the evacuation movement. The lone actor and the free agent will decide to evacuate much more quickly than the social actor who is embedded in social relations, is concerned for others in the group, takes their opinions and interests into account before deciding when and what to do, and evacuate with the group.

Still in need of further research is the impact of group size and cohesion on the individual risk of fire fatality. Cornwell (2003) has shown, on the basis of information on the Beverly Hills Supper Club Fire of 1977, that group size and social cohesion increases this risk, but his findings are in need of replication and expansion, for they do not control for the differences among the groups to life threatening dangers, the resources of the groups' critical masses, and relevant differences in the built environment and the hazards precipitating the evacuation behavior.

As discussed previously, it is often the case than in the pre crisis situation groups are embedded in gatherings that take place during occasions, or culturally defined activities such as the $4^{\text {th }}$ of July or going to work in the corporate work environment of the World Trade Center. When crises impact these gatherings, they transform the occasions; people then need to engage in symbolic interaction to develop new emergent definitions of the situation. New social relations and new norms or rules guiding behavior often take place within and among these groups as they fashion a collective response to the crisis. People exchange information, discuss alternatives, try to convince each other of what is going on, and eventually agree on what they must do to respond to the crisis. Importantly, the situation is such that it demands an individual and collective response; there is a sense of urgency. Once this emergent norm is created, members of the group that do not agree with it keep quiet out of fear of group censure, or are ignored by the group. Group members then try to convince people in other groups to adopt their new definition of what is going on, what needs to be done, and what is proper and necessary to do under the circumstances. Thus, as Goffman argued, it can be expected that there will be inter-group 
proselytism and competition for hegemony in providing the master definition of the situation and what should be done to respond to it that will delay the evacuation response: the greater the initial diversity of definitions in the groups about what is happening and what should be done to respond to the crisis---to the extent that people are exposed to these competing alternatives---the longer it will take for people to make up their minds about what they should do (compare to Drury and Scott, 2001). Inter-group differences should also slow the evacuation movement in constrained spaces in which the groups cannot evade each other. Fire drills in high-rise buildings in which there are multiple firms in given floors and multiple firms in the building around which work groups form, would need to recognize the presence of inter-group competition, to make such drills more effective in establishing a master definition of what should be the appropriate evacuation behavior that everyone in the building will follow irrespective of group membership.

Groups also vary in the amount of resources available to them, and this variation will impact the start of evacuations. Paradoxically, our expectation is that the greater the amount of resources available to the groups, the slower will be their adoption of evacuation behavior, for it will take more time for the groups to agree on how to use these resources and integrate them into their new division of labor. Resources become items around which group dialogue ensues.

Perceptions of danger are socially determined. Dangerous conditions by themselves are not always effective triggers for evacuation response, except perhaps in situation of mass behavior previously identified, in which the evacuation response is forced upon the person. Instead, members of the group must interpret the situation as dangerous before they become a stimulus for collective action. Numerous studies of disasters indicate that there is a persistent and strong normalcy bias, in which people misunderstand the signs of dangers produced by the hazards and developing disasters and interpret them as normal features of daily routines. Such normalcy bias must be nullified before people will react to the crisis. Ambiguities and mixed messages and inaccurate interpretations of dangers often impact evacuation behavior, so that while it is true that the presence of inter subjectively verified and consistent signs of danger that are accurately perceived, such as smoking and loud sounds, facilitate the adoption of new behavior, this situation should not be assumed to be the normal state of affairs in simulation models. The current explosion of electronic communication technology facilitates a flood of information to would be evacuees that increases the ambiguity of the crisis situations, for these alternative sources of information often offer contrary alternatives to official information and directives and encourage a multiplicity of interpretations that impact decision making in emergency evacuations both at the individual and the group level. This is a problem that has received almost no research attention at present. Experimental results indicate that ambiguity facilitates suggestibility in crowds, and that suggestibility shortens the time to achieve consensus and facilitate the occurrence of more extreme consensus (Johnson and Feinberg, 1990). According to Leik and Gifford (1986) greater amounts of information increases the time needed to take protective action. Thus, it seems as if greater information has multiple and somewhat contradictory direct and indirect effects on decision making: a direct effect increasing the time needed for taking decisions, and indirectly increasing ambiguity which in turn increases suggestibility which shortens the time needed for taking decisions. 
Human imagination, particularly how the actual or perceived physical incapacity of the actors, and the extent to which the physical tasks of evacuating present important challenges to them, impact their timing of evacuation behavior. People are able to imagine the physical demands of their response to the crisis and thus respond in terms of what they think they can do within the time and other considerations that they consider relevant as they formulate responses to the crisis. Thus, the elderly, the physically infirm, caretakers, women, the injured, will have a greater tendency to begin evacuating sooner than other categories of victims and will have a higher probability of becoming obstacles to the evacuation movement in constrained spaces. Signs of dangers such as smoke or fire are thus filtered through these personal attributes and impact both the decision to evacuate and the evacuation movement.

There is also a need to incorporate in simulation models more meaningful conceptions of leadership during the response to the crisis. Crisis contexts often neutralize pre existing norms and power arrangements in social organizations. The new situation demands new leadership skills. Moreover, it is also a fluid social organization, in which leadership is very often unstable and in which the procedures for the exertion of leadership are not established. In these crises contexts, persons that become leaders of the group are not necessarily those who conform to the norms of the group, since the normative system is in fact emerging. Nor are they necessarily the leaders of the group existing prior to the precipitating event. It is more likely the case that the member of the group that will become the leader is one that proposes an innovative solution to the collective problem that is judged plausible and credible by the other members of the group. Innovators will have a greater probability of being leaders in crisis situations with high uncertainty. Suggestively, Feinberg and Johnson's (1988) simulation study of crowds indicate that the agitator, or the person in the crowd with an extreme, innovative solution, is more likely to sway others in small gatherings, in highly ambiguous situations, and when others in the gathering trust her. Moreover, Johnson, Stemler and Hunter (1977; see also Johnson and Glover, 1978), in another experiment, showed that there is a shift to risk, in that collective decisions are on average more extreme than the sum of individual decisions about the same item. Presumably, group leaders will be more likely members of the critical mass, with the right skills and knowledge and the innovative ideas that are perceived as maximizing the chance of escape for everyone in the group.

It is worthwhile to conceptualize leadership in simulation models in terms of the keynoting process identified by Turner and Killian. In this sense the question of leadership reduces to the problem of what keynoting will be adopted by the group from the various suggestions that will be forthcoming as the group tries to determine a collective course of action to respond to the crisis. Such adoption is a symbolic process in which group members consider various alternative ways to respond and then explore the appropriateness of the alternatives. It is also impacted by the presence of culturally appropriate symbols of legitimate authority, such as uniforms and official looking paraphernalia, although the success of the keynoting by social control agents will depend on the extent to which their suggestions are in agreement with the basic values and perceptions of the group that they are trying to lead and with the emergent leadership in these groups. It is an interactive and not a unidirectional process; official directives are often ignored because of inaccurate understanding by the authorities of the priorities and needs of people (Stott and Reicher, 1998). 


\section{Conclusion}

We have identified important social processes that impact emergency evacuations. Embedded in them are many worthwhile research questions still in need of answers, questions that assume the presence, in emergency evacuations, of heterogeneous actors that in their collective behavior act normatively and rationally. Studies of panic come to mind. The oldest view of panic assumed that people in dire emergencies lost their humanity and became animals overwhelmed by fear. A second view, sponsored by E. L. Quarantelli (1957) in the 1950s and 1960s, advanced a conceptualization of panic as a-social collective behavior. People did not become animals but rather attended to their own needs; they did not care for the fate of others. This view was replaced in the 1980s and 1990s by the work of Norris Johnson and other scholars (Keating, 1982) who pointed out that people did not panic, did not become animals, and did not abandon their ties to others. Instead, people in situations of great danger continued to be social actors embedded in social organizations. They continued to be deeply concerned for the fate of others so that they often imperiled their own lives on their behalf (compare to Helbing, Farkas and Vicsek, 2000; for an excellent review of theories of panic see Chertkoff and Kushigian, 1999). The assumption of heterogeneous actors acting rationally and normatively has a number of important implications that we have tried to identify. It has implications for the modeling of the direction of movement in simulations of emergency evacuation, which cannot be assumed to be unidirectional, since it is rational and normative and the product of symbolic interaction rather than the action of a herd or of robots. Rather, it is multidirectional, including people returning to the place they evacuated to help others, try to rescue friends, and salvage important belongings (Johnson, 1987; Johnson et al., 1994).

Simulation modeling of emergency evacuations has gone through three phases, flow, individual, and group (Low, 2000). Nowadays it is in the last two phases, in which simulation work begins to incorporate socio psychological and social organizational dynamics. The present day multiplicity of models of emergency evacuation, each with their own strengths and weaknesses, and without the appropriate methods of validation must be superseded by a governmentsponsored effort to create a uniform simulation platform that would combine what is good in existing models, provide proper validation tools, and encourage multi disciplinary collaboration to advance them. That such effort is needed has been widely recognized. For example, Kuligowski's (2003) empirical analysis of EXIT89 and Simulex simulated a high-rise hotel building evacuation in which the same design elements were used, but yet reported “significant differences in egress times...EXIT89's evacuation times were found to be $25-40 \%$ lower than Simulex for the design scenarios, attributed to differences in unimpeded speeds, movement algorithms, methods of simulating slow occupants, density in the stairs, and stair configuration input between the models...EXIT89 produced maximum evacuation times $30-40$ \% lower than Simulex."

Such wide disparity between two popular simulation programs could probably be duplicated with other models available nowadays, a potentially misleading situation that needs to be corrected.

In such context, research and theory in the social sciences can have an important effect in grounding the models in realistic assumptions regarding social behavior in crisis situations, and such modeling in turn could enrich our understanding of collective behavior in crisis situations. Simulation models of emergency evacuations can have enormous practical and scientific payoffs 
not only for the social sciences but also for other sciences such as engineering and public health. However, simulation models can realize their full potential as a tool for emergency planning and intervention only if they are inextricably linked to fieldwork and empirical investigations of emergency evacuations that would provide computer scientists and mathematicians with the appropriate parameters for social behavior. Thus, their future is multi disciplinary, involving the expertise of computer scientists, engineers, fire scientists, social scientists, and emergency planners, among others.

\section{References}

AEA Technology. EGRESS. www.aeat-safety-and-risk.com/html/egress demo.html

AEA Technology. "A Technical Summary of the AEA EGRESS Code." AEA Technology, Warrington, UK.

Aguirre, B. E., D. Wenger, G. Vigo. 1998. "A Test of Emergent Norm Theory of Collective Behavior." Sociological Forum, vol. 13, no. 2: 301-320.

Aguirre, B. E. "A Conceptual Framework for Collective Behavior and Action and its Application to U.S. Student Riots in the 1990s." Unpublished manuscript.

Aveni, A. (1977). The Not So Lonely Crowd: Friendship Groups in Collective

Behaviour. Sociometry 40 (1) 96-99.

Brown, Michael and Amy Goldin. 1973. Collective Behavior: A Review and Reinterpretation of the Literature. Pacific Palisades, California: Goodyear Publishing Company.

Chertkoff, Jerome M. and Russell H. Kushigian. 1999. Don’t Panic. The Psychology of Emergency Egress and Ingress. Westport, Connecticut: Praeger.

Cornwell, Benjamin. 2003. "Bonded Fatalities: Relational and Ecological Dimensions of a Fire Evacuation.” The Sociological Quarterly, vol. 44 (4): 617-638.

Drabek, Thomas E. 1991. "Anticipating Organizational Evacuations: Disaster Planning By Managers of Tourist-Oriented Private Firms." International Journal of Mass Emergencies and Disasters, vol. 9 (2): 219-245.

Drabek, Thomas E. 2000. "Pattern Differences in Disaster-Induced Employee Evacuations." International Journal of Mass Emergencies and Disasters, vol. 18 (2): 289-315.

Drury, John and Clifford Stott. 2001. "Bias as a Research Strategy in Participant Observation: The Case of Intergroup Conflict.” Field Methods, vol. 13 (1): 47-67.

Elliot, Dominic and Denis Smith. 1993. "Football stadia disasters in the United Kingdom: learning from tragedy." Industrial and Environmental Crisis Quarterly, vol. 7 (3): 205-229. 
Fahy, R.F., 1999. User's Manual, EXIT89 v 1.01, An Evacuation Model for High-Rise Buildings, National Fire Protection Association, Quincy, Mass.

Fahy, R.F. 1996. "EXIT89 - High-Rise Evacuation Model -Recent Enhancements and Example Applications." Interflam '96, International Interflam Conference $-7^{\text {th }}$ Proceedings; Cambridge, England, pg. 1001-1005.

Feinberg, W. E. and Norris r. Johnson. 1988. "Outside Agitators and Crowds: Results from a Computer Simulation Model.” Social Forces, vol. 67 (2): 398-423.

Feinberg, W. E. and Norris R. Johnson. 1995. "Firescap: A Computer Simulation Model of Reaction to a Fire Alarm." Journal of Mathematical Sociology, vol. 20 (2/3):247-269.

Filippidis, L., Galea, E., Gwynne, S., and Lawrence, P.J. "Simulating the Interaction of Pedestrians with Wayfinding Systems." Proc 2nd Int Pedestrian and Evacuation Dynamics Conference, Ed: E.R.Galea, CMS Press, Greenwich, UK, ISBN 1904521088, pp39-50, 2003.

Fraser-Mitchell, J. 2001. "Simulated Evacuations of an Airport Terminal Building, Using the CRISP Model." 2nd International Symposium in Human Behavior in Fire, Boston, MA, pp. 89100.

Fruin, John J. 1970. Designing for Pedestrians- A Level-of-Service Concept. Ph.D. Dissertation, The Polytechnic Institute of Brooklyn.

Goffman, Erving. 1963. Behavior in Public Places. New York: Free Press.

Gwynne, S., E. R. Galea, M. Owens, P. J. Lawrence. 2000. An Investigation of the Aspects of Occupant Behavior Required for Evacuation Modeling. Pp. 31-71 in Paul R. DeCicco, editor. Evacuation from Fires. Amityville, New York: Baywood Publishing Company, Inc.

Helbing, D., I. Farkas, T. Vicsek. 2000. Simulating Dynamical Features of Escape Panic. Nature, vol. 487: 487-490.

Helbing, D. and Bernardo A. Huberman. 1998. "Coherent Moving States in Highway Traffic." Nature, vol. 396: 738-740

Heskestad, A.W. and Meland, O.J. 1998. "Determination of Evacuation Times as a Function of Occupant and Building Characteristics and Performance of Evacuation Measures." Human Behavior in Fire-Proceedings of the $1^{\text {st }}$ International Symposium, pp. 673-680.

Houts, P. S., M. K. Lindell, T. W. Hu, G. Tokuhata, C. B. Flynn. 1984. "The Protective Action Decision Model Applied to Evacuation During the Three Mile Island Crisis." International Journal of Mass Emergencies and Disasters, vol. 2 (1): 27-39. 
Ikle, Fred C., E. L. Quarantelli, J. F. Rayner, S. B. Withey. 1957. Withdrawal Behavior in Disasters: Escape, Flight, and Evacuation Movements. Washington, D.C. National Academy of Sciences-national Research Council, Division of Anthropology and Psychology Committee on Disaster Studies.

Jennings, Charles. 2000. High-Rise Office Building Evacuation Planning: Human Factors Versus "Cutting Edge" Technologies. Pp. 17-30 in Paul R. DeCicco, editor. Evacuation from Fires. Amityville, New York: Baywood Publishing Company, Inc.

Johnson, Norris R. 1987. "Panic and the Breakdown of Social Order: Popular Myth, Social Theory, Empirical Evidence.” Sociological Focus 20: 171-183.

Johnson, Norris. 1987. "Panic at 'The Who' concert 'stampede': an empirical assessment." Social Problems 34:362-373.

Johnson, Norris R. and W. E. Feinberg. 1990. "Ambiguity in Crowds: Results from a Computer Simulation Model." Research in Social Movements, Conflict, and Change, vol. 12, pp. 35-66.

Johnson, Norris R., W. E. Feinberg, D. M. Johnston. 1994. Microstructure and Panic: The Impact of Social Bonds on Individual Action in Collective Flight from the Beverly Hills Supper Club Fire. Pp. 168-189 in R. R. Dynes and K. Tierney, editors, Disasters, Collective Behavior and Social Organization. Newark, Delaware: University of Delaware Press.

Johnson, Norris R. and Maryline Glover. 1978. "Individual Shifts to Extreme: Laboratory Experiment on Crowd Polarization." Sociological Focus, vol. 11 (4): 247-254.

Johnson, Norris R., James G. Stemler, Deborah Hunter. 1977. "Crowd Behavior as "Risky Shift”: A Laboratory Experiment." Sociometry, vol. 40 (2): 183-187.

Keating, J. P. and E. F. Loftus. 1977. "Vocal Alarm Systems for High Rise Buildings-A Case Study." Mass Emergencies, vol. 2: 25-34.

Keating, J. P. 1982. “The Myth of Panic.” Fire Journal, May: 56-61, 147.

Kelly, Harold H. and John C. Condry, Jr. 1965. "Collective Behavior in a Simulated Panic Situation.” Experimental Social Psychology, vol. 1: 20-54.

Kendik, E. 1995. Methods of Design for Means of Egress : Towards a Quantitative Comparison of National Code Requirements. Fire Safety Science - 1st International Symposium, 1995. pp. 497-511.

Kisko, T.M., Francis, R.L., Nobel C.R. 1998. EVACNET4 User's Guide. University of Florida, http://www.ise.ufl.edu/kisko/files/evacnet/EVAC4UG.HTM. 
Kuligowski, Erica Dawn. 2003. The evaluation of Performance-Based Design Process for a Hotel Building: The Comparison of two Egress Models. Master of Science Thesis. Department of Fire Protection Engineering, University of Maryland, College Park, Maryland.

Leik, Robert K. and Gregory A. Glifford. 1986. "Decision Making Under Threat of Disaster: An Experimental Simulation." Pp. 131-165 in Anthony R. Harris, editor, Rationality and Collective Belief. Norwood, New Jersey: Ablex Publlishing Corporation.

Low, David J. 2000. "Statistical Physics: Following the Crowd. "Nature, vol. 407, 465-466. Marwell, Gerald and Pamela Oliver. 1993. The Critical Mass in Collective Action. A MicroSocial Theory. London: Cambridge University Press.

McPhail, Clark. 1991. The Myth of the Madding Crowd. New York: Aldine de Gruyter. Muller Vogt, Barbara. 1991. "Issues in Nursing Home Evacuations.” International Journal of Mass Emergencies and Disasters, vol. 9 (2): 247-265.

Murakami, Y., Minami, K., Kawasoe, T., and Ishida, T. "Multi-Agent Simulation for Crisis Management." Department of Social Informatics, Kyoto University, JST CREST Digital City Project, www.lab7.kuis.kyoto-u.ac.jp/ publications/02/yohei-kmn2002.pdf

Okazaki, Shigeyuki and Matsushita, Satoshi. 1993. "A Study of Simulation Model for Pedestrian Movement with Evacuation and Queuing." http://www.anc-d.fukuiu.ac.jp/ sat/ECS93.pdf).

Owen, M., Galea, E., Lawrence, P. The EXODUS Evacuation Model Applied to Building Evacuation Scenarios. http://fseg.gre.ac.uk/exodus/.

Quarantelli, E. L. 1981. Panic Behavior in Fire Situations: Findings and a Model from the English Language Literature. Publication \#144, University of Delaware, Disaster Research Center.

Quarantelli, E. L. 1957. "The Behavior of Panic Participants.” Sociology and Social Research, vol. 41: 187-194.

Parks, Craig D. and Lawrence J. Sanna. 1999. Group Performance and Interaction. Boulder : Westview Press.

Pauls, J.L. 1975. "Movement of People in Buildings." Prepared for presentation to Symposium on Human Response to Tall Buildings, Chicago, 1975.

Pauls, J. L. 1978. Management and Movement of Building Occupants in Emergencies. Ottawa: National Research Council Canada, Division of Building Research, DBR Paper No. 788, NRCC 16845 .

Pauls, J.L. 1980. "Building Evacuation: Research Methods and Case Studies," in Fires and Human Behavior, J. Canter, ed. New York: J. Wiley Sons, Pp. 227-249. 
Perry, Ronald. 1978. "Letter to the Editor." Disasters, vol. 2 (2/3): 169-170.

Perry, Ronald. 1994. A Model of Evacuation Compliance Behavior. Pp. 85-98 in R. R. Dynes and K. Tierney, editors, Disasters, Collective Behavior and Social Organization. Newark, Delaware: University of Delaware Press.

Perry, Ronald W., M. K. Lindell, M. R. Greene. 1981. Evacuation Planning and Emergency Management. Lexington: D. C. Heath and Company, Lexington Books.

Schneider, V. 2001. "Application of the Individual-Based Evacuation Model ASERI in Designing Safety Concepts." $2^{\text {nd }}$ International Symposium on Human Behavior in Fire, Boston, MA. Pp.41-51.

Seidler, John, Katherine Meyer, Lois Mac Gillivray. 1976. "Collecting Data on Crowds and Rallies A New Method of Stationary Sampling.” Social Forces, vol. 55 (2): 507-519.

Simenko, Peter. 2001. EGRESSPRO. http://www.firemodelsurvey.com/pdf/EgressPro_2001.pdf

Stahl, F.I. 1982. "BFIRES-II: A Behavior Based Computer Simulation of Emergency Egress During Fires." Fire Technology, February.

Stallings, Robert A. 1984. "Evacuation Behavior at Three Mile Island." International Journal of Mass Emergencies and Disaters, vol. 2 (1):11-26.

Stott, Clifford and John Drury. 2000. "Crowds, context and identity: Dynamic categorization processes in the 'poll tax riot'." Human Relations, vol. 52 (2): 247-273.

Stott, Clifford and Stephen Reicher. 1998. "Crowd Action as Intergroup Process: Introducing the Police Perspective.” European Journal of Social Psychology, vol. 28: 509-529.

Sorensen, John H. 1991. "When Shall We Leave? Factors Affecting the Timing of Evacuation Departures.” International Journal of Mass Emergencies and Disasters, vol. 9 (2): 153-165.

Sorensen, John H., B. N. Vogt, D. S. Mileti. 1987. Evacuation: An Assessment of Planning and Research. Washington, D.C.: Federal Emergency Management Agency, US. Government Printing Office, RR-9/November.

Thompson, P.A., Wu., J., and Marchant E.W. "Modelling Evacuation in Multi-storey Buildings with Simulex." Fire Engineers Journal, Vol. 56, no. 185. Nov. 1996, pp. 6-11

Turner, R. and L. M. Killian. 1987. Collective Behavior. Englewood Cliffs: Prentice Hall.

Weller, Jack and E. L. Quarantelli. 1973. "Neglected Characteristics of Collective Behavior." The American Journal of Sociology, vol. 79 (3): 665-685. 


\title{
3.4 An All-Hazards Approach is Needed to Support Building Movement Strategies
}

\author{
Norman E. Groner \\ City University of New York
}

People face a variety of hazards in built environments. The emergency management field has developed various approaches applicable to building emergencies, and the "all-hazards" or "multi-hazards" approach is among the most potentially valuable. At all levels of government, from the Federal Emergency Management Agency to local governments, officials recognize that the same basic functions must be activated in response to any and all hazardous events. Unfortunately, at the level of building management, this is not typically the case. Even with its great concentration of large buildings, many New York City building owners and managers employ both fire safety and security directors who may not work well together during emergencies despite their interdependence on achieving favorable outcomes. Different people may organize an evacuation in response to a fire and a bomb threat. The current situation inhibits efficient and effective engineering mitigation and responses to building emergencies.

To facilitate an interdisciplinary cooperative deployment of emergency strategies, we need to develop a common terminology and taxonomy of strategies that researchers, systems designers, officials, and practitioners can use regardless of their backgrounds and the hazards with which they are concerned.

There are only a few basic "people movement" strategies that must be used regardless of the type of emergencies, so developing common terms and classifications is not difficult in principle. Despite a myriad of terms, people movement strategies are invariably combinations of only three basic approaches:

- Keep people where they are

- Relocate people into another part of the building

- Evacuate people from the building

At present, there seems to be scant attention to standardizing an approach that cuts across responses to all hazards. The current state of theory about designing and using movement strategies is fragmented because it has been generated by people with different backgrounds concerned about different hazards. An example illustrates the problem. The use of some sort of protected building space is a common strategy used in response to a variety of hazards. The duration that people must remain in relatively protected spaces depends on the nature of the hazard and how the particular scenario plays out, but the fundamental strategy still appliespeople wait inside of a space in the building where they are relatively protected from the hazard. The variety of terms labeling this fundamental approach reflects the problem: Remain-, protect-, shelter- and defend-in-place, refuge area, area of evacuation assistance, safe rooms, and lockdowns all refer to this fundamental strategy. 
- The fire safety community advocates this strategy in building occupancies where people cannot be quickly evacuated, either because of vertical travel distances (e.g., high rise buildings) or occupants are unable to evacuate without assistance (e.g., heath care facilities).

- The public health community advocates this strategy in response to exterior releases of airborne biological, chemical and radiological contaminants.

- The disaster community discusses the use of building spaces for protecting occupants from severe weather such as hurricanes and tornadoes.

- The security community advocates this strategy in response to armed and dangerous persons who are somewhat remote to their potential victims.

The engineering means for protecting spaces differ radically depending on the hazard, but the same basic approach of keeping people at or relocating them to protected spaces applies.

Developing a common all-hazards jargon and taxonomy is not technically demanding, but is a difficult managerial task. An organization is needed to champion an overarching approach intended to provide a coherent and systematic approach towards research and development of building protection strategies, much in the manner that FEMA champions the all hazard approach towards community emergency planning. The National Institute of Standards and Technology seems to be in an advantageous position to undertake this task. Identifying the various disciplines working on this problem is a logical place to start. A good beginning might be a follow-up workshop where representatives from various disciplines can meet to describe their various approaches, identify where their approaches are compatible and where they diverge, and learn each others jargon. Ideally, the workshop would yield an action plan for achieving a standardized terminology and taxonomy of occupant protection strategies. 


\title{
3.5 Achieving Situation Awareness is the Primary Challenge to Optimizing Building Movement Strategies
}

\author{
Norman E. Groner \\ John Jay College of Criminal Justice, City University of New York
}

Understanding how strategies that protect building occupants can best be selected and effectively deployed is a critical task for a research agenda that tackles the problem of when, where and how to move people during an emergency. Of course, this is not the only obstacle to effective use of building emergency strategies. Physical engineering that supports various strategies (e.g., pressurization of spaces in response to the interior and exterior locations of hazards) is of critical importance. Communicating recommended responses to building occupants is of critical importance. Nonetheless, perhaps the most challenging obstacle for building managers and occupants concerns the problem of initially assessing the situation and selecting the appropriate strategy.

The challenge is great. The chaotic and dynamic nature of building emergencies requires an exceedingly rapid assessment of the situation. The timeframe is measured in seconds and minutes, not hours and days. The rapid onset of many events means that the process should be well underway before emergency responders arrive at the building.

Human factors professionals have been actively researching this problem under the generally accepted term of "situation awareness." Endsley (1988) has provided a well-accepted definition: "The perception of the elements in the environment within a volume of time and space, the comprehension of their meaning and the projection of their status in the near future." As noted in the definition, it is insufficient to understand the momentary status of the situation; projecting its development is of great importance in choosing a strategy to safeguard building occupants.

A closely related body of research and theory from the human factors field can be loosely classified under the labels of "cognitive task analysis" and "cognitive task design." The former term has been defined by Schaaftal and Schraagen (2000): "A cognitive task analysis is an analysis of the knowledge and skills required for a proper performance of a particular task. The framework consists of three elements: (a) an analysis of the task that has to be carried out to accomplish particular goals..., (b) an analysis of the knowledge and skills required to accomplish these tasks..., and (c) an analysis of the cognitive (thought) processes of experienced and less experienced [persons]."

We need to learn how to design systems that help persons in positions of managing an emergency in their efforts to achieve an acceptable level of situation awareness. The task of designing systems that help emergency managers and responders achieve an acceptable level of situation awareness is technically complicated and challenging. The task must be approached from an interdisciplinary perspective, as exemplified by the following insight: these systems will have to include both technological and human components working in concert. Of considerable importance is the concept of "distributed cognition" or "joint cognitive systems" whereby data is collected, analyzed and represented using a variety of agents, human and otherwise. Significant 
amounts of information may need to be collected, compiled, analyzed and presented within a very short time frame, a task at which technology excels. However, severe emergencies are inherently chaotic and uncertain where the meaning of information from disparate sources (including people) must be quickly synthesized and interpreted, a task at which people excel. Designing systems will require the "functional allocation" of these tasks to the agents, both technological and human, that perform them best.

Progress in helping building management and emergency responders achieve situation awareness will require a fundamental change in how we approach the design of building protection systems. At present, our buildings are not well designed to achieve the needed level of situation awareness, despite the availability of many technological tools. Addressable detection devices can pinpoint the locations of detection of hazards, but the building interfaces used to display the information does not supply an immediately comprehensible understanding of the situation. Technological devices like CCTV cameras and smoke detectors are not deployed in ways that help building management and emergency responders understand the status of key egress systems like stairs and corridors.

Research and development towards the support of situation awareness in buildings is a priority. Providing designs that protect building spaces and move people is essential, but the value of such efforts is limited to the extent that we fail to support the people who must decide when and how to use these features.

\section{References}

Endsley, M. R. (1988) Design and evaluation for situation awareness enhancement. In Proceedings of the Human Factors Society $32^{\text {nd }}$ Annual Meeting (pp. 97-101). Santa Monica, CA: Human Factors Society.

Schaaftal, A. and Schraagen, J. M. (2000) In J. M. Schraagen, S. F. Chapman, \& V. L. Shalin (Eds.) Cognitive Task Analysis. Mahwah, NJ: Lawrence Erlbaum. 


\section{Data Needs for Predictive Building Movement Models}

The usefulness of a model-based predictive capability is heavily dependent on an understanding of its accuracy and limits of applicability. However, the current situation is such that small amounts of data exist and that they are not generally available to groups studying this topic. Additional experimental data gathering efforts are needed in order to quantify current and future egress predictive capabilities. Areas of interest may include pre-evacuation timing and behavior, disabled occupant responses to fires, exhaustion on stairs and interaction of occupants and building systems with the environment of the event. Several efforts have been pursued in recent years in the areas of evacuation and egress modeling in the context of fire protection engineering. Outside of the fire-protection engineering field, models are being created to simulate evacuation from cities and/or human behavior in response to terrorist events. This session aims to discuss new methods in modeling, especially by providing an interdisciplinary information exchange on the prediction of human behavior and threat evolution in emergencies. Also of interest are new models, results and experimental data gathering related to the use of models to investigate the building system behavior during emergencies.

\subsection{Presentations}

\section{"Available Data and Input into Models," Rita Fahy, National Fire Protection Association, Massachusetts}

In order to better understand human behavior in fire, to enhance the effectiveness and completeness of evacuation models, and to provide better information for the users of evacuation models, additional study is needed in a range of areas. We need more data on all the time components of behavior, particularly those that are not a simple matter of speed and distance; data on the variability of those time components; and data or models on the factors driving behavior choices and the variability in time to perform certain actions. Some of the more specific areas will be listed and described.

\section{“A Comprehensive Review of 28 Evacuation Models," Erica Kuligowski, NIST}

To aid with the difficult task of choosing an appropriate model, a comprehensive model review of 28 past and current egress models has recently been completed. This model review provides information on model purpose, availability, modeling method, model structure and perspective, methods for simulating movement and behavior, output, use of fire data, use of visualization and CAD drawings, etc. The model review organizes the evacuation programs into three basic categories that aim to describe the models' level of sophistication in simulating behavior of the occupants. These categories are movement models (no behavioral capabilities), partialbehavioral models (implicit behavior is simulated), and behavioral models (occupant decisionmaking and behavior is simulated). 


\section{"Simulex: Simulated People Have Needs Too," Peter Thompson, Integrated Environmental Solutions, Ltd., Glasgow, UK}

This presentation will address a number of keys areas of evacuation modeling and data collection, drawing on the knowledge and experiences of the author. The following areas will be discussed: 1. Detailed human-movement data that were collected in order to create the evacuation model Simulex. 2. Use of the computer program to model situations where data are not available. 3. Required areas of concentration for future data collection efforts. 4. Notes about some current data collection activities in the UK.

\section{"Uncertainty in Egress Models and Data: Investigation of Dominant Parameters and Extent of Their Impact on Predicted Outcomes - Current Status," James Lord (presenting) and Brian Meacham, Arup Fire}

Computer egress modeling is becoming a common tool in the building design industry. Models can provide insight into the movement of people through buildings, and sometimes provide a visual tool that is useful for presentation of a design to architects, clients, and authorities. The reality of egress modeling is that current methods of calculation must somehow account for a degree of human behavior that is not necessarily predictable. Most egress models attempt this through use of correlations based on available data, or through the addition of safety factors to the model results. When using an egress model in building design, there are many uncertain variables. However, as discussed by Fahy at the National Research Council Workshop to Identify Innovative Research Needs to Foster Improved Fire Safety in the United States, there is a severe lack of data for use in predicting evacuation times from buildings, and for the data that do exist, there has been little or no identification or assessment of uncertainty and variability, or of the impact of the uncertainty or variability on the predictive capability of egress models. Notarianni and others have discussed the importance of identifying and addressing uncertainty, as the failure to do so can lead to misapplication of models, and of the results obtained from the models as used in design and performance evaluations.

To begin addressing the above concerns, a three-year research program is underway, funded by a grant from the National Institute of Standards and Technology, Building and Fire Research Laboratory (Grant 60NANB2D0138), that aims to improve the predictive capabilities of egress models. The primary goals of this work are to: 1 . Understand sources of uncertainty and variability in egress models. 2. Apply and refine a method of uncertainty analysis to computer egress modeling. 3. Identify "cross-over" variables that may have an impact on the results of the egress model that is significant enough to cause a change in an engineer's design of a building. 4. Provide building engineers with guidance in the appropriate use of computer egress models. This presentation will provide a brief overview of the current status of the research program, including the methodology and initial findings. 


\section{"Estimating Evacuation Time Components: Lessons from Nuclear Power Plants, Hurricanes and the First World Trade Center Bombing," Michael Lindell, Hazards Reduction and Recovery Center, Texas A\&M University}

Data from the first WTC bombing show that this ambiguous situation elicited an orderly process of information seeking that tended to delay evacuation (Aguirre, Wenger, \& Vigo, 1997; Prater, Wenger \& Lindell, 1997; Wenger, Aguirre \& Vigo, no date). Consistent with emergent norm theory, the information seeking (milling) process was influenced by pre-existing social relationships. Moreover, though there was a widespread and increasing perception of danger and some of the conditions for panic existed, the evacuation was orderly. This similarity in occupant behavior to that displayed by community residents in other types of disasters suggests that building evacuations in response to threats or acts can also be defined by a series of stagesdetection/warning, psychological preparation, logistical preparation, and protective action selection/implementation (Lindell \& Perry, 2004). There has been a considerable amount of research that has studied the relationship between detection/warning and evacuation. However, there has been very little research to date that has attempted to characterize household preparation times or the variables that account for differences among households in their preparation times. The available studies have found few, if any, reliable predictors of this evacuation time component (Aguirre, Wenger, \& Vigo, 1997; Lindell \& Perry, 1987; Lindell \& Perry, 1992; Lindell \& Perry, 2004; Lindell, Prater, Sanderson, Lee, Zhang, Mohite \& Hwang, 2001; Lu, Lindell \& Prater, 2004; Sorensen, 1991; Tierney, Lindell \& Perry, 2001). However, further research is needed to determine the applicability of existing research to building evacuations. This is because social units within a building are defined more ambiguously than households within a community, employers can exercise more control over employees' threat responses than public officials can exercise over community residents, and occupants' perceptions of alternative protective actions in buildings are likely to be different from residents' perceptions of the available protective actions in communities.

\section{"Evacuation Time from a Single Family Home," Guylène Proulx, National Research Council, Canada}

This presentation identifies several factors that can affect evacuation time from a typical single family home in the event of a fire. Through a review of the literature, evacuation time is found to depend on the characteristics of the occupant(s), the characteristics of the building, the fire detection system in place, the location, cause, and time of the fire. Recent studies performed by NIST suggest that less then 3 minutes might be available for the safe evacuation from homes. This available safe egress time is of great concern since the require time to evacuate all occupants from a home fire might be much longer than 3 minutes in many fire scenarios.

\subsection{Session Summary}

After the session, the discussion addressed several themes that serve as an effective summary. These fall under four main categories: 1) Data needs for prediction and training 2) A repository for information and information sharing 3) Evacuation models, and 4) A discussion/working group to continue efforts after the workshop is over . 
From the first set of presentations in this session, several data needs were outlined for both prediction methods and for training purposes. A few examples of data needs expressed were the evacuation of disabled occupants, flows on different types of stairs, behavior of occupants during evacuation, pre-evacuation delay times, and toxic effect on occupants (movement and decision making). After being presented with information from various types of disciplines which study behavior, participants in the data needs session were asking the following question: Are we dealing with a complete lack of data or a lack of known data? It became increasingly clear that other disciplines outside of fire research, such as human factors, sociology, psychology, and others, could contribute their wealth of knowledge to the study of evacuation from fires. Another related question that originated from the data needs session was the following: How much do we need to understand about evacuation from a building to make sure that the building is safe? Another theme of the discussion from the data needs session revolved around the need for a repository of data on human behavior and a way to share this type of data among colleagues. NIST was looked to as a provider of this type of repository.

The third theme discussed in the data needs session was the topic of evacuation models. Many questions were posed relating to the assumptions of the models, their validation techniques, and whether they provided the appropriate information to users. Also, it was established that many current evacuation models neglect to include important aspects of an evacuation such as social/group movement, disabled movement and use of evacuation devices, and the effect of staff and other occupant roles on evacuation procedures. Among the model developers in the session, it was suggested that there be a standard for data format in all models so that the model packages can talk to one another. If this was the case, users could potentially create the "super-model" that can incorporate smoke and fire effects, people movement, behavioral aspects (if such a model existed), and building sensors to provide information to the occupants.

The third theme also addressed the issues of uncertainty in evacuation modeling. With the lack of data in some areas of evacuation and the choice of different types of data (i.e. movement data) for evacuation model inputs, a user is faced with difficult choices to make when providing inputs to the model. Work is currently being done in this area with different models to identify the inputs that have the largest impact on the results from the model, as well as to provide guidance to model users. With this information, the users can spend time collecting accurate data for the inputs that are the most significant to the individual model.

Lastly, a suggestion was made during the data needs session to develop a working group that would continue discussion and strive to eventually develop a research agenda in the area of human behavior in fire. An email discussion digest is in the works for those participants who are interested in continuing discussion from the workshop.

The session chairs of all three sessions were asked to summarize all session discussion answering the following four questions.

- What is the current state of knowledge from research and in theory?

- What is the current state of putting that theory into practice?

- What is the gap between that and where we need to be?

- What activities and resources are needed to close this gap? 
The current state of research in the field of fire evacuation is that several disciplines are primarily working independently on various projects related to the field. However, collaboration is lacking between these disciplines. It was clearly shown that sociology, psychology, engineering, human factors, computer science, and others could collaborate in several areas related to data needs, since much of the data are scarce and/or outdated.

The presentations and discussion established that there were several gaps in the data used for prediction methods. Also, there were gaps in the actual model inputs, simulation techniques, and users' understanding of the models' assumptions and limitations.

To bridge this gap, knowledge transfer between the disciplines would be a step in the right direction. Work in other areas would help to fill in gaps within data and help to increase the overall understanding of human behavior. Also, additional research in needed areas as well as information sharing among researchers would be important to developing a better understanding of occupant evacuation from buildings. Along with additional research, an understanding of how specific and accurate our predictions methods have to be is essential. Lastly, an institution, such as NIST needs to step forward and volunteer to be the central repository for evacuation data and information sharing among research disciplines. 


\title{
4.3 Available Data and Input Into Models
}

\author{
Rita Fahy, PhD \\ National Fire Protection Association
}

\begin{abstract}
There is a need for better data to improve our knowledge of human behavior in fire. This data can be used in the development and refinement of evacuation models and in the use of such models. Once collected, human behavior data must be published in peer-reviewed journals and conference proceedings. A central repository should be created to store the data in a format that enhances its use by researchers, fire safety engineers and the regulatory community. The data collection itself must be adequately funded. We need a coordinated effort to collect this sort of information, rather than ad hoc projects when major incidents occurs. Valuable time can be lost in the pursuit and processing of funding. One important method for collecting this data is postincident surveys and interviews. Although there are some disadvantages to this technique, it provides valuable insight into actions and behaviors in real-life emergencies.
\end{abstract}

\section{Introduction}

Evacuation models are key tools for the evaluation of engineered designs. Fire growth models can predict the spread of smoke and other toxic products throughout a structure. Evacuation models can predict the location of people as they exit the structure. Used together in the evaluation of a design, these models can provide some indication of the risk that occupants might face under a modeled scenario.

Evacuation models vary in complexity, but all rely on data, either in their development (i.e., they are calculation methods based on observations) or as input. The models may simply provide estimates of evacuation times, or they may be intended to more fully simulate occupant behavior, including decisions.

\section{Brief Overview of Evacuation Models}

There are different types of evacuation models. There are simple straightforward calculation methods for estimates of evacuation times. These equations or simple computer models may be based on observed movement from drills and experiments.

The next level of complexity is network flow models that handle large numbers of people. These models are useful for benchmarking designs, but they cannot be used to predict what any one person might experience, since they treat the occupants like water in a pipe rather than as individuals.

Behavioral simulation models are the most complex, treating more of the variables related to both movement and behavior. Their added complexity requires tremendous amounts of data for their development, if the assumptions they contain regarding behavior are to be based on reality 
rather then expediency. Their users also need a fuller understanding of the components of human behavior in fire in order to choose appropriately among available options.

\section{Types of Data Needed for Models}

Data can be used to develop the equations or algorithms in models or to serve as input to the models. Data is also needed to test the validity of the models.

All evacuation models require data on the characteristics of occupants, their actions during evacuation, delays that may occur, and travel speeds for different types of occupants. Data is needed on, for example:

- delay times, i.e., the time that elapses between when people are first alerted to an incident and when they begin to leave, including the time they may take to prepare for evacuation;

- walking speeds on different types of surfaces, up and down stairs, under different degrees of crowdedness, and for people with a range of physical abilities;

- occupant characteristic, including age, gender, degree of training, familiarity, etc., to account for differences in actions and reactions among the different types of people for different types of occupancies;

- the variety of specific actions people may engage in during evacuation, since these will impact the time people take to leave the building;

- effects of obstructions in travel paths, which can cause delays or block egress; and

- exit choice decisions, which determine travel paths and affect travel times.

\section{Sources of Data}

The appropriate methods for collecting the needed data vary, and each collection method has its advantages and disadvantages.

Videotaped observations of actual evacuations are ideal, since they show exactly what different people did, and the elapsed time can be calculated directly from the tape. They will show how long it takes people to react to cues, to seek information and/or prepare to evacuate, and will record their movement (including queueing, walking speed, flows through doorways, in corridors or on stairs, precedence behavior at merges, etc.) The characteristics of their individuals, including any mobility impairments, can be determined from the tape, or can be obtained later in interviews. However, videotapes are rarely available for actual fire incidents, so what is obtained is information that, though valuable, is not directly applicable to decisions and movement of people under actual stressful conditions. Regardless of its limitations, extensive and valuable work in this area has been undertaken in recent years in mid- and highrise apartment and office buildings. [Proulx et al 1994, 1995a, 1996]

Laboratory experiments have been done to test the effects of smoke on decision-making and travel speed. [Jin 1997, Kubota 2001] Because of ethical issues and increasing restrictions and outright bans on the use of human subjects, however, researchers rarely undertake such experiments. 
Post-incident surveys and interviews can be used to obtain information from survivors of actual fires. This method has been used for a great many years (Bryan 1977 and 1983, Woods 1990, Best 1977, Proulx et al 1995b, Fahy and Proulx 1996). A methodology for conducting post-fire interviews is detailed in (Keating and Loftus 1984). Although these methods will give real-life evidence, there are disadvantages. Recollections and descriptions will be subjective. The elapsed times are not recorded objectively, and the reported times may be distorted. Details can be lost as time passes after an incident, making timeliness of data collection an important issue. Recollections of a group of people may converge over time as they share their stories and meld details.

\section{Research Needs}

In order to better understand human behavior in fire, to enhance the effectiveness and completeness of evacuation models, and to provide better information for the users of evacuations model, additional study is needed in a range of areas.

The areas of study involve the need for more data on all the time components of behavior, particularly those that are not a simple matter of speed and distance; data on the variability of those time components; and data or models on the factors driving behavior choices and the variability in time to perform certain actions. Some of the more specific areas are listed and described here:

- effects on counterflows in stairs: what do we know about the impact of firefighters going upstairs while occupants evacuate or of rescuers (e.g., in hospitals or nursing homes) returning for more people?

- movement capabilities of a wide cross-section of society: how much do we know about variations in movement capability by age or by walking impairment?

- evacuation of disabled people: how are wheelchair users expected to evacuate and how long with that take; how might their evacuation impact the overall evacuation flow?

- differences in response to a range of cues: do people respond differently to different types of alarms or different fire cues?

- waking effectiveness of a range of cues: what would be the most effective method or design to awaken people and alert them to a fire?

- delay times before beginning evacuation: what is the effect of being alone, being with others, the types and number of cues, the type of occupancy, a person's experience with false alarms?

- flows on different types of stairway configurations: what do we know about the use of space on stairs, flows on spiral stairs, the effect of the geometry of stairs?

- behaviors: who decides to stay and who decides to go; what is the basis for exit choice; how can we predict stopping and turning back behaviors; who queues and who doesn't; do we know how to predict an individual's need for rest during long evacuations?

- effects of training of staff and/or occupants: how can we begin to quantify the impact of training of staff or occupants on reducing delay times and/or improving travel times?

- perception of risk: what factors impact perception of risk and how does risk perception impact judgment? 
- toxic effects: at what levels do toxic products affect decision making, movement speeds and survival and how do those effects vary among people?

- interaction between people -- how do the presence of social groups impact evacuation delays and movement?

- elevator use: assuming they were safe to use, how would they be used effectively for evacuation, and would they be used by everyone or only by those with mobility impairments?

- alarms: can building occupants recognize alarms and how audible are they throughout a building, given ranges in ambient noise and light levels?

\section{Education and Training}

Research in human behavior is a discipline that could benefit greatly from improved partnerships with researchers in the behavioral sciences. (Horasan and Saunders, 2001) Differences in approach to research between physical and social sciences must be bridged so that the best information can be identified and applied to the fire problem.

Once data is collected, it must be put in the hands of the people who can use and apply it. Two international symposia were held in recent years which have helped to focus attention on this research field, which has been an essential first step and the proceedings from the symposia are valuable resources (ISHBF 1998, 2001). However, there were few practitioners in the field of fire safety engineering present at either symposium. They need a place to find the current state of knowledge in human behavior so that they can effectively and appropriately apply available evacuation models. Model developers need access to the data so that they can use it as the basis for assumptions and calculations. Building and fire regulators need the data so that they can better understand and evaluate the analyses of engineered designs. In the overall field of fire safety sciences, researchers studying the physics and chemistry of fire need to appreciate the role of human factors in the use of products, the maintenance of systems, the response to real-world fires, and their vulnerability to fire's effects. This all points to the need for a cross-disciplinary approach to the study of human behavior in fire.

\section{Barriers to Improved Collection and Use of Data}

We lack a central repository for research on human behavior in fire. A central storage system for data would require that efforts begin to standardize the collection or reporting of collected data so that retrieval would be simplified. A first attempt to consolidate some of the available movement and delay time data has been proposed, but that was only a very preliminary first step (Fahy and Proulx, 2001).

There are several barriers that exist today that limit our ability to create such a clearinghouse. Much of the data collected over the past few decades was never published, and so, cannot be used. Any data collection project must be published in peer-reviewed literature.

A standard reporting mechanism would allow data from various sources to be compared, without unduly constraining the approaches researchers choose to use. For example, every data set should include a description of the occupancy, the capabilities of the occupants, their number, 
the fire safety systems present, the effectiveness of those systems and any other information that supplies a context for the data. This would enable researchers to identify the similarities between data sets and allow comparisons or aggregations where appropriate. Aggregated data should be reported in terms of distributions that will capture the range of observations, rather than just summary statistical measures.

And finally, data must be shared. This is difficult when the research is funded by an entity that will claim a propriety right to the data. Government-funded research, however, should be disseminated as widely as possible, so that all can benefit.

\section{Conclusion}

Human behavior in fire is clearly an area that would benefit from increased research efforts. If only one aspect of the research had to be given top priority, it should be the timely collection of post-fire incident data. The U.S. Fire Administration of the Federal Emergency Management Agency contracts for the investigation of significant fires. The incidents to be investigated are agreed upon by the contractor and contract officer, with the cooperation of the responding fire department. Very little delay occurs after notification of the fire and the dispatch of the investigation team.

A similar program for the collection of survey or interview data could be instituted. This would reduce the delays that now occur while proposals seeking funding are developed and reviewed. General agreement on approach (which can vary from incident to incident) can be reached beforehand. A schedule for completion of reports and planning for their dissemination would also be agreed. Every incident needs a methodology tailored to that incident, and that unavoidable customization step takes long enough. Coordination with USFA may be necessary, since an on-scene incident investigation, including information on the fire, the geometry of the structure, the presence and performance of fire protection systems, etc., bear on the actions of the occupants in attempting evacuation.

\section{References}

Best, RL, Reconstruction of a Tragedy -- The Beverly Hills Supper Club Fire, National Fire Protection Association, Boston MA, 1977.

Bryan, JL, Smoke as a Determinant of Human Behavior in Fire Situations (Project People), National Bureau of Standards, Gaithersburg MD, 1977.

Bryan, JL, Implications for Codes and Behavior Models from the Analysis of Behavior Response Patterns in Fire Situations as Selected from the Project People and Project People II Study Reports, National Bureau of Standards, Gaithersburg MD, 1983a.

Bryan, JL, An Examination and Analysis of the Dynamics of the Human Behavior in the Westchase Hilton Hotel Fire, revised edition, National Fire Protection Association, Quincy MA, $1983 b$. 
Bryan, JL, An Examination and Analysis of the Dynamics of the Human Behavior in the MGM Grand Hotel Fire, revised report, National Fire Protection Association, Quincy MA, 1983c.

Fahy, RF, and Proulx, G, "A Study of Occupant Behavior During the World Trade Center Evacuation," Conference Proceedings of the Seventh International Interflam Conference, Interscience Communications Ltd., London, 1996, pp. 793-802.

Jin, Y, "Studies on Human Behavior and Tenability in Fire Smoke, Fire Safety Science Proceedings of the Fifth International Symposium, International Association for Fire Safety Science, 1997, pp. 3-21.

Keating, JP, and Loftus, EF, Post Fire Interviews: Development and Field Validation of the Behavioral Sequence Interview Technique, National Bureau of Standards, Gaithersburg MD, 1984.

Kubota, K, and Murasaki, Y, "Correlation between Physiological Index and Psychological Index during Stressful Fire Experiments," Proceedings of the $2^{\text {nd }}$ International Symposium on Human Behaviour in Fire, Interscience Communications Ltd., London, 2001, pp. 263-274.

Proulx, G, Latour, JC, and MacLaurin, J, Housing Evacuation of Mixed Abilities Occupants, Internal Report No. 661, National Research Council of Canada, Ottawa ON, 1994.

Proulx, G, Latour, JC, McLaurin, JW, Pineau, J, Hoffman, LE, and Laroche, C, Housing Evacuation of Mixed Abilities Occupants in Highrise Buildings, Internal Report No. 706, National Research Council of Canada, Ottawa ON, 1995a.

Proulx, G, Pineau, J, Latour, JC, and Stewart, L, A Study of the Occupants' Behaviour during the 2 Forest Laneway Fire in North York, Ontario, January 6, 1995, Internal Report No. 705, National Research Council of Canada, Ottawa ON, 1995 b.

Proulx, G, Kaufman, A, and Pineau, J, Evacuation Time and Movement in Office Buildings, Internal Report No. 711, National Research Council of Canada, Ottawa ON, 1996.

Wood, PG, "A Survey of Behaviour in Fires," Fires and Human Behaviour, $2^{\text {nd }}$ edition, D. Canter Editor, David Fulton Publishers Ltd., London, 1990, pp. 83-95.

Human Behaviour in Fire -- Proceedings of the First International Symposium, University of Ulster, Belfast, 1998.

Proceedings of the $2^{\text {nd }}$ International Symposium on Human Behaviour in Fire, Interscience Communications Ltd., London, 2001. 


\title{
4.4 Review of 28 Egress Models
}

\author{
Erica Kuligowski \\ National Institute of Standards and Technology
}

\section{Introduction}

Evacuation calculations are increasingly becoming a part of performance-based analyses to assess the level of life safety provided in buildings ${ }^{1}$. In some cases, engineers are using backof-the-envelope (hand) calculations to assess life safety, and in others, evacuation models are being used. Hand calculations usually follow the equations given in the Emergency Movement Chapter of the Society of Fire Protection Engineers (SFPE) Handbook ${ }^{2}$ to calculate mass flow evacuation from any height of building. The occupants are assumed to be standing at the doorway to the stair on each floor as soon as the evacuation begins. The calculation focuses mainly on points of constriction throughout the building (commonly the door to the outside) and calculates the time for the occupants to flow past that point and to the outside.

To achieve a more realistic evacuation calculation, engineers have been looking to evacuation computer models to assess a building's life safety. Currently, there are a number of evacuation models to choose from, each with unique characteristics and specialties. A concern with current evacuation models is whether they can accurately simulate the unique scenarios that accompany a certain type of building. How would a user know which model to choose for his/her design?

To aid with the difficult task of choosing an appropriate model, a comprehensive model review of 28 past and current egress models has recently been completed ${ }^{3}$. This model review was completed with large influence from the work done by Gwynne and Galea at the University of Greenwich $^{4}$ and Olenick from Combustion Science and Engineering, Inc ${ }^{5}$. The model review provides information on model purpose, availability, modeling method, model structure and perspective, methods for simulating movement and behavior, output, use of fire data, use of visualization and CAD drawings, etc. The model review organizes the evacuation programs into three basic categories that aim to describe the models' level of sophistication in simulating behavior of the occupants. These categories are movement models (no behavioral capabilities), partial-behavioral models (implicit behavior is simulated ${ }^{4}$ ), and behavioral models (occupant decision-making and behavior is simulated).

\section{Available Egress Model Reviews}

Three evacuation model reviews are available, which were significant in the organization and data gathering found in this chapter. The most substantial review to date was performed by Gwynne and Galea ${ }^{4}$ at the University of Greenwich. This report offers a review of 16 evacuation models and is referenced throughout this section. Second, Combustion Science and Engineering released an article on a review of fire and evacuation models, as well as developed a website where this information is available to the public ${ }^{5,6}$. Also, a review was performed by Watts ${ }^{7}$ where he introduced early network algorithm models, queuing models, and "simulation" models 
and gave examples of each type. Lastly, Friedman ${ }^{8}$ also reviewed egress models, much in the same fashion as was performed by Gwynne and Galea.

However, there is a still a need for an updated, unbiased, and more detailed review to aid evacuation model users in choosing the appropriate model for their particular project. The previous three reviews listed were written before some of the newer models were developed, showing a need for a more updated review. Also, the previous three model reviews can be expanded as far as providing additional detailed information for each model. Therefore, more explanation was given in this review to the details of interest to model users, the inner workings of each model, and each model's validation methods and limitations.

\section{Features of Egress Models}

In developing any model review, it is important to first list the features and capabilities that are of interest to potential users. Each of the following evacuation models reviewed were categorized according to the following list of features and capabilities.

- Purpose

- Availability for public use

- Modeling method; movement, partial-behavioral, behavior

- $\quad$ Structure of model

- Perspective of model and perspective of occupants

- Occupant behavior

- Occupant movement

- Use of fire data

- Output

- Use of CAD drawings

- Visualization capabilities

- Validation studies

- Special Features

- Limitations

This review covers a total of 28 computer models that focus on providing evacuation data from buildings. Many of the models reviewed can also simulate other types of scenarios; however evacuation from buildings is the main focus of this review. The models are organized in the review by modeling method; movement models, partial behavioral models, and behavioral models. However because of its uniqueness, the model, Myriad, is not categorized with a particular movement method (even though it resides in the behavioral models section below). A list of the models in the review is provided here in the order that they appear in the detailed review:

- Movement models: FPETool ${ }^{9}$, EVACNET4 $^{10,11}{ }^{1}$ Takahashi's Fluid Model $^{12}$, PathFinder $^{13}$, TIMTEX $^{14}$, WAYOUT $^{15}$, Magnetic Model $^{16}$, EESCAPE $^{17}$, EgressPro $^{18}$, ENTROPY Model $^{19}$ 20, and STEPs ${ }^{21-25}$. 
- Partial Behavioral models: PEDROUTE/PAXPORT ${ }^{26-32}$, EXIT89 $^{33-39}$, Simulex $^{40-47}$, GridFlow $^{48}$, and ALLSAFE ${ }^{49-51}$.

- Behavioral models: CRISP ${ }^{52-55}$, ASERI ${ }^{56-59}$, BFIRES-2 ${ }^{60-62}$, buildingEXODUS , $^{4-63-68}$, EGRESS $^{69-71}$, EXITT $^{72,73}$, VEgAS $^{74-76}$, E-SCAPE $^{77}$, BGRAF $^{78-81}$, EvacSim $^{82, ~ 83}$, Legion $^{84-86}$, and Myriad ${ }^{75,76}$ (uncategorized).

For each model, a special feature section is included in this review. These are included as features of interest for model users who are searching for the appropriate model to simulate a certain type of scenario or set of scenarios. The special features section verifies whether the model is capable of simulating at least one of the ten specialized features. It is of interest whether or not the model can simulate the first nine features listed and lastly, how the model simulates occupant route choice. However, just because a model attempts to simulate a feature does not always mean that there is adequate data to support the feature. The specific features included in the review are as follows.

- Counterflow

- Manual exit block/obstacles

- Fire conditions affect behavior?

- Defining groups

- Disabilities/slow occupant groups

- Delays/pre-movement times

- Elevator use

- Toxicity of the occupants

- Impatience/drive variables

- Route choice of the occupants/occupant distribution

For each model in the review, the feature is listed and described only if it is apparent that the model has the capability of simulating it. Also, for each model, the method of simulating route choice is listed and described.

This report provides only a summary of the full-length model review ${ }^{3}$, which describes the features and capabilities of 28 different evacuation models individually.

This report aims to summarize the full-length review by providing a series of quick reference tables for model users to identify the models with which they should research further. Due to lack of information in the designated categories of interest for certain models, two models are included in the detailed review but will not be included in the following summary and tables. These models are FPETool ${ }^{9}$ and Myriad $^{76}$ :

- FPETool is not included in the tables due to the fact that it is not primarily an evacuation model, but more so a total package fire model with an egress calculation. It is included in the review for completeness. However, since FPETool lacks many of the features that other egress models contained, it was determined unnecessary to include its features in Tables 1-3.

- Since Myriad is very different from the other evacuation models, focuses on crowd movement, and lacks information on the important categories outlined in the review, it is also not included in the conclusion tables. Because of the difference in modeling method as well 
as lack of detailed data on the inner workings of the model, only the categories for which data was obtained are included in the Myriad write-up section.

The reference tables, Tables 1 through 3, organize the detailed data presented from the full length report ${ }^{3}$ as summary guides. Table 1 details the overall organization of the categorical data for each model. Tables 2 and 3 focus on the special features of each model. The features of evacuation models and the corresponding abbreviations used throughout Table 1 are explained in the following paragraphs.

Purpose:

This subcategory describes the use of the model, as it pertains to certain building types. Some of the models in this review focus on a specific type of building and others can be used for all building types. The main purpose in using this as a category is to understand if the model can simulate the user's chosen building design.

The current model categories for purpose, as labeled in Table 1, involve models that can simulate any type of building (1), models that specialize in residences (2), models that specialize in public transport stations (3), models that are capable of simulating low-rise buildings (under 75 feet) only (4), and models that only simulate 1-route/exit of the building (5).

Availability to the Public:

The subcategory of availability becomes important if the user is interested in modeling the building in-house or hiring the developing company to provide evacuation results. In this subcategory, some models are available to the public for free or a fee (Y). Others are not available due to the following circumstances; the model has either not yet been released (N1), the model is no longer in use (N2), or the company uses the model for the client on a consultancy basis (N3). If the status of the model is unknown, it is labeled as (U) in Table 1.

\section{Modeling Method:}

Past and current evacuation models have been categorized using a primary category labeled modeling method ${ }^{4}$. This category describes the method that each model uses to calculate evacuation times for certain types of building. Under the modeling method category, models are assigned one of the following three labels:

- Behavioral models (B): those models that incorporate occupants performing actions, in addition to movement toward a specified goal (exit). These models can also incorporate decision-making by occupants and/or actions that are performed due to conditions in the building. For those models that have risk assessment capabilities, a label of (B-RA) is given.

- Movement models (M): those models that move occupants from one point in the building to another (usually the exit or a position of safety). These models are key in showing congestion areas, queuing, or bottlenecks within the simulated building. For those models that are specifically optimization models, a label of (M-O) is given.

- Partial behavior models (PB): those models that primarily calculate occupant movement, but begin to simulate behaviors. Possible behaviors could be implicitly represented by premovement time distributions among the occupants, unique occupant characteristics, overtaking behavior, and the introduction of smoke or smoke effects to the occupant. These 
are models capable of simulating an entire building, and occupants' movements throughout the model are based on research of observed human behavior data.

\section{Grid/Structure:}

The subcategory of grid/structure is used to assess the method of occupant movement throughout the building. A fine network (F) model divides a floor plan into a number of small grid cells that the occupants move to and from. The coarse network $(\mathrm{C})$ models divide the floor plan into rooms, corridors, stair sections, etc. and the occupants move from one room to another. A continuous (Co) network applies a 2D (continuous) space to the floor plans of the structure, allowing the occupants to walk from one point in space to another throughout the building. Fine and continuous networks have the ability to simulate the presence of obstacles and barriers in building spaces that influence individual path route choice, whereas the coarse networks "move" occupants only from one portion of a building to another.

\section{Perspective of the model/occupant:}

The perspective subcategory explains how 1) the model views the occupants and 2) how the occupants view the building.

1) How the model views the occupants:

There are two ways that a model can view the occupant; globally $(\mathrm{G})$ and individually (I). An individual perspective of the model is where the model tracks the movement of individuals throughout the simulation and can give information about those individuals (ex. their positions at points in time throughout the evacuation). When the model has a global view of the occupants, the model sees its occupants as a homogeneous group of people moving to the exits. It is clear to see that an individual perspective of the occupants is more detailed, but it depends on the purpose of the simulation as to which alternative is best. If the user is not interested in knowing the position of each occupant throughout the simulation or assigning individual characteristics to the population, than a global view is sufficient.

2) How the occupant views the building:

The occupant can view the building in either a global $(G)$ or individual (I) way. An occupant's individual view of the building is one where the occupants are not all knowing of the building's exit paths and decide their route based on information from the floor, personal experience, and in some models, the information from the occupants around them. A global perspective of the occupants would be one where they automatically know their best exit path and seem to have an "all knowing" view of the building.

Each model is categorized by both the perspective of the model and of the occupant. If only one entry is listed in this column, both the model and occupant have the same perspective.

\section{Behavior:}

The behavior of occupants is represented in many different ways by the evacuation models in this review. The organization associated with this sub category is the following: no behavior $(\mathrm{N})$, implicit behavior (I), rules or conditional behavior $(\mathrm{R} / \mathrm{C})$, functional analogy $(\mathrm{FA})$, or artificial intelligence (AI). Also, some models have the capability of assigning probabilities of performing certain behaviors to specific occupant groups. Many of the partial behavioral models 
allow for a probabilistic distribution of the pre-evacuation times, travel speeds, and/or FED or smoke susceptibility.

- $\quad$ No behavior $(\mathrm{N})$ denotes that only the movement aspect of the evacuation is simulated

- Implicit behavior ${ }^{4}$ (I) represents those models that attempt to model behavior implicitly by assigning certain response delays or occupant characteristics that affect movement throughout the evacuation

- Conditional (or rule) (C) behavior reflects models that assign individual actions to a person or group of occupants that are affected by structural or environmental conditions of the evacuation (as an "if, then" behavioral method)

- Functional Analogy (FA) resembles models that apply a set of equations to the entire population. Usually the equations are taken from another field of study, such as Physics, to represent occupant movement.

- Artificial Intelligence (AI) resembles the models that attempt to simulate human intelligence throughout the evacuation.

- Probabilistic $(\mathrm{P})$ represents that many of the rules or conditional-based models are stochastic, allowing for the variations in outcome by repeating certain simulations.

When incorporating fire conditions, several models use the data from Bryan and Wood ${ }^{87}$, and $\mathrm{Jin}^{88}$ to develop rules for occupants faced with such conditions. These behaviors involve turn back behavior, slowing of occupant movement, and the physical movement of crawling, based on the changing environmental conditions.

\section{Movement:}

The movement subcategory categorizes how the models move occupants throughout the building. For most models, occupants are usually assigned a specific unimpeded (low density) velocity by the user or modeling program. The differences in the models occur when the occupants become closer in a high density situation, resulting in queuing and congestion within the building. The different ways that models represent occupant movement and restricted flow throughout the building are listed here:

- Density correlation (D): The model assigns a speed and flow to individuals or populations based on the density of the space. When calculating movement dependent on the density of the space, three key players come to mind from which the data originated that is used in current evacuation models. These three sources of occupant movement data for evacuation models are Fruin ${ }^{89}$, Pauls $^{90,91}$, and Predtechenskii and Milinskii ${ }^{92}$

- User's choice (UC): The user assigns speed, flow, and density values to certain spaces of the building

- Inter-person distance (ID): Each individual is surrounded by a $360^{\circ}$ "bubble" that allows them only a certain minimum distance from other occupants, obstacles, and components of the building (walls, corners, handrails, etc.)

- Potential (P): Each grid cell in the space is given a certain number value, or potential, from a particular point in the building that will move occupants throughout the space in a certain direction. Occupants follow a potential map and attempt to lower their potential with every step or grid cell they travel to. Potential of the route can be altered by such variables as patience of the occupant, attractiveness of the exit, familiarity of the occupant with the building, etc. (which are typically specified by the user). 
- Emptiness of next grid cell (E): In some models, the occupant will not move into a grid cell that is already occupied by another occupant. Therefore, the occupant will wait until the next cell is empty, and if more than one occupant is waiting for the same cell, the model will resolve any conflicts that arise when deciding which occupant moves first.

- Conditional (C): With conditional models, movement throughout the building is dependent upon the conditions of the environment, the structure, the other evacuees, and/or fire situation. For this designation only, not much emphasis is placed on congestion inside the space.

- Functional analogy (FA): The occupants follow the movement equations specified by the topic area, such as fluid movement or magnetism. In some cases, the equations (such as fluids) depend on the density of the space.

- Other model link (OML): The movement of the occupants is calculated by another model, which is linked to the evacuation model reviewed.

- Acquiring knowledge (Ac K): Movement is based solely on the amount of knowledge acquired throughout the evacuation. For this model, there is no real movement algorithm because evacuation time is not calculated; only areas of congestion, bottlenecks, etc.

- Unimpeded flow (Un F): For this model, only the unimpeded movement of the occupants is calculated. From the calculated evacuation time, delays and improvement times are added or subtracted to produce a final evacuation time result.

\section{Fire Data:}

The fire data subcategory explains whether or not the model allows the user to incorporate the effects of fire into the evacuation simulation. However, the models incorporate fire data in a variety of ways and it is important for the user to understand the complexity of the coupling. The model can incorporate fire data in the following ways: Importing fire data from another model (Y1), allowing the user to input specific fire data at certain times throughout evacuation (Y2), or the model may have its own simultaneous fire model (Y3). If the model cannot incorporate fire data, it simply runs all simulations in "drill" mode $(\mathrm{N})$. "Drill" mode is the equivalent of a fire drill taking place in a building, without the presence of a fire.

The purpose for evacuation models to include such data is ultimately to assess the safety of the occupants who travel through such conditions. Purser has developed a model to calculate a fractional incapacitating dose for individuals exposed to $\mathrm{CO}, \mathrm{HCN}, \mathrm{CO}_{2}$, and reduced $\mathrm{O}_{2}{ }^{93,94}$. Many models that incorporate a fire's toxic products throughout the building spaces, use Purser's model to calculate time to incapacitation of the individual occupants. Purser also developed mechanisms for models to calculate certain effects due to heat and irritant gases.

Some models also go as far as to use data collected by Jin in Japan ${ }^{88}$ on the physical and physiological effects of fire smoke on evacuees. Jin performed experiments with members of his staff, undergraduates, and housewives subjected to smoke consisting of certain levels of density and irritation. He tested visibility and walking speed through irritant smoke in $1985^{88}$ and correct answer rate and emotional stability through heated, thick, irritant smoke-filled corridors in the late $1980 \mathrm{~s}^{88}$. This data is used in certain models to slow occupant movement through smoke and also to change occupant positioning in certain spaces to a crawl position, instead of upright. 
Bryan and Wood concentrated on the correlation between visibility distance in the smoke and the percentage of occupants within that smoke that would move through it ${ }^{87}$. This work was done in the United States (Bryan) and the UK (Wood) and was obtained by occupant self-reporting. This data is used by current models to assess when certain occupants will turn back, instead of move forward into the smoke-filled space.

There is a limited amount of information or data available on the validity of these optical density and occupant behavior requirements.

$C A D$ :

It is important to note whether or not the model allows the user to import files from a computeraided design (CAD) program into the model. In many instances, this method is time saving and more accurate. If a user can rely on the CAD drawings instead of laying out the building by hand, there is less room for input error of the building. If the model allows for the input of CAD drawings, the label (Y) will be used in Table 1. On the other hand, the label of $(\mathrm{N})$ is used in cases where the model does not have that capability. In some instances, the model developer is in the process of upgrading their model to include this capability, which is labeled as (F).

\section{Visual:}

Visualization allows the user to see where the bottlenecks and points of congestion are inside the space. Many of the models allow for at least 2-D visualization (2-D), and recently more have released versions or collaborate with other virtual programs that will present results in 3-D (3D). Other models do not have any visualization capabilities (N).

\section{Validation:}

The models are also categorized by their method of validation studies. The current ways of validating evacuation models are included here: validation against code requirements $(C)$, validation against fire drills or other people movement experiments/trials (FD), validation against literature on past evacuation experiments (flow rates, etc) (PE), and validation against other models (OM). For some models, no indication of validation of the model is provided (N). Some of the behavioral models will perform a qualitative analysis on the behaviors of the population. Although problematic since occupant behaviors are often difficult to obtain in fire drills, past drill survey data is sometimes used to compare with model results. 
Table 1. Overall features of egress models detailed in Appendix A.

\begin{tabular}{|c|c|c|c|c|c|c|c|c|c|c|c|}
\hline Model & Purpose & $\begin{array}{c}\text { Available to } \\
\text { public }\end{array}$ & $\begin{array}{l}\text { Modeling } \\
\text { Method }\end{array}$ & $\begin{array}{c}\text { Grid/ } \\
\text { Structure }\end{array}$ & $\begin{array}{c}\text { Perspective } \\
\text { of } M / O\end{array}$ & Behavior & Movement & $\begin{array}{l}\text { Fire } \\
\text { data }\end{array}$ & $C A D$ & Visual & Valid \\
\hline EVACNET4 & 1 & $\mathrm{Y}$ & $\mathrm{M}-\mathrm{O}$ & $\mathrm{C}$ & $\mathrm{G}$ & $\mathrm{N}$ & $\mathrm{UC}$ & $\mathrm{N}$ & $\mathrm{N}$ & $\mathrm{N}$ & FD \\
\hline $\begin{array}{l}\text { Takahashi's } \\
\text { Fluid }\end{array}$ & 1 & $\mathrm{~N} 2$ & $\mathrm{M}-\mathrm{O}$ & $\mathrm{C}$ & $\mathrm{G}$ & N/FA & FA-D & $\mathrm{N}$ & $\mathrm{N}$ & $2-\mathrm{D}$ & FD \\
\hline PathFinder & 1 & N3 & M & $\mathrm{F}$ & $\mathrm{I} / \mathrm{G}$ & $\mathrm{N}$ & $\mathrm{D}$ & $\mathrm{N}$ & $\mathrm{Y}$ & $2-\mathrm{D}$ & $\mathrm{N}$ \\
\hline TIMTEX & 4 & $\mathrm{Y}$ & M & $\mathrm{C}$ & $\mathrm{G} / \mathrm{I}$ & $\mathrm{N}$ & $\mathrm{D}$ & $\mathrm{N}$ & $\mathrm{N}$ & $\mathrm{N}$ & PE \\
\hline WAYOUT & 5 & $\mathrm{Y}$ & M & $\mathrm{C}$ & $\mathrm{G}$ & $\mathrm{N}$ & $\mathrm{D}$ & $\mathrm{N}$ & $\mathrm{N}$ & $2-\mathrm{D}$ & FD \\
\hline Magnetic Model & 1 & $\mathrm{U}$ & M & $\mathrm{F}$ & I & $\mathrm{FA} / \mathrm{I}$ & FA & $\mathrm{N}$ & $\mathrm{N}$ & $2-\mathrm{D}$ & $\mathrm{N}$ \\
\hline EESCAPE & 5 & N3 & M & $\mathrm{C}$ & $\mathrm{G}$ & $\mathrm{N}$ & $\mathrm{D}$ & $\mathrm{N}$ & $\mathrm{N}$ & $\mathrm{N}$ & FD \\
\hline EgressPro & 5 & $\mathrm{~N} 2$ & M & $\mathrm{C}$ & $\mathrm{G}$ & $\mathrm{N}$ & $\mathrm{D}$ & Y2 & $\mathrm{N}$ & $\mathrm{N}$ & $\mathrm{N}$ \\
\hline ENTROPY & 5 & $\mathrm{U}$ & $\mathrm{M} / \mathrm{PB}$ & $\mathrm{C}$ & $\mathrm{G} / \mathrm{I}$ & $\mathrm{N}$ & Ac K, FA & $\mathrm{N}$ & $\mathrm{N}$ & $\mathrm{N}$ & OM \\
\hline STEPs & 1 & $\mathrm{Y}$ & $\mathrm{M} / \mathrm{PB}$ & $\mathrm{F}$ & I & FA & $P, E$ & $\mathrm{~N}$ & $\mathrm{Y}$ & $3-\mathrm{D}$ & $\mathrm{C}$ \\
\hline PED/PAX & 3 & $\mathrm{Y} / \mathrm{N} 2$ & PB & $\mathrm{C}$ & $\mathrm{G}$ & I & $\mathrm{D}$ & $\mathrm{N}$ & $\mathrm{Y}$ & $2,3-\mathrm{D}$ & $\mathrm{N}$ \\
\hline EXIT89 & $1 *$ & N1 & PB & $\mathrm{C}$ & I & $\mathrm{I} / \mathrm{C}(\mathrm{smk})$ & $\mathrm{D}$ & Y1 & $\mathrm{N}$ & $\mathrm{N}$ & FD \\
\hline Simulex & 1 & $\mathrm{Y}$ & PB & Co. & I & I & ID & $\mathrm{N}$ & $Y$ & $2-\mathrm{D}$ & FD,PE \\
\hline GridFlow & 1 & $\mathrm{Y}$ & PB & Co. & I & I & $\mathrm{D}$ & $\mathrm{N}$ & $\mathrm{Y}$ & $2,3-\mathrm{D}$ & $\mathrm{FD}, \mathrm{PE}$ \\
\hline ALLSAFE & 5 & N3 & PB & $\mathrm{C}$ & $\mathrm{G}$ & I & Un F & $\mathrm{Y} 1,2$ & $\mathrm{~N}$ & $2-\mathrm{D}$ & OM \\
\hline CRISP & 1 & N3 & B-RA & $\mathrm{F}$ & I & $\mathrm{R} / \mathrm{C}, \mathrm{P}$ & E,D & Y3 & Y & $2,3-\mathrm{D}$ & FD \\
\hline ASERI & 1 & $\mathrm{Y}$ & B-RA & Co. & I & $\mathrm{R} / \mathrm{C}, \mathrm{P}$ & ID & $\mathrm{Y} 1,2$ & $\mathrm{~N}, \mathrm{~F}$ & $2,3-\mathrm{D}$ & $\mathrm{FD}^{*-}$ \\
\hline BFIRES- 2 & 4 & $\mathrm{~N} 2 / \mathrm{U}$ & B-RA & $\mathrm{F}$ & I & $\mathrm{R} / \mathrm{C}, \mathrm{P}$ & $\mathrm{UC}^{* *}$ & Y2 & $\mathrm{N}$ & $\mathrm{N}$ & $\mathrm{N}$ \\
\hline BldEXO & 1 & $\mathrm{Y}$ & B & $\mathrm{F}$ & I & $\mathrm{R} / \mathrm{C}, \mathrm{P}$ & $P, E$ & $\mathrm{Y} 1,2$ & $\mathrm{Y}$ & $2,3-\mathrm{D}$ & FD \\
\hline EGRESS 2002 & 1 & N3 & B & $\mathrm{F}$ & I & $\mathrm{R} / \mathrm{C}, \mathrm{P}$ & P,D & Y2 & $\mathrm{N}$ & $2-\mathrm{D}$ & FD \\
\hline EXITT & 2 & Y & B & $\mathrm{C}$ & I & $\mathrm{R} / \mathrm{C}$ & $\mathrm{C}$ & $\mathrm{Y} 1,2$ & $\mathrm{~N}$ & 2-D & $\mathrm{N}$ \\
\hline VEgAS & 1 & $\mathrm{~N} 2 / \mathrm{U}$ & B & $\mathrm{F}$ & I & AI & ID & Y1? & $\mathrm{Y}$ & $3-\mathrm{D}$ & $\mathrm{N}$ \\
\hline E-SCAPE & 1 & $\mathrm{U}$ & B & $\mathrm{C}$ & I & $\mathrm{R} / \mathrm{C}, \mathrm{P}$ & OML & Y2 & $\mathrm{N}$ & $2-\mathrm{D}$ & $\mathrm{N}$ \\
\hline BGRAF & 1 & N1 & B & $\mathrm{F}$ & I & $\mathrm{R} / \mathrm{C}, \mathrm{P}$ & UC? & $\mathrm{Y} 1,2$ & $\mathrm{~N}, \mathrm{~F}$ & $2-\mathrm{D} ?$ & FD \\
\hline EvacSim & 1 & N1 & $\mathrm{B}$ & $\mathrm{F}$ & I & $\mathrm{R} / \mathrm{C}, \mathrm{P}$ & $\mathrm{D}$ & Y2 & $\mathrm{N}$ & $\mathrm{N}$ & $\mathrm{N}$ \\
\hline Legion & 1 & $\mathrm{Y}$ & B & Co. & I & AI & $\mathrm{D}, \mathrm{C}$ & Y2 & Y & 2,3-D & $\mathrm{FD}, \mathrm{OM}$ \\
\hline
\end{tabular}

*Especially for high-rise buildings; **User specifies \# of time frames, an occupant moves to a grid point during each time frame; *- Fire drills and sensitivity analyses on the model

? indicates that a category is unclear or unknown 
Table 2. Movement models

\begin{tabular}{|cccccc|}
\hline Characteristics/Model & Evacnet 4 & Fluid & PathFinder & TIMTEX & WAYOUT \\
\hline Avail to public & $\mathrm{Y}$ & $\mathrm{N} 2$ & $\mathrm{~N} 3$ & $\mathrm{Y}$ & $\mathrm{Y}$ \\
Method & Movement-O & Movement-O & Movement & Movement & Movement \\
Structure & Coarse & Coarse & Fine & Coarse & Coarse \\
Perspective of M/O & Global & Global & I/G & G/I & Global \\
People Beh & None & N-FA & None & None & None \\
Import CAD drawings & $\mathrm{N}$ & $\mathrm{N}$ & $\mathrm{Y}$ & $\mathrm{N}$ & $\mathrm{N}$ \\
Visual Simulation & $\mathrm{N}$ & $\mathrm{Y}$ & $\mathrm{Y}$ & $\mathrm{N}$ & $\mathrm{Y}$ \\
Counterflow & $\mathrm{N}$ & $\mathrm{N}$ & $\mathrm{N}$ & $\mathrm{N}$ & $\mathrm{N}$ \\
Manual exit block & $\mathrm{N}$ & $\mathrm{N}$ & $\mathrm{N}$ & $\mathrm{N}$ & $\mathrm{N}$ \\
Fire Conditions & $\mathrm{N}$ & $\mathrm{N}$ & $\mathrm{N}$ & $\mathrm{N}$ & $\mathrm{N}$ \\
Defining Groups & $\mathrm{N}$ & $\mathrm{N}$ & $\mathrm{N}$ & $\mathrm{N}$ & $\mathrm{N}$ \\
Disabl/Slow Occ grps & $\mathrm{N}$ & $\mathrm{N}$ & $\mathrm{N}$ & $\mathrm{N}$ & $\mathrm{N}$ \\
Delays/Pre-evacuation & $\mathrm{N}$ & $\mathrm{Y}$ & $\mathrm{N}$ & $\mathrm{N}$ & $\mathrm{Y}$ \\
Rte. Choice & Optimal & Optimal & 2 Choices & Split choice & 1 route, flows \\
& & & & $\mathrm{N}$ & merge \\
Elevator use & $\mathrm{Y}$ & $\mathrm{N}$ & $\mathrm{N}$ & $\mathrm{N}$ \\
Toxicity to occ & $\mathrm{N}$ & $\mathrm{N}$ & $\mathrm{N}$ & $\mathrm{N}$ & $\mathrm{N}$ \\
Impatience/Drive & $\mathrm{N}$ & $\mathrm{N}$ & $\mathrm{N}$ & $\mathrm{N}$ & $\mathrm{N}$ \\
Occ. Distribution & Optimization & Optimization & $\mathrm{UC}-2$ choices & User chooses & 1 choice only \\
& & from rooms & & flow split & \\
& & and to exits & & & \\
\hline
\end{tabular}

\begin{tabular}{|c|c|c|c|c|c|}
\hline Characteristics/Model & $\begin{array}{l}\text { Magnetic } \\
\text { Model }\end{array}$ & EESCAPE & EgressPro & ENTROPY & STEPs \\
\hline $\begin{array}{l}\text { Avail to public } \\
\text { Method }\end{array}$ & $\begin{array}{c}\mathrm{U} \\
\text { Movement }\end{array}$ & $\begin{array}{c}\mathrm{N} 3 \\
\text { Movement }\end{array}$ & $\begin{array}{c}\mathrm{N} 2 \\
\text { Movement }\end{array}$ & $\begin{array}{c}\mathrm{U} \\
\text { Movement/ } \\
\text { PB }\end{array}$ & $\begin{array}{c}\mathrm{Y} \\
\text { Movement/ } \\
\text { PB }\end{array}$ \\
\hline Structure & Fine & Coarse & Coarse & Coarse & Fine \\
\hline Perspective of $\mathrm{M} / \mathrm{O}$ & Individual & Global & Global & $\mathrm{G} / \mathrm{I}$ & Individual \\
\hline People Beh & FA/I & None & None & None & FA \\
\hline Import CAD drawings & $\mathrm{N}$ & $\mathrm{N}$ & $\mathrm{N}$ & $\mathrm{N}$ & $\mathrm{Y}$ \\
\hline Visual Simulation & $\mathrm{Y}$ & $\mathrm{N}$ & $\mathrm{N}$ & $\mathrm{N}$ & $\mathrm{Y}$ \\
\hline Counterflow & $\mathrm{N}$ & $\mathrm{N}$ & $\mathrm{N}$ & $\mathrm{N}$ & $\mathrm{N}$ \\
\hline Manual exit block & $\mathrm{N}$ & $\mathrm{N}$ & $\mathrm{N}$ & $\begin{array}{l}\mathrm{N}, \mathrm{Y} \text { with } \\
\text { improvements }\end{array}$ & $\mathrm{Y}$ \\
\hline Fire Conditions & $\mathrm{N}$ & $\mathrm{N}$ & $\mathrm{Y}$ & $\mathrm{N}$ & $\mathrm{N}$ \\
\hline Defining Groups & Y & $\mathrm{N}$ & $\mathrm{N}$ & $\mathrm{N}$ & Y \\
\hline Disabl/Slow Occ grps & Y & $\mathrm{N}$ & $\mathrm{N}$ & $\begin{array}{c}\mathrm{N}, \mathrm{Y} \text { with } \\
\text { improvements }\end{array}$ & $\mathrm{Y}$ \\
\hline Delays/Pre-evacuation & $\mathrm{Y}$ & $\mathrm{N}$ & Y & $\mathrm{N}$ & $\mathrm{Y}$ \\
\hline Rte. Choice & 3 choices & 1 route & 1 route & 1 exit & Score \\
\hline Elevator use & $\mathrm{N}$ & $\mathrm{N}$ & $\mathrm{N}$ & $\mathrm{N}$ & $\mathrm{Y}$ \\
\hline Toxicity to occ & $\mathrm{N}$ & $\mathrm{N}$ & $\mathrm{N}$ & $\mathrm{N}$ & $\mathrm{N}$ \\
\hline Impatience/Drive & $\mathrm{N}$ & $\mathrm{N}$ & $\mathrm{N}$ & $\mathrm{N}$ & $\mathrm{Y}$ \\
\hline Occ Distribution & UC -3 choices & 1 choice only & 1 choice only & 1 choice & $\begin{array}{c}\text { Score/user } \\
\text { chooses } \\
\text { target }\end{array}$ \\
\hline
\end{tabular}


Table 3. Behavioral models

\begin{tabular}{|c|c|c|c|c|}
\hline Characteristics/Model & $P E D / P A X$ & EXIT89 & Simulex & GridFlow \\
\hline Avail to public & $\mathrm{Y} / \mathrm{N} 2$ & N1 & $\bar{Y}$ & $\mathrm{Y}$ \\
\hline Method & Partial Behavior & Partial Behavior & Partial Behavior & Partial Behavior \\
\hline Structure & Coarse & Coarse & Continuous & Continuous \\
\hline Perspective of $M / O$ & Global & Individual & Individual & Individual \\
\hline People beh & Implicit & Implicit/C (smk) & Implicit & Implicit \\
\hline Import CAD drawings & Y & $\mathrm{N}$ & Y & $\mathrm{Y}$ \\
\hline Visual simulation & $\mathrm{Y}$ & $\mathrm{N}$ & $\mathrm{Y}$ & Y \\
\hline Counterflow & $\mathrm{N}$ & $\mathrm{Y}$ & $\mathrm{N}$ & Y \\
\hline Manual exit block & $\mathrm{N}$ & $\mathrm{Y}$ & $\mathrm{Y}$ & $\mathrm{Y}$ \\
\hline Fire conditions & $\mathrm{N}$ & Y, CFAST & $\mathrm{N}$ not yet & $\mathrm{N}$, only FED input \\
\hline Defining groups & $\mathrm{Y}$ & $\mathrm{N}$ & $\mathrm{Y}$ & $\mathrm{Y}$ \\
\hline Disabl/Slow occ grps & $\mathrm{Y}$ & $\mathrm{Y}$ & $\mathrm{Y}$ & Y \\
\hline Delays/Pre-evacuation & $\mathrm{Y}$ & $\mathrm{Y}$ & $\mathrm{Y}$ & $\mathrm{Y}$ \\
\hline Rte. choice & $\begin{array}{l}\text { Quickest route, } \\
\text { optimize, or follow } \\
\text { signs }\end{array}$ & $\begin{array}{l}\text { Shortest distance } \\
\text { or user-defined }\end{array}$ & $\begin{array}{l}\text { Shortest distance } \\
\text { or altered distance } \\
\text { map }\end{array}$ & $\begin{array}{c}\text { Shortest distance, } \\
\text { random, or } \\
\text { user-defined }\end{array}$ \\
\hline Elevator use & $\mathrm{N}$ & $\mathrm{N}$ & $\mathrm{N}$ & $\mathrm{N}$ \\
\hline Toxicity to occ & $\mathrm{N}$ & $\mathrm{N}$ & $\mathrm{N}$ & $\mathrm{Y}$ \\
\hline Impatience/Drive & $\mathrm{N}$ & $\mathrm{N}$ & $\mathrm{N}$ & $\mathrm{N}$ \\
\hline Occ. distribution & 3 choices? & 2 choices & 2 choices & 3 choices \\
\hline Characteristics/Model & ALLSAFE & CRISP & ASERI & BFIRES-2 \\
\hline Avail to public & N3 & N3 & Y & $\mathrm{N} 2 / \mathrm{U}$ \\
\hline Method & Partial Behavior & B-RA & Behavioral-RA & Behavioral-RA \\
\hline Structure & Coarse & Fine & Continuous & Fine \\
\hline Perspective of $M / O$ & Global & I & I & I \\
\hline People beh & Implicit & Conditional & Conditional & Conditional \\
\hline Import CAD drawings & $\mathrm{N}$ & $\mathrm{Y}$ & $\mathrm{N}, \mathrm{F}$ & $\mathrm{N}$ \\
\hline Visual simulation & $\mathrm{Y}$ & $\mathrm{Y}$ & $\mathrm{Y}$ & $\mathrm{N}$ \\
\hline Counterflow & $\mathrm{N}$ & Y & $\mathrm{N}$ & $\mathrm{N}$ \\
\hline Manual exit block & $\mathrm{N}$ & $\mathrm{Y}$ & Y & Y \\
\hline Fire conditions & $\mathrm{Y}$ & $\begin{array}{l}\mathrm{Y}-\text { not in drill } \\
\text { mode }\end{array}$ & Y & Y \\
\hline Defining groups & Y & $\mathrm{Y}$ & $\mathrm{Y}$ & $\mathrm{N}$ \\
\hline Disabl/Slow occ grps & $\mathrm{N}$ & Y & Y & Y \\
\hline Delays/Pre-evacuation & $\mathrm{Y}$ & $\mathrm{Y}$ & $\mathrm{Y}$ & Y \\
\hline Rte. choice & All to 1 exit & $\begin{array}{l}\text { Shortest, user } \\
\text { defined door } \\
\text { difficulty }\end{array}$ & $\begin{array}{l}\text { Shortest or user- } \\
\text { defined, then } \\
\text { conditional }\end{array}$ & Conditional \\
\hline Elevator use & $\mathrm{N}$ & $\mathrm{N}$ & $\mathrm{N}$ & $\mathrm{N}$ \\
\hline Toxicity to occ & $\mathrm{N}$ & $\mathrm{Y}-$ not in drill & Y & Y-smk tolerance \\
\hline Impatience/Drive & $\mathrm{N}$ & $\mathrm{N}$ & $\mathrm{N}$ & $\mathrm{N}$ \\
\hline Occ distribution & 1 choice & Conditional & Various & Various \\
\hline
\end{tabular}


Table 3. Behavioral models, cont.

\begin{tabular}{|c|c|c|c|c|}
\hline Characteristics/Model & EXODUS & EGRESS & EXITT & $V E g A S$ \\
\hline Avail to public & $\bar{Y}$ & N3 & $\bar{Y}$ & $\mathrm{~N} 2 / \mathrm{U}$ \\
\hline Method & Behavioral & Behavioral & Behavior & Behavioral \\
\hline Structure & Fine & Fine & Coarse & Fine \\
\hline Perspective of $\mathrm{M} / \mathrm{O}$ & I & Individual & Individual & Individual \\
\hline People beh & Conditional & Conditional & Conditional & AI \\
\hline Import CAD drawings & Y & $\mathrm{N}$ & $\mathrm{N}$ & $\mathrm{Y}$ \\
\hline Visual simulation & Y & $\mathrm{Y}$ & Y & $\mathrm{Y}$ \\
\hline Counterflow & $\mathrm{Y}$ & $\mathrm{Y}$ & $\mathrm{N}$ & $\mathrm{N}$ \\
\hline Manual exit block & Y & Y & Y & $\mathrm{Y}$ \\
\hline Fire conditions & Y & Y & Y & $\mathrm{Y}$ \\
\hline Defining groups & $\mathrm{Y}$ & Y & $\mathrm{Y}$ & $\mathrm{Y}$ \\
\hline Disabl/Slow occ grps & $\mathrm{Y}-$ mobility & Y & $\mathrm{Y}$ & $\mathrm{N}$ \\
\hline Delays/Pre-evacuation & $\mathrm{Y}$ & $\mathrm{Y}$ & Y & $\mathrm{Y}$ \\
\hline Rte. choice & Conditional & Conditional & Conditional & User-dfnd/Cond \\
\hline Elevator use & $\mathrm{N}$ & $\mathrm{N}$ & $\mathrm{N}$ & $\mathrm{N}$ \\
\hline Toxicity to occ & Y & Y & $\mathrm{N}$ & $\mathrm{Y}$ \\
\hline Impatience/Drive & $\mathrm{Y}$ & $\mathrm{N}$ & $\mathrm{N}$ & $\mathrm{N}$ \\
\hline Occ distribution & Various & Various & Various & Various \\
\hline Characteristics/Model & E-SCAPE & BGRAF & EvacSim & Legion \\
\hline Avail to public & $\overline{\mathrm{U}}$ & N1 & N1 & $\mathrm{Y}$ \\
\hline Method & Behavioral & Behavioral & Behavioral & Behavioral \\
\hline Structure & Coarse & Fine & Fine & Continuous \\
\hline Perspective of $\mathrm{M} / \mathrm{O}$ & I & Individual & Individual & Individual \\
\hline People beh & Conditional & Conditional & Conditional & $\mathrm{AI}$ \\
\hline Import CAD drawings & $\mathrm{N}$ & $\mathrm{N}, \mathrm{F}$ & $\mathrm{N}$ & $\mathrm{Y}$ \\
\hline Visual simulation & Y & $\mathrm{Y}$ & $\mathrm{N}$ & $\mathrm{Y}$ \\
\hline Counterflow & $\mathrm{N}$ & $\mathrm{N}$ & $\mathrm{N}$ & Y \\
\hline Manual exit block & $\mathrm{N}$ & $\mathrm{N}$ & Y-locked doors & Y \\
\hline Fire conditions & $\mathrm{Y}$ & Y & $\mathrm{Y}$ - user & $\mathrm{N}$, not yet \\
\hline Defining groups & Y & Y & Y & Y \\
\hline Disabl/Slow occ grps & $\mathrm{N}$ & $\mathrm{Y}$ & Y & $\mathrm{Y}$ \\
\hline Delays/Pre-evacuation & $\mathrm{Y}$ & Y & Y & $\mathrm{Y}$ \\
\hline Rte. choice & Conditional & Conditional & Conditional & Conditional \\
\hline Elevator use & $\mathrm{N}$ & $\mathrm{N}$ & Y & Y \\
\hline Toxicity to occ & $\mathrm{N}$ & Y & $\mathrm{N}$ & $\mathrm{N}$ \\
\hline Impatience/Drive & $\mathrm{N}$ & $\mathrm{N}$ & $\mathrm{N}$ & $\begin{array}{c}\mathrm{Y}-\text { alternate } \\
\text { naming of variables }\end{array}$ \\
\hline Occ distribution & Various & Various & Various & Various \\
\hline
\end{tabular}

\section{Summary of Egress Model Features}

The purpose of this section is to generally describe the three categories of modeling methods and identify general trends in the model features for each category. Table 1 to Table 3 outline this type of data and are to be used as a quick-reference guide to the details included in the fulllength report ${ }^{3}$. 
The division of models into categories; movement, partial behavioral, and behavioral, classify evacuation models primarily by the sophistication of their modeling techniques. In this context, sophistication is used to describe the complexity of the modeling techniques used to simulate the egress situation and the occupant behavior throughout the evacuation. The movement models are labeled as the least sophisticated and the behavioral models are labeled as having the most modeling sophistication. However, it should be noted that a high modeling sophistication does not necessarily indicate that the evacuation model uses and/or provides the appropriate data to model such behaviors. The user should be aware of the validation methods and associated limitations of each model used.

Overall, the use (purpose) of the models range from use on only one exit (5) to use for all types of buildings (1). The movement models section contains models used for 1-exit building arrangements, low-story buildings, and all types of buildings. As sophistication in modeling increases (partial-behavioral models), only one model requires a 1-exit arrangement, one model is used for transport stations, and the rest can be used for all types of building. Lastly, as sophistication increases to an additional behavioral level, these models can be used for all types of buildings (with the exception of one used for residences and one used for low-story buildings).

Also provided in the tables is the availability of each model to the public. In some cases, the model is available to the public for personal use for free or for a fee (the fee varies depending upon the model). On the other hand, some models are labeled as unavailable, i.e. not yet released, discontinued, or used by the company on a consultancy basis.

For many of the older models in this review, their availability is either unknown or they are no longer available. These older models are found in all three of the modeling categories. Some of the more sophisticated models, EvacSim and BGRAF for example, have not yet been released. The majority of the models in Table 1 are either available for use by the public or by the consulting agency that developed the model.

\section{Movement Models}

Movement models are those models that focus on the movement of occupants from one point in the building to another (usually the exit or a position of safety). The main types of output include the total evacuation time, locations of bottlenecks inside the building, and flow through openings.

A distinct feature simulated by two models in this category is that of optimizing the evacuation results. This is noted by "M-O" in the Modeling Method column and is used to describe EVACNET4 and Takahashi's Fluid model. Optimization is a movement technique whereby the occupants are moved in a certain direction (not necessarily their shortest distance) only to achieve occupant distributions that produce a minimal evacuation time. The optimization technique is inherent in these models, instead of a users' choice. This is a unique simulation technique, since most models move occupants the shortest distance. 
Table 1 shows the many characteristics of movement models. Many times with a low sophistication model, the structure and perspective of the model follow suit. Most of the movement models represent the structure with a coarse network, instead of a fine network. This involves the use of nodes (representing rooms or sections of rooms) connected by arcs (the distance from the middle of one node to the middle of the next), which can be a crude representation of the building. Also associated with most of the movement models is a global perspective of the model as well as a global perspective of the occupants. A global perspective of the model describes models that view the occupants as a homogeneous mass, instead of individuals. Also, a global perspective of the occupants describes the occupants as "all knowing" of the building exits and the quickest way to exit the building.

The movement models all lack high behavioral simulation and contain generally the same technique for moving occupants throughout the structure. Almost all of the movement models in this review lack behavioral simulation capabilities and move occupants throughout the building with the use of density vs. speed correlations (as density increases, the velocity of the occupants in the space slows via an empirical relationship from collected data). However, an exception to this behavioral and movement simulation trend is the Magnetic Model. The Magnetic Model offers a complex queuing system for special building types, such as airports, railway stations, office buildings, and department stores. The three types of queuing behaviors available are 1) queuing in front of a counter; 2) queuing in front of a gate; and 3) queuing in front of vehicles, such as a train. These behaviors originated from observed behaviors in different types of buildings. Also unique to the Magnetic Model is the movement technique. Instead of moving the occupants under empirical density vs. speed relationships, this model uses Columb's Law to move occupants as magnetic objects in a magnetic field. More information on this model can be found in the full-detail report ${ }^{3}$.

None of the movement models allow for the inclusion of fire data, with the exception of Egress Pro. This unique model incorporates a limited amount of (user-supplied) fire data to the program to simulate the time of the alarm sounding. Also, none of the models, with the exception of PathFinder, allow the use of CAD drawings to define the building structure.

Many times it is easier to review data from the model visually. Half of the movement models has a 2-dimensional visualization capability, while the other half does not provide this feature.

Two evacuation models found in Table 1, ENTROPY and STEPS, are labeled as both movement and partial-behavioral models. This is due to the special features included in both models (shown in Table 2), that require an increased level of modeling sophistication. In the case of the ENTROPY model, the use of acquired knowledge to move occupants was unique in nature and can be categorized as partial-behavioral. In STEPs, the use of groups with different characteristics, pre-evacuation times, and visualization could categorize this model as a partialbehavioral model. However, due to the basic movement and behavioral techniques used in both of these models, the movement category still applies. 


\section{Partial-Behavioral Models}

Five models in Table 1 fall under the category of partial-behavioral models. These models primarily calculate occupant movement, however begin to simulate behaviors in a less complex way. These models simulate behaviors implicitly by simulating pre-evacuation time distributions among the occupants, unique occupant characteristics, overtaking behavior, and the introduction of smoke or smoke effects to the occupant. These are models capable of simulating an entire building, and occupants' movements throughout the model are frequently based on research of observed human behavior data.

As shown in Table 1, partial-behavioral models contain a mix of coarse, fine and continuous networks, as well as a mix of global and individual perspectives. Depending upon the needs of the user, the appropriate combination of characteristics should be chosen for each project. All partial-behavioral models simulate behaviors implicitly, which is essentially the characteristic that defines this category. And, similar to the movement models, density correlations are a popular mode to simulate occupant movement throughout the structure.

Different from the movement models, the partial-behavioral models contain more sophistication in the areas of fire data, CAD, and visualization. More of the models in this category can incorporate fire data and CAD drawings to describe the structure. Also, almost all of the partialbehavioral models have the capability of visualizing the evacuation.

The main difference between this category and the behavioral category is that the "behaviors" in this category are implicitly modeled by providing inputs of body size, occupant characteristics, the inclusion of pre-evacuation times, fire data, etc. This category begins to apply the effects of individual movement toward a goal for the evacuation.

\section{Behavioral Models}

Ten models fall under the category of behavioral models (Table 1); which are labeled as the most sophisticated type of models for evacuation. Again, the user should be aware of the limited amount of data (or the lack of data) supporting some of the more sophisticated simulation techniques.

Behavioral models are those models that incorporate occupants' decisions and behaviors, in addition to movement toward a specified goal (exit). Many of these models can incorporate decision-making by occupants and/or actions that are performed due to conditions in the building. Most of these models represent the building with a fine or continuous network and all of these models incorporate an individual perspective of the model and the occupants.

In all models, except VEgAS and Legion, occupants exhibit behaviors based on rules specified in the model and/or the conditions of the situation. For instance, if there is a layer of smoke residing in front of a stairway, this represents a smoky condition that the occupant is faced with. It is possible that the model will contain the following rule, "if the smoke contains a density of , the occupant will turn around and walk to the next nearest exit stair." The behavior of models in this section is mostly dominated by "rules" and conditions of the environment, including the fire environment (if the model has this capability). 
Along with the rules and conditional behavior, almost all behavioral models have the capability of assigning probabilities to activities performed by each occupant. These probabilities are associated both with the likelihood of performing the action and a probable distribution of the time assigned to each action.

All of the behavioral models described in this section are capable of accepting some type of fire data, and most are capable of providing a visualization of the evacuation simulation and using $\mathrm{CAD}$ drawings to represent the structure.

Although there is an increase in sophistication and simulation capabilities, the user must be aware of the kinds of validation performed on the model, as well as the documented data used to support various types of simulation. A note of the validation work done on each model is included in Table 1, and a more detailed version of the validation for each model is included in the detailed report ${ }^{3}$.

\section{Special Features}

As an additional way to describe the capabilities of each model, Table 2 and Table 3 are included to identify any special features of the model that users may be interested in simulating. These tables are included for users interested in simulating certain evacuation scenarios and/or for users to understand the differences in model sophistication. It can be seen that the number of special features simulated by the model increase as the level of sophistication increases.

Among the special features are the capabilities of the models to simulate occupant characteristics, elevator use, toxicity, pre-evacuation delays, fire conditions, and exit block. Also of importance, which is shown in Table 2 and 3 , is how the models simulate occupant route choice and occupant distribution to exits. Again, as model sophistication increases, the route choice of occupants is conditional upon the situation (behavioral models) instead of a "1 route" possibility.

\section{Additional Egress Models}

In addition, not all of the available models are explained in this review. Since development of this review, two additional models have been developed and will be mentioned briefly in this section. The first model, $\mathrm{PedGo}^{95}$, is available through the TraffGo Company. It is discussed as an individual, cellular automaton evacuation model that can be used for any type of layout. The second model, the $\mathrm{SGEM}^{96,97}$ package, was developed in City University of Hong Kong. Similar to PedGo, SGEM is also an individual, cellular automaton model; however route choice can also be affected by situational changes of the environment, such as familiarity and signage effects.

\section{Conclusions}

As this egress model review has shown, even within model categories, each model is unique due to the various choices and modeling methods used to calculate evacuation output. This report provides model users with the information to narrow down choices on the appropriate model to 
use for specific projects. It is then up to the model user to then review the detailed guide ${ }^{3}$ and make a final and informed decision as to which model is best for the project at hand.

As time passes, more and more evacuation models are developed and many of the current models are constantly being updated by developers. It should be noted that this review will require updates as new models are used and older ones retire. It is up to the user to take the model version, the publish date of the report, and any more recent publications on particular evacuation models into account when choosing the appropriate model.

\section{References}

1. Custer, R. L. P. \& Meacham, B. J. (1997). Introduction to Performance-Based Fire Safety Bethesda, MD: Society of Fire Protection Engineers.

2. Nelson, H. E. \& Mowrer, F. W. (2002). Emergency Movement. In P.J.Denno \& W. D. Walton (Eds.), The SFPE Handbook of Fire Protection Engineering (Third ed., pp. 3-3673-380). Bethesda, MD: Society of Fire Protection Engineers.

3. Kuligowski, E. D. Modeling Building Evacuation: A Review of Issues in Theory and Application. NIST Special Publication, (in press).

4. Gwynne, S., Galea, E. R., Lawrence, P.J., Owen, M., \& Filippidis, L. (1999). A Review of the Methodologies used in the Computer Simulation of Evacuation from the Built Environment, Building and Environment, 34, 741-749.

5. Fire Model Survey (2002). http://www.firemodelsurvey.com/EgressModels.html [On-line]. Available: http://www.firemodelsurvey.com/EgressModels.html

6. Olenick, S. M. \& Carpenter, D. J. (2003). Updated International Survey of Computer Models for Fire and Smoke. Journal of Fire Protection Engineering, 13, 87-110.

7. Watts, J. M. (1987). Computer Models for Evacuation Analysis. Fire Safety Journal, 12, 237-245.

8. Friedman, R. (1992). An International Survey of Computer Models for Fire and Smoke. Journal of Fire Protection Engineering, 4, 81-92.

9. Deal, S. (1995). Technical Reference Guide for FPETool Version 3.2 (Rep. No. NISTIR 5486-1). Natl. Inst. Stand. Technol.

10. Francis, R. L. \& Saunders, P. B. (1979). EVACNET: Prototype Network Optimization Models for Building Evacuation (Rep. No. NBSIR 79-1593). Natl. Bur. Stand., (U.S.).

11. Kisko, T. M., Francis, R. L., \& Nobel, C. R. (1998). EVACNET4 User's Guide, Version 10/29/98 University of Florida. 
12. Takahashi, K., Tanaka, T., \& Kose, S. (1988). An Evacuation Model for Use in Fire Safety Designing of Buildings. In Fire Safety Science -- Proceedings of the 2nd International Symposium (pp. 551-560).

13. Cappuccio, J. (2000). Pathfinder: A Computer-Based Timed Egress Simulation. Fire Protection Engineering, 8, 11-12.

14. Harrington, S. S. (1996). TIMTEX: A Hydraulic Flow Model for Emergency Egress. MS Department of Fire Protection Engineering, University of Maryland.

15. Shestopal, V. O. \& Grubits, S. J. (1994). Evacuation Model for Merging Traffic Flows in Multi-Room and Multi-Story Buildings. In Fire Safety Science -- Proceedings of the 4th International Symposium (pp. 625-632).

16. Okazaki, S. \& Matsushita, S. (2004). A Study of Simulation Model for Pedestrian Movement with Evacuation and Queing. http://www.anc-d.fukui-u.ac.jp/ sat/ECS93.pdf [On-line].

17. Kendik, E. (1995). Methods of Design for Means of Egress: Towards a Quantitative Comparison of National Code Requirements. In Fire Safety Science -- Proceedings of the 1st International Symposium (pp. 497-511).

18. Semenko, P. (5-13-2003). Internet Communication

19. Donegan, H. A., Pollock, A. J., \& Taylor, I. R. (1994). Egress Complexity of a Building. In Fire Safety Science -- Proceedings of the 4th International Symposium (pp. 601-612).

20. Donegan, H. A. \& Taylor, I. R. (1998). How Complex is the Egress Capability of your Design? In T. J. Shields (Ed.), Human Behaviour in Fire, Proceedings of the First International Symposium.

21. Wall, J. M. \& Waterson, N. P. Predicting Evacuation Times -- A Comparison of the STEPS Simulation Approach with NFPA 130. Fire Command Studies, (in press).

22. MacDonald, M. (2003). STEPS Simulation of Transient Evacuation and Pedestrian Movements User Manual. Unpublished Work

23. Hoffman, N. A. \& Henson, D. A. (1997). Simulating Emergency Evacuation in Stations. In APTA Rapid Transit Conference Washington, DC: American Public Transit Association.

24. Hoffman, N. A. \& Henson, D. A. (1997). Simulating Transient Evacuation and Pedestrian Movement in Stations. In 3rd International Conference on Mass Transit Management Kuala Lumpur, Malaysia.

25. Hoffman, N. A. \& Henson, D. A. (1998). Analysis of the Evacuation of a Crush Loaded Train in a Tunnel. In 3rd International Conference on Safety in Road and Rail Tunnels Nice, France. 
26. Pedestrian Planning for the Olympic Park Railway Station, Sydney - Transport planning for the Olympic Games (2004). http://www.arup.com/insite/feature.cfm?featureid=38 [Online].

27. PAXPORT and PEDROUTE brochures (2004). http://www.halcrow.com [On-line].

28. Barton, J. and Leather, J. (1995). Paxport -- Passenger and Crowd Simulation. Passenger Terminal '95, 71-77.

29. Buckmann, L. T. \& Leather, J. (1994). Modelling Station Congestion the PEDROUTE Way. Traffic Engineering and Control, 35, 373-377.

30. Clifford, P. \& du Sautoy, C. Pedestrian and Passenger Activity Modeling. Vineyard House, 22 Brook Green, Hammershith, London, Halcrow Fox.

31. du Sautoy, C. (5-16-2003). Internet Communication

32. Transport Strategies Limited (2004). A Guide to Transport Demand Forecast Models: PEDROUTE \& PAXPORT. http://www.tsl.dircon.co.uk/dempedroute.htm [On-line].

33. Fahy, R. F. (1994). EXIT89 -- An Evacuation Model for High-rise Buildings -- Model Description and Example Applications. In Fire Safety Science -- Proceedings of the 4th International Symposium (pp. 657-668).

34. Fahy, R. F. (1996). EXIT89 -- High-rise Evacuation Model -- Recent Enhancements and Example Applications. In Interflam '96, International Interflam Conference -- 7th Proceedings (pp. 1001-1005). Cambridge, England.

35. Fahy, R. F. (1999). User's Manual, EXIT89 v 1.01, An Evacuation Model for High-Rise Buildings Quincy, Ma: National Fire Protection Association.

36. Fahy, R. F. (1999). Development of an Evacuation Model for High-Rise Buildings, Volume 1 of 2. DPhil by published works School of the Built Environment, Faculty of Engineering of the University of Ulster.

37. Fahy, R. F. (2001). Verifying the Predictive Capability of EXIT89. In 2nd International Symposium on Human Behaviour in Fire (pp. 53-63).

38. Fahy, R. F. (2003). Calculation Methods for Egress Predicition. In Fire Protection Handbook 19th ed., Quincy, MA: National Fire Protection Association.

39. Fahy, R. F. (5-2-2003). Internet Communication

40. IES. (2000). Simulex Technical Reference; Evacuation Modeling Software. Integrated Environmental Solutions, Inc.

41. IES. (2001). Simulex User Manual; Evacuation Modeling Software. Integrated Environmental Solutions, Inc. 
42. Thompson, P. A. \& Marchant, E. W. (1994). Simulex; Developing New Computer Modelling Techniques for Evaluation. In Fire Safety Science -- Proceedings of the 4th International Symposium 613-624.

43. Thompson, P. A. \& Marchant, E. W. (1995). A Computer Model for the Evacuation of Large Building Populations. Fire Safety Journal, 24, 131-148.

44. Thompson, P. A. \& Marchant, E. W. (1995). Testing and Application of the Computer Model 'SIMULEX'. Fire Safety Journal, 24, 149-166.

45. Thompson, P. A. (1995). Developing New Techniques for Modelling Crowd Movement. $\mathrm{PhD}$ Department of Building and Environmental Engineering, University of Edinburgh, Scotland.

46. Thompson, P. A., Wu, J., \& Marchant, E. W. (1996). Modelling Evacuation in Multi-storey Buildings with Simulex. Fire Engineering, 56, 7-11.

47. Thompson, P. A. (2003). Internet Communication

48. Bensilum, M. \& Purser, D. A. (2002). Gridflow: an object-oriented building evacuation model combining pre-movement and movement behaviours for performance-based design. In 7th International Symposium on Fire Safety Science Worcester, MA: Worcester Polytechnic Institute.

49. http://www.cibprogram.dbce.csiro.au/program/survey_view.cfm?S_ID=55 (2003). [Online].

50. Heskestad, A. W. \& Meland, O. J. (1998). Determination of Evacuation Times as a Function of Occupant and Building Characteristics and Performance of Evacuation Measures. In Human Behaviour in Fire -- Proceedings of the 1st International Symposium (pp. 673-680).

51. Jensen, G. (2003). Internet Communication

52. Boyce, K., Fraser-Mitchell, J., \& Shields, J. (1998). Survey Analysis and Modelling of Office Evacuation Using the CRISP Model. In T. J. Shields (Ed.), Human Behaviour in Fire -- Proceedings of the 1st International Symposium (pp. 691-702).

53. Fraser-Mitchell, J. (2001). Simulated Evacuations of an Airport Terminal Building, Using the CRISP Model. In 2nd International Symposium in Human Behaviour in Fire (pp. 89100). Boston, MA.

54. Fraser-Mitchell, J. (2003). 'CRISP' Fire Risk Assessment by Simulation. Presentation given at the University of Greenwich.

55. Fraser-Mitchell, J. (2003). Internet Communication 
56. ASERI (Advance Simulation of Evacuation of Real Individuals) A model to simulate evacuation and egress movement based on individual behavioural response (2004). http://www.ist-net.de [On-line].

57. Schneider, V. (2001). Application of the Individual-Based Evacuation Model ASERI in Designing Safety Concepts. In 2nd International Symposium on Human Behaviour in Fire (pp. 41-51). Boston, MA.

58. Schneider, V. \& Konnecke, R. (2001). Simulating Evacuation Processes with ASERI. In Tagungsband International Conference on Pedestrian Evacuation Dynamics (PED) Duisburg.

59. Schneider, V. (5-19-2003). Internet Communication

60. Stahl, F. I. (1979). Final Report on the 'BFIRES/VERSION 1' Computer Simulation of Emergency Egress Behavior During Fires: Calibration and Analysis (Rep. No. NBSIR 791713). Natl. Bur. Stand., (U.S.).

61. Stahl, F. I. (1982). BFIRES-II: A Behavior Based Computer Simulation of Emergency Egress During Fires. Fire Technology, 18, 49-65.

62. Stahl, F. I. (1980). BFIRES/Version 2: Documentation of Program Modifications (Rep. No. NBSIR 80-1982). Natl. Bur. Stand., (U.S.).

63. Exodus Introduction (2003). http://fseg.gre.ac.uk/exodus/ [On-line].

64. Gwynne, S., Galea, E. R., Lawrence, P.J., Owen, M. \& Filippidis, L. (1998). A Systematic Comparison of Model Predictions Produced by the buildingEXODUS Evacuation Model and the Tsukuba Pavilion Evacuation Data, Applied Fire Science, Vol. 7, No. 3, 235-266.

65. Gwynne, S., Galea, E. R., Owen, M., Lawrence, P.J. \& Filippidis, L. (1998). A Comparison of Predictions from the buildingEXODUS Evacuation Model with Experimental Data, In Human Behaviour in Fire: Proceedings of the $1^{\text {st }}$ International Symposium, Ed: Shields, J., University of Ulster, ISBN 1859231039, TextFlow Ltd., 711-721.

66. Parke, J., Gwynne, S., Galea, E. R., \& Lawrence, P. (2003). Validating the buildingEXODUS Evacuation Model using Data from an Unannounced Trial Evacuation, Proceedings of the $2^{\text {nd }}$ International Conference on Pedestrian and Evacuation Dynamics (PED 2003), ISBN 1904521088, CMS Press, University of Greenwich, UK, 295-306.

67. Gwynne, S., Galea, E. R., Lawrence, P.J., \& Filippidis, L. (2001). Modelling Occupant Interaction with Fire Conditions Using the buildingEXODUS model. Fire Safety Journal, 36, 327-357.

68. Gwynne, S. (2003). Personal Communication

69. AEA Technology (2002). A Technical Summary of the AEA EGRESS Code Warrington, UK: AEA Technology. 
70. Ketchell, N., Cole, S. S., \& Webber, D. M. (1994). The EGRESS Code for Human Movement and Behaviour in Emergency Evacuation. In R.A.Smith \& J. F. Dickie (Eds.), Engineering for Crowd Safety (pp. 361-370). London: Elsevier.

71. Ketchell, N., Bamford, G. J., \& Kandola, B. (1995). Evacuation Modelling: A New Approach. In ASIAFLAM '95, Proceedings of the 1st International Conference on Fire Science and Engineering (pp. 499-505).

72. Levin, B. M. (1988). EXITT: A Simulation Model of Occupant Decisions and Actions in Residential Fires (Rep. No. NBSIR 88-3753). Natl. Inst. Stand. Technol.

73. Levin, B. M. (1988). EXITT - A Simulation Model of Occupant Decisions and Actions in Residential Fires. In Fire Safety Science - Proceedings of the Second International Symposium (pp. 561-570).

74. Still, G. K. (1993). New Computer System Can Predict Human Behavioural Response During Building Fires. Fire, 85, 40-42.

75. Still, G. K. (2003). Internet Communication

76. Still, G. K. (2004). VEgAS (Virtual Egress and Analysis System). http://www.crowddynamics.com [On-line]. Available: http://www.crowddynamics.com

77. Reisser-Weston, E. (1996). Simulating Human Behaviour in Emergency Situations. In RINA, International Conference of Escape, Fire, and Rescue.

78. Ozel, F. (1985). A Stochastic Computer Simulation of the Behavior of People in Fires: An Environmental Cognitive Approach. In Proceedings of the International Conference on Building Use and Safety Technology.

79. Ozel, F. (1991). Simulation of Processes in Buildings as a Factor in the Object Representation of Built Environments. In Proceedings of Building Simulation '91 (pp. 250256).

80. Ozel, F. (1993). Computer Simulation of Behavior in Spaces. In R.W.Marans \& D. Stokols (Eds.), Environmental Simulation: Research and Policy Issues (pp. 191-204). New York: Plenum Press.

81. Ozel, F. (2003). Internet Communication

82. Poon, L. S. (1994). EvacSim: A Simulation Model of Occupants with Behavioural Attributes in Emergency Evacuation of High-Rise Buildings. In Fire Safety Science -Proceedings of the 4th International Symposium (pp. 681-692).

83. Poon, L. S. (4-1-2003). Internet Communication

84. Legion International, L. (2003). http://www.legion.biz/system/research.cfm. http://www.legion.biz/ [On-line]. 
85. Kagarlis, M.A. (2004). "Movement of an autonomous entity through an environment," International Patent Application, Publication No. WO 2004/023347 A2.

86. Williams, A. (2004). Go with the Flow, The Architects' Journal, February 12, 2004.

87. Bryan, J. L. (2002). Behavioral Response to Fire and Smoke. In P.J.DiNenno \& W. D. Walton (Eds.), The SFPE Handbook of Fire Protection Engineering (Third ed., pp. 3-3153-340). Bethesda, MD: Society of Fire Protection Engineers.

88. Jin, T. (1997). Studies on Human Behavior and Tenability. In Fire Safety Science Proceedings of the Fifth International Symposium (pp. 3-21).

89. Fruin, J. J. (1987). Pedestrain Planning and Design. (Revised Edition ed.) Mobile, AL: Elevator World, Inc.

90. Pauls, J. (1995). Movement of People. In P.J.DiNenno, C. L. Beyler, R. L. P. Custer, W. D. Walton, J. M. Watts, D. Drysdale, \& J. R. Hall (Eds.), The SFPE Handbook of Fire Protection Engineering (Second ed., pp. 3-263-3-285). Bethesda, MD: Society of Fire Protection Engineers.

91. Pauls, J. (1980). Effective-Width Model for Crowd Evacuation Flow in Buildings. In Proceedings: Engineering Applications Workshop Boston, MA: Society of Fire Protection Engineers.

92. Predtechenskii, V. M. \& Milinskii, A. I. (1978). Planning for Foot Traffic in Buildings. New Delhi: Amerind Publishing Co. Pvt. Ltd.

93. Purser, D. A. (2002). Toxicity Assessment of Combustion Products. In P.J.DiNenno \& C. L. Beyler (Eds.), The SFPE Handbook of Fire Protection Engineering (Third ed., pp. 2-832-171). Bethesda, MD: Society of Fire Protection Engineers.

94. Klote, J. H. \& Milke, J. A. (2002). Principles of Smoke Management. Atlanta, GA: American Society of Heating, Refrigeration, and Air-Conditioning Engineers, Inc.

95. Klupfel, H. \& Meyer-Konig, T. (2003). Characteristics of the PedGo Software for Crowd Movement and Egress Simulation. In 2nd International Conference in Pedestrian and Evacuation Dynamics (PED) (pp. 331-340). London, U.K.: University of Greenwich.

96. Lo, S. M., Fang, Z., \& Zhi, G. S. (2004). An Evacuation Model: the SGEM package. Fire Safety Journal, 169-190.

97. Lo, S. M. \& Fang, Z. (2000). A Spatial-Grid Evacuation Model for Buildings. Journal of Fire Sciences, 18, 376-394. 


\title{
4.5 Estimating Evacuation Time Components: Lessons from Nuclear Power Plants, Hurricanes, and the First World Trade Center Bombing
}

\author{
Michael K. Lindell and Carla S. Prater \\ Hazard Reduction \& Recovery Center, Texas A\&M University
}

Protective actions in response to environmental threats can be defined by a series of stagesdetection/warning, psychological preparation, logistical preparation, and protective action selection/implementation. In this formulation, which Lindell and Perry (2004) call the Protective Action Decision Model (PADM), detection is defined by environmental cues received directly from the environment, whereas warning is obtained from authorities, news media, and peers (friends, relatives, neighbors, and coworkers). Psychological preparation consists of predecisional processes, decision making, and information seeking. The predecisional processes are exposure (being in a position to receive threat information either from the environment or from other persons), attention (noticing the information that is available), and interpretation of the environmental cues or comprehension of the warning messages. Decision making consists of a series of stages of conscious information processing. The first stage is risk identification, which seeks to answer the question "Is there a real threat?" The second stage is risk assessment, which seeks to answer the question "Do I need to take protective action?" The third stage, protective action search seeks to answer the question "What can be done to achieve protection?" The fourth stage, protective action assessment, seeks an answer to the question "What are the merits of alternative methods of protection?" The fifth stage, protective action selection seeks to answer the question "What is the best method of protective action for this situation?" and the last stage, protective action implementation asks the question "Does protective action need to be taken now?"

It is frequently the case that those at risk do not know the answers to these questions, so information seeking routines are initiated. The first of these is information needs assessment, which seeks to answer the question "What additional information do I need?" The second stage, communication action assessment/selection seeks to answer the question "Where and how can I obtain the needed information?" The third stage, communication action implementation seeks to answer the question "Do I need the information now?" These stages of decision making and information seeking are followed very systematically by some people, heuristically by others, and (rarely) not at all by still others. Defective information seeking and processing is caused by incorrect schemas about the hazard and protective actions (e.g., failure to anticipate the future consequences of present conditions), faulty assumptions (e.g., incorrectly assuming that people will panic if they are warned), or emotional overload.

Once a protective action is selected, logistical preparation is often needed before implementation. This can include gathering persons who will evacuate as a group, packing any essential items, protecting personal property that can't be moved, and securing the location against intrusion.

The model can be represented as a decision tree or network of nodes (answers to questions) and arcs (information processing activities). Individuals differ in the paths they take through the 
network, the amount of time taken to traverse each arc, and the number of iterations in decision making and information seeking loops. Transfer of organizational roles and training from other situations can facilitate response.

There are a number of critical elements to the PADM. The first one is that threatened populations respond as social units, not as isolated individuals. The second is that people rarely are satisfied that they already know enough to protect themselves, so they seek information and reassurance from others. A third element is that information sources often provide conflicting information, which is difficult to reconcile because of lack of complete credibility by any single source. A fourth element is that people often have very little accurate information about protective actions and correct information is rarely contained in warning messages. A fifth element is that people independently examine official protective action recommendations (including the absence of any official recommendations) and make an independent evaluation of the situation that might result in their taking protective action even though authorities believe that this is not needed (e.g., shadow evacuation). Finally, people can iterate through the stages of decision making and information seeking, thus delaying adaptive responses.

\section{Application to nuclear power plant and hurricane evacuations}

The time required for a single household to evacuate is the sum of the times required to receive a warning, prepare to evacuate, travel on collector routes to the primary evacuation route, wait for access to the primary evacuation route, and travel on the primary evacuation route. The time required for all households to initiate and evacuation is defined by distributions of the individual evacuation time components. Empirically based trip generation time (TGT) distributions for risk area residents can be generated by combining the times required to receive a warning, and prepare to evacuate.

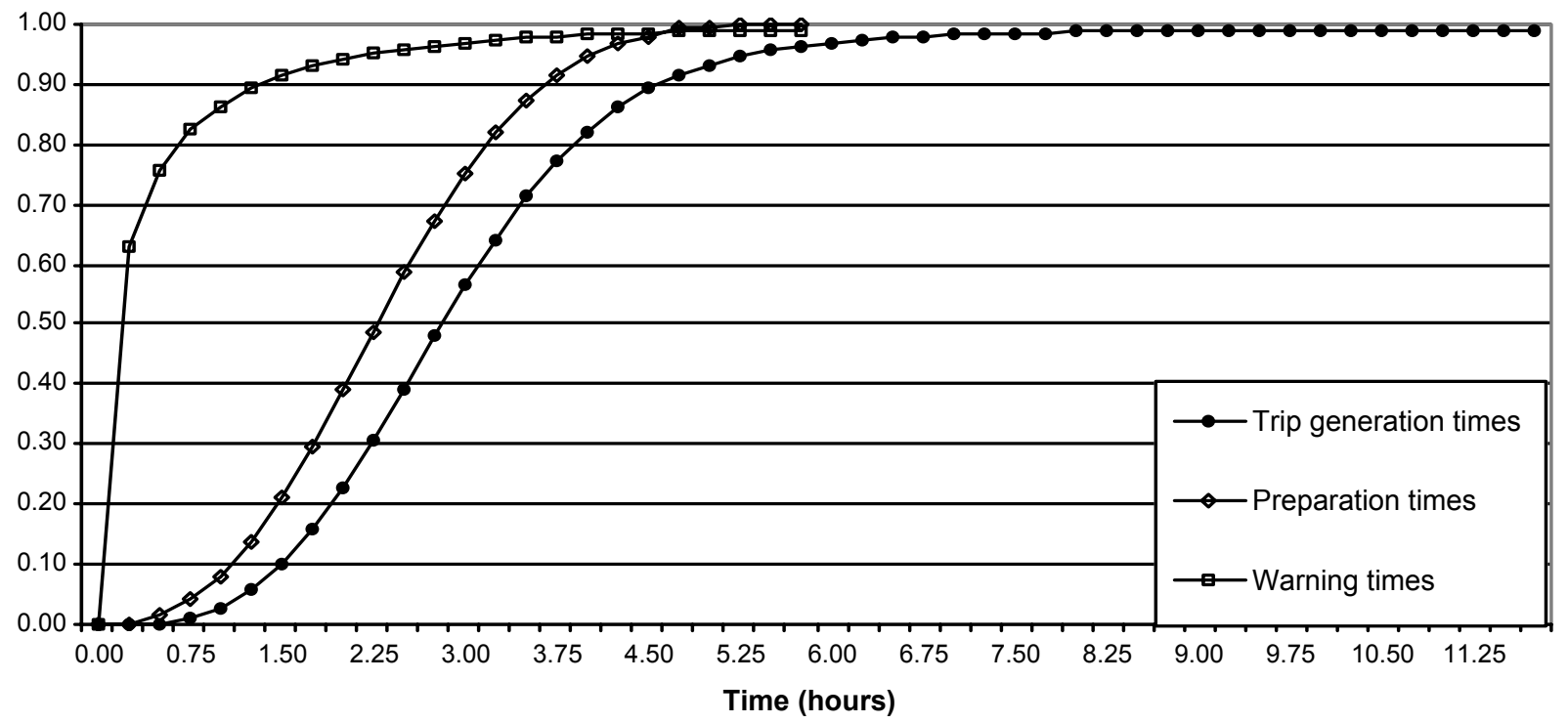

Figure 1: A TGT distribution for households 
Travel time from home via collector routes to the primary evacuation route is a function of the distance from the home to the primary evacuation route, and the average travel speed on the collector route. The time required for evacuating vehicles to wait for access to the primary evacuation route can be computed by means of four recursive equations.

$$
\Delta D_{t}=\Delta A_{t}+Q_{t-1}
$$

where $\Delta D_{t}$ is the incremental traffic demand at time $t, \Delta A_{t}$ is the incremental flow on arterial/collector routes at time $t$, and $Q_{t}$ is the size of the queue awaiting access to the primary evacuation route at time $t\left(Q_{0}\right.$ is assumed to be zero). Moreover,

$$
P_{t}=\operatorname{Min}\left(\Delta D_{t}, C\right)
$$

where $P_{t}$ is the primary evacuation route's traffic flow at time $t$, and $C$ is evacuation route capacity. Next,

$$
E_{t}=P_{t}+E_{t-1}
$$

where $E_{t}$ is the total number of vehicles that have entered the evacuation route system through time $t$. Finally,

$$
Q_{t}=\Delta D_{t}-C
$$

These four equations are solved repeatedly at successive time intervals $t \geq 1$ until all transients have entered the primary evacuation route, and all households intending to evacuate (compliant evacuees + spontaneous evacuees) have entered the primary evacuation route.

\section{Application to Building Evacuations}

Data from the first WTC bombing show that this ambiguous situation elicited an orderly process of information seeking that tended to delay evacuation (Aguirre, Wenger, \& Vigo, 1997; Prater, Wenger \& Lindell, 1997; Wenger, Aguirre \& Vigo, no date). Consistent with emergent norm theory, the information seeking (milling) process was influenced by pre-existing social relationships. Moreover, though there was a widespread and increasing perception of danger and some of the conditions for panic existed, the evacuation was orderly. This similarity in occupant behavior to that displayed by community residents in other types of disasters suggests that building evacuations in response to threats or acts can also be explained by Lindell and Perry's (2004) PADM. There has been a considerable amount of research that has studied the relationship between detection/warning and evacuation. However, there has been very little research to date that has attempted to characterize household preparation times or the variables that account for differences among households in their preparation times. The available studies have found few, if any, reliable predictors of this evacuation time component (Aguirre, Wenger, \& Vigo, 1997; Lindell \& Perry, 1987; Lindell \& Perry, 1992; Lindell \& Perry, 2004; Lindell, Prater, Sanderson, Lee, Zhang, Mohite \& Hwang, 2001; Lu, Lindell \& Prater, 2004; Sorensen, 1991; Tierney, Lindell \& Perry, 2001). 
However This is because social units within a building are defined more ambiguously than households within a community, employers can exercise more control over employees' threat responses than public officials can exercise over community residents, and occupants' perceptions of alternative protective actions in buildings are likely to be different from residents' perceptions of the available protective actions in communities.

Although the data from the first WTC bombing are consistent with the PADM, there are three major reasons why further research is needed to determine the correspondence between community evacuations and building evacuations. First, the social units within a building are defined more ambiguously than households within a community. Alternate bases for defining social groups include physical structures (buildings, floors, office complexes) formal organizations (companies, divisions, branches, sections), and informal organizations such as friendship groups. All three of these bases can lead to the same patterns of social grouping, thus reinforcing them, but need not necessarily do so.

A second difference from community evacuations is that employers can exercise more control over employees' threat responses than public officials can exercise over community residents. This would decrease the independence of response that is often seen in community evacuations.

A third difference from community evacuations is that perceptions of alternative protective actions are likely to be different in buildings. One example is that capacity constraints on evacuation routes are likely to be more apparent within buildings than in communities. In addition, occupants are likely to perceive the costs of building evacuation to be lower than those of community evacuation because they are abandoning the employer's property, not their own. Finally, the safety risks of sheltering in-place are likely to be more apparent within buildingsespecially high-rise buildings - than in communities.

\section{Acknowledgement}

This material is based upon work supported by the National Science Foundation under Grant CMS-0219155. Any opinions, findings, and conclusions or recommendations expressed in this material are those of the authors and do not necessarily reflect the views of the National Science Foundation.

\section{References}

Aguirre, B.E., Wenger, D.E. \& Vigo, G. (1997). A test of the emergent norm theory of collective behavior. Sociological Forum, 13, 301-320.

Lindell, M.K. \& Perry, R.W. (1987). Warning mechanisms in emergency response systems. International Journal of Mass Emergencies and Disasters, 5, 137-153.

Lindell, M.K. \& Perry, R.W. (1992). Behavioral Foundations of Community Emergency

Planning. Washington DC: Hemisphere Press. 
Lindell, M.K. \& Perry, R.W. (2004). Communicating Environmental Risk in Multiethnic Communities. Thousand Oaks CA: Sage.

Lindell, M. K., Prater, C. W., Sanderson, W. G., Jr., Lee, H. M., Zhang, Y., Mohite A. \& Hwang, S.N. (2001). Texas Gulf Coast residents' expectations and intentions regarding hurricane evacuation. College Station TX: Texas A\&M University Hazard Reduction \& Recovery Center.

Lu, J.C., Lindell, M.K. \& Prater, C.S. (2004). Household evacuation decisions in Hurricane Lili. College Station TX: Texas A\&M University Hazard Reduction \& Recovery Center.

Prater, C.S., Wenger, D.E. \& Lindell, M.K. (1997). The WTC evacuation; A behavioral study. College Station TX: Texas A\&M University Hazard Reduction \& Recovery Center.

Sorensen, J.H. (1991). When shall we leave? Factors affecting the timing of evacuation departures. International Journal of Mass Emergencies and Disasters, 9, 153-165.

Tierney, K.J., Lindell, M.K. \& Perry, R.W. (2001). Facing the Unexpected: Disaster Preparedness and Response in the United States. Washington DC: Joseph Henry Press.

Wenger, D.E., Aguirre, B.E. \& Vigo, G. (no date). Evacuation behavior among tenants of the World Trade Center following the bombing of February 26, 1993. College Station TX: Texas A\&M University Hazard Reduction \& Recovery Center. 


\title{
4.6 On Not Putting the Cart before the Horse: Design Enables the Prediction of Decisions about Movement in Buildings
}

\author{
Norman E. Groner \\ John Jay College of Criminal Justice, City University of New York
}

Our principle obstacle to predicting building movement is not movement, it is our ability to predict human decision making about when, where and how to move during building emergencies. However, we will be unable to predict decision making as long as we fail to engineer systems that provide the information that building occupants need to make adaptive decisions. We need to get on with the business of learning how to design these systems that provide an informational cognitive task environment without first waiting for the creation of validated predictive models.

In my view, we are in good shape as regards the optimized physical movement of people. This is not to say that models of physical movement can't be improved. There is an acute need to acquire better data to refine and validate these models. However, we are in poor shape as regards modeling the decision-making processes that determine when people start to move, and how they decide by what means that will try to reach what safe destination. I would like to address the issue of how we might go about designing for and modeling decision making.

First and foremost, we are putting the cart before the horse when we try to predict decisions as a means to drive the design of buildings. Simply put, the converse is more accurate - design enables prediction. Without better design1, there it too much uncertainty about the information available to building occupants. Without reasonably detailed data about the information received by building occupants during emergencies, it will be impossible to predict decisions at a useful level of precision.

(Most accurately, the relationship between design and prediction is iterative. Design enables prediction, but prediction enables better design. To the extent that design is improved, earlier predictions are invalidated. However, at this formative stage, we need to start the process with design before we can predict behaviors at a level of validity that allows confidence in new designs based on those predictions.)

An analogy between predicting human decisions and predicting fire development is useful (Groner, 1996). Information about context is essential to both endeavors. Fire protection engineers are unable to predict fire growth and spread without information about fuel loads, room geometry and ventilation. Similarly, we can't predict human decision making without data that describes the informational context encountered by building occupants. Just as contextual information is large determined by design (e.g., knowledge of geometries, existence of suppression systems, restrictions on fuel loads), design is needed to provide the informational context of decision making before it can be predicted at an acceptable level of validity.

1 By design, I mean to include hardware-enabled, electronic and human procedural systems components. 
A large body of theory and practice exists that concerns how to engineer systems that support human decision making. The discipline of human factors engineering is increasingly concerned with discovering and validating approaches that provide people with an engineered context that supports reliable and effective adaptations to dynamic and uncertain environments. These approaches can be generally subsumed under the labels of "cognitive engineering" and "cognitive ergonomics design." These terms have been nicely defined as follows: "Cognitive Ergonomics, a term synonymous with Cognitive Engineering, concerns the design, structure \& operation of the interface between the human end-user (operator) of a system and system states and processes. This approach assumes that the way people see, hear, pay attention, think, remember (and forget), and make decisions has direct implications for the design of the artifacts and environments that they use. If the features of their physical surroundings reflect and support their natural cognitive tendencies, then at least users should make less errors when using such systems; at most, their performance and productivity could receive a positive boost."2

Engineers who design the informational environments need to be provided with cognitive task analytical tools that will "yield information about the knowledge, thought processes, and goal structures that underlie observable task performance (Chipman, Shraagen, \& Shalin, 2000, p. 3)." We need to survey the human factors literature to find theories and methods that seem promising when applied to human decision making during building emergencies. Hopefully, we will find methods that can be adapted to our domain of interest. At the very least, we are likely to discover valuable insights that will guide our own efforts to support the informational needs of decision makers during building emergencies.

Unfortunately, the large body of cognitive engineering research is not easily transferred to our domain of interest — decision making during building emergencies. Major obstacles must be overcome, because most of this cognitive engineering work concerns domains that differ in important ways from the contexts that people face during fires. As one example, aviation cockpits are exceedingly well-researched domains where operators are trained to a level of expertise using a well-articulated interface to control tightly coupled systems. The following are a few ways in which the building emergency domain differs from those in which human factors professionals are typically concerned.

- Building protective systems are loosely coupled, that is, there is a large amount of uncertainty linking causes to effects. Most cognitive task design methods are applied in domains characterized by tightly coupled systems where operators can effectively control outcomes using a reliable clearly articulated interface.

- People responding to building emergencies typically lack expertise because emergencies are rare chaotic events and extensive training resources are unavailable. Much of the cognitive task design literature concerns domains where people can be trained to achieve some level of proficiency.

2 (http://connect.haworth.com/txmas/White_Papers/CognitiveErgonomicsDef.doc) 
(There are exceptions. The use of elevators to evacuate building occupants is an example. In this instance, it might be feasible train operators to some level of proficiency in controlling a tightly coupled system using an engineered interface.)

First and foremost, we should get on with the business of analyzing and designing cognitive task environments that provide building occupants with accurate and timely information that support their goals of survival and protection. We should not wait until we have methods that predict and model human decision making during building emergencies. Building valid decision models is an important task, but its pursuit is of limited value until we have designed cognitive task environments that enable an acceptable level of predictive validity

To be clear, I strongly support research that studies actual events, but it is premature to accrue predictive data for use in decision models. The better reason for studying incidents is to reveal the naturally occurring information processing and goals that occur during incidents. Cognitive task designs need to be compatible with people's natural inclinations, more so in this domain than others. Hands-on experiential training in real emergencies is rare, and training resources are always limited, even for persons selected as emergency team members' roles like floor wardens, so trying to supplant their natural inclinations seems unlikely to be effective. As an example, we have been largely unsuccessful in educating people to immediately evacuate when they hear a simple alarm signal, principally because simple signals provide little useful information about situations, and because people are naturally inclined to assess situations before taking protective actions.

As a final thought, we should keep in mind that predicting human responses is not the goal of design. If we design environments based on the sole criterion of predicting human responses, that is, to maximize human reliability, then we run the risk of interfering with human adaptive abilities. We could conceivably design a system whereby we could constrain decision making such that we could accurately predict which egress routes building occupants choose, but this is not a good idea in itself. We want design environments that enable people to choose the most effective route in response to the chaotic and dynamic environments they face, even at the loss of the predictive validity of our calculations.

\section{References}

Chipman, S.F., Shraagen, J. M., \& Shalin, V. L. (2000) Introduction to cognitive task design analysis. In J. M. Shraagen, S. F. Chipman, \& V. L. Shalin (Eds.) Cognitive Task Analysis. Mahwah, NJ: Lawrence Erlbaum Associates.

Groner, N.E. (1996) Viewpoint: Putting people into the performance-based design option, Fire Technology, Vol. 32, No. 3, Aug/Sep. pp. 281-284.

SFPE Task Group on Human Behavior (2003). Engineering Guide to Human Behavior in Fire. Bethesda, MD: Society of Fire Protection Engineers. 


\section{Workshop Summary}

Participants at the workshop representing varied disciplines - psychology, human factors, sociology, engineering, computer science, government agencies, and toxicology - discussed common efforts towards more accurate prediction methods and information on human behavior in fires and other emergencies. There is a great deal of work already completed in many disciplines (information flow, building technology sensors, elevator use, community evacuation planning, group dynamics, etc.) that can be used to provide better prediction tools.

\subsection{Overall}

Participants of the workshop were introduced to research in many different disciplines with common links between their research and what is going on in the fire field. The collaboration of the disciplines can provide guidance on the several aspects of evacuation:

- How to design buildings for more effective evacuation (building sensors, user-centered integrated model, risk factors).

- How to train occupants for different types of emergencies (emergency planning guidance).

- How to incorporate data/knowledge into current evacuation models (current models are lacking realistic behaviors such as group movement, information on assumption and model limitations are not provided to users).

Several research needs were expressed during the workshop. These include:

- Real-time data of occupant evacuation from buildings (movement and behavioral data such as flows on stairs, speeds, pre-evacuation decisions and times, etc.),

- A method of data/information sharing among researchers and model developers,

- Appropriate design or code changes which reflect the risk of the specific building, instead of reactionary changes,

- A central repository for this type of data in one central place available to the public, and

- Accurate guidance on development of emergency plans for different types of emergencies.

\subsection{Specific Needs Obtained From Workshop Participants}

There is a need to understand how the people, the building, and the environment react together. This involves an integrated "model" and more of a systems view of the evacuation. Suggestions were made to use technology in buildings (sensors) to help people during their evacuation. For instance, giving them specific information on which route to take or providing them with a sensor at each door to let them know if there is fire or smoke behind the door.

There is a need to better understand the behavioral aspect of evacuation for better prediction methods and more effective training techniques. However, it is not clear how specific this understanding should be to accurately provide safety for building occupants. For instance, do we 
need to outline each decision made by every occupant during the pre-evacuation stage or is it enough to simply assign a distribution of pre-evacuation time delays to represent time spent before beginning movement toward an exit? In either case, data are needed.

There is a need to collaborate with other disciplines on providing more effective emergency planning. On one hand, we need to know what to expect from occupants and base the emergency plan on that. For instance, people tend to leave the way they come into a building. Because of this, we could possibly widen main doors and/or plan for elevator use in certain emergencies. On the other hand, behavior is pliable and we need to impact occupant behavior in our building design and the information given to occupants. Emergency plans should involve input from the actual occupants and involve extensive practice (even including motivational rewards).

There is a need to include the impacts of human behavior in predictive models. Currently used evacuation models lack certain behavioral aspects of an evacuation, including group behavior and accurate representation of the disabled population. Projects are in the works to help identify gaps in the evacuation models and eventually update current models with needed data. NIST is working to provide a central repository for such data on human behavior and movement during evacuation to make data widely available to researchers. The key is to ensure that available data are sufficiently documented to make it useful to researchers who were not involved in the original data collection or those in disciplines different from the original researchers.

There is a need for building codes and regulations to better reflect the impact of human behavior during emergencies. Much work is needed in the code area to make sufficient changes to current codes in response to recent events. Workshop participants expressed a desire that codes and standards be based on appropriate scientific study rather than reaction to specific events. This would include study not only of changes to specific code requirements but also the overall scope and the balance of cost with benefits provided by major revisions to existing codes and standards. 